\title{
क
}

AUTARQUIA ASSOCIADA À UNIVERSIDADE DE SÃO PAULO

\section{ESTUDO DO PROCESSO DE REDUÇÃO TÉRMICA EM VÁCUO DO ÓXIDO DE GRAFENO VISANDO À OBTENÇÃO DE MATÉRIA-PRIMA PARA SUPERCAPACITOR}

\author{
Quezia de Aguiar Cardoso
}

Dissertação apresentada como parte dos requisitos para obtenção do Grau de Mestre em Ciências na Área de Tecnologia Nuclear

- Materiais

Orientador:

Prof. Dr. Rubens Nunes de Faria Junior

São Paulo 
INSTITUTO DE PESQUISAS ENERGÉTICAS E NUCLEARES

AUTARQUIA ASSOCIADA À UNIVERSIDADE DE SÃO PAULO

\section{ESTUDO DO PROCESSO DE REDUÇÃO TÉRMICA EM VÁCUO DO ÓXIDO DE GRAFENO VISANDO À OBTENÇÃO DE MATÉRIA-PRIMA PARA SUPERCAPACITOR}

Quezia de Aguiar Cardoso

Dissertação apresentada como parte dos requisitos para obtenção do Grau de Mestre em Ciências na Área de Tecnologia Nuclear - Materiais

Orientador:

Prof. Dr. Rubens Nunes de Faria Junior

Versão Original

São Paulo 
DEDICATÓRIA

Aos meus pais, Elias e Edinê Minha irmã, Raquel Meu esposo, Fagner 


\section{AGRADECIMENTOS}

Agradeço a Deus, por ter me dado condições para esta realização, e por me sustentar ao longo desta jornada, afinal Ele é o maior mestre que alguém pode conhecer.

Aos meus pais, Elias e Edinê, pelo amor, incentivo e apoio incondicional.

Agradeço a minha irmã Raquel, pelas inúmeras palavras de garra quando eu pensava em desistir (e não foram poucas vezes);

Fagner, meu amor! Obrigada pela compreensão nos momentos de cansaço, por entender minhas ausências, e principalmente por sempre acreditar no meu sonho.

Agradeço ao Dr. Rubens Nunes de Faria Junior por ter aceitado me orientar em um novo tema com dez meses para o término do prazo regulamentar de depósito da dissertação. Obrigada pela sua impaciência, sem a qual não teria conseguido terminar este trabalho em tão curto tempo.

A Dra. Solange Kazumi Sakata, minha co-orientadora, pela compreensão e ajuda para tornar possível a conclusão deste trabalho, e pelas boas risadas que ela me proporcionou neste período.

Ao Dr. Júlio César Casini pela amizade e participação no desenvolvimento e nas pesquisas de redução do óxido de grafeno a vácuo, ao Dr. Eguiberto Galego pelo auxilio nas análises de fluorescência de raios $\mathrm{X}$ e de microscopia eletrônica de varredura e a Dra. Marilene Morelli Serna, pela contribuição na pesquisa de número de planos empilhados e revisão deste trabalho.

A Luiza Sobrinho e Pedro Victor da Cruz, por toda ajuda nas análises e confecção dos supercapacitores. Obrigada! Sem vocês muitas respostas aqui não seriam possíveis!

A liderança das empresas Axalta Coatings Systems e LuxÓttica, por autorizarem minhas ausências 2x por semana para a realização deste sonho profissional e pessoal.

Ao amigo Dr. Marcos Fernandes de Oliveira, pelas boas conversas acadêmicas.

Agradeço aos órgãos de fomento (FAPESP/CNPq) pelo suporte financeiro aos Laboratórios do Grupo de Baterias, Supercapacitores e Células Fotovoltaicas do IPENCCTM possibilitando a realização desta investigação. 


\section{EPÍGRAFE}

Mas graças a Deus que nos dá a vitória por nosso Senhor Jesus Cristo.

1 Coríntios 15:57 


\title{
Estudo do processo de redução térmica em vácuo do óxido de grafeno visando à obtenção de matéria-prima para supercapacitor
}

\author{
Quezia de Aguiar Cardoso
}

\section{RESUMO}

Neste estudo foi investigado o processo de redução térmica do óxido de grafeno em médio vácuo como uma rota viável de baixo custo econômico para obtenção do óxido de grafeno reduzido para aplicação em supercapacitores. O objetivo principal foi estudar a influência da temperatura de processamento no grau de redução do óxido de grafeno utilizando um sistema de vácuo com bomba mecânica de duplo estágio. O processamento constituiu na exposição do óxido de grafeno em várias temperaturas $(200,400,600,800$ e $\left.1000{ }^{\circ} \mathrm{C}\right)$ com pressão reduzida $\left(10^{-2} \mathrm{mbar}\right)$ - condição de médio vácuo. Foram utilizadas técnicas convencionais para caracterização dos materiais precursores e processados, tais como: microscopia eletrônica de varredura (MEV), difração de raios-X (DRX) e espectroscopia no infravermelho com transformada de Fourier (FTIR). Com os resultados deste estudo foi demostrado que é possível obter o óxido de grafeno reduzido utilizando um sistema de vácuo com bomba mecânica de duplo estágio e temperaturas de processamento superiores a $200^{\circ} \mathrm{C}$.

Palavras-chave: grafeno; redução do óxido de grafeno; supercapacitores 



\title{
Study of the process of thermal reduction in vacuum of the graphene oxide for obtaining starting material for supercapacitor
}

\author{
Quezia de Aguiar Cardoso
}

\begin{abstract}
In this study the process of medium vacuum thermal reduction of the graphene oxide as a low cost route for obtaining reduced graphene oxide has been investigated. The main objective was to study the influence of the processing temperature on the degree of reduction of the graphene oxide using a vacuum system with two stage backing pump. The processing was carried out by exposing the graphene oxide at various temperatures $(200,400,600,800$ e $\left.1000^{\circ} \mathrm{C}\right)$ with reduced pressure $\left(10^{-2} \mathrm{mbar}\right)$. Conventional techniques have been employed to the characterization of the starting and processed materials, such as: scanning electron microscopy (SEM), X-ray diffraction and Fourier transformed infrared spectroscopy (FTIR). With the results of this study it has been demonstrated that it is possible to obtain the reduced graphene oxide using a vacuum system with a two stage backing pump and processing temperatures superior to $200^{\circ} \mathrm{C}$.
\end{abstract}

Keywords: graphene; reduction of graphene oxide; supercapacitors 


\section{SUMÁRIO}

1. INTRODUÇÃO _ 01

2. OBJETIVOS 05

3. REVISÃO DA LITERATURA__ 06

3.1 Capacitores 06

3.2 Supercapacitores _ 10

3.3. Grafeno, óxido de grafeno, e óxido reduzido___ 14

4. MATERIAIS E MÉTODOS

4.1 Preparação do óxido de grafeno pelo método de Hummers ___ 18

4.2 Redução do óxido de grafeno _ 20

4.3 Caracterização por difração de raios X (DRX) _ 22

4.4 Caracterização por espectroscopia no infravermelho com transformada de Fourier _ 24

4.5 Microscopia eletrônica de varredura ___ 26

4.6 Termogravimetria (TG)__ 26

4.7 Espectroscopia de fluorescência ___ 27

4.8 Preparação de supercapacitores de óxido de grafeno ___ 28

5. RESULTADOS_ 31

5.1 Caracterização do óxido de grafeno___ 31

5.1.1 Microscopia eletrônica de varredura ___ 31

5.1.2 Fluorescência de raios _ 32

5.2 Redução do óxido de grafeno em vácuo ___ 33

5.3 Espectroscopia no infravermelho com transformada de Fourier (FTIR) ___ 36

5.4 Difração de raios $X_{-} \longrightarrow 40$

5.5 Estimativa do número de planos empilhados __ 44

5.6 Termogravimetria (TG)_ 47

5.7 Propriedades elétricas dos supercapacitores de óxido de grafeno___ 52

6. CONCLUSÕES_ 54

REFERÊNCIAS BIBLIOGRÁFICAS _ 55

PRODUÇÃO TÉCNICO-CIENTÍFICA___ 61 


\section{LISTA DE TABELAS}

Tabela 1 - Identificação das principais bandas presentes no óxido de grafeno reduzido __ 25

Tabela 2 - Análise de fluorescência de raios X semi quantitativa do óxido de grafeno__ 33

Tabela 3 - Posição dos picos em diferentes condições de processamento ___ 43

Tabela 4 - Tamanho do cristalito $\left(\mathrm{L}_{002}\right)$ e número de planos $00 \mathrm{~L}$ empilhados $(\mathrm{N}) \_46$

Tabela 5 -Porcentagem de perdas de massa para o Óxido de Grafeno e suas respectivas reduções

Tabela 6 - Propriedades elétricas dos supercapacitores de óxido de grafeno antes e depois da redução em vácuo 52 


\section{LISTA DE FIGURAS}

Figura 1 - Capacitor constituído por duas placas planas e paralelas 06

Figura 2 - Representação esquemática de um supercapacitor 12

Figura 3 - (a) Grafeno, um material 2-D que serve de estrutura básica para alótropos de carbono em todas as dimensões. Pode (b) formar um fulereno, (c) ser enrolado na forma de um nanotubo ou (d) ser empilhado formando a grafite 15 Figura 4a - Modelo esquemático do método de Hummers modificado para obtenção do óxido de grafeno

Figura 4b - Processo de obtenção do óxido de grafeno (resfriamento, aquecimento, lavagem com água deionizada e esfoliação) 19

Figura 4c - Etapa intermediária de adição de água e aquecimento 19

Figura 4d - Início da etapa de precipitação e adição de peróxido

Figura 4e - Processo de obtenção do óxido de grafeno finalizado por meio de separação em centrífuga e esfoliação em ultra sonicador 20

Figura 5 - Equipamentos utilizados para processamento do OG, com o objetivo de reduzilo a temperaturas acima de $200{ }^{\circ} \mathrm{C}$ 21

Figura 6 - Microscópio Eletrônico de Varredura 26

Figura 7 - Micrografia do óxido de grafeno preparado pelo método Hummers modificado

$\begin{array}{ll} & 27 \\ \text { Figura } 8 \text { - Processo básico da FRX } \_ & 28\end{array}$

Figura 9 - Clipe de metal utilizado para unir os eletrodos do supercapacitor 29

Figura 10 - Analisador Arbin BT-4 com Software MITS Pro-4 29

Figura 11 - Micrografia do óxido de grafeno preparado pelo método Hummers modificado

Figura 12 - Espectro de fluorescência de raios X do material do óxido de grafeno preparado pelo método Hummers modificado 32

Figura 13 - Variação da pressão em função da temperatura a $200^{\circ} \mathrm{C}$ 34

Figura 14 - Variação da pressão em função da temperatura a $400^{\circ} \mathrm{C}$ 34

Figura 15 - Variação da pressão em função da temperatura a $600^{\circ} \mathrm{C}$ 35

Figura 16-Variação da pressão em função da temperatura a $800^{\circ} \mathrm{C}$ 35

Figura $17-$ Variação da pressão em função da temperatura a $1000^{\circ} \mathrm{C}$ 36

Figura 18-Espectro FTIR para a amostra de óxido de grafeno reduzida a $200^{\circ} \mathrm{C}$ 37

Figura 19 - Espectro FTIR para a amostra de óxido de grafeno reduzida a $400^{\circ} \mathrm{C}$ 38 
Figura 20 - Espectro FTIR para a amostra de óxido de grafeno reduzida a $600^{\circ} \mathrm{C}$ 38

Figura 21 - Espectro FTIR para a amostra de óxido de grafeno reduzida a $1000^{\circ} \mathrm{C} \_39$

Figura 22 - Espectro FTIR para a amostra de óxido de grafeno ___ 39

Figura 23 - Difratograma de raios X do óxido de grafeno ___ 40

Figura 24 - Difratograma de raios $\mathrm{X}$ do óxido de grafeno reduzido a $200^{\circ} \mathrm{C} \_41$

Figura 25 - Difratograma de raios $\mathrm{X}$ do óxido de grafeno reduzido a $400^{\circ} \mathrm{C} \_41$

Figura 26 - Difratograma de raios $\mathrm{X}$ do óxido de grafeno reduzido a $600^{\circ} \mathrm{C}$ 42

Figura 27 - Difratograma de raios $\mathrm{X}$ do óxido de grafeno reduzido a $800^{\circ} \mathrm{C}$ 42

Figura 28 - Difratograma de raios $\mathrm{X}$ do óxido de grafeno reduzido a $1000^{\circ} \mathrm{C}$ 43

Figura 29 - Padrões de difração de raios X 45

Figura 30 - Detalhamento reflexão 002 46

Figura 31 - Análise termogravimétrica do óxido de grafeno reduzido a $200{ }^{\circ} \mathrm{C}$ sob atmosfera de Nitrogênio 47

Figura 32 - Análise termogravimétrica do óxido de grafeno reduzido a $400{ }^{\circ} \mathrm{C}$ sob atmosfera de Nitrogênio 48

Figura 33 - Análise termogravimétrica do óxido de grafeno reduzido a $600{ }^{\circ} \mathrm{C}$ sob atmosfera de Nitrogênio 48

Figura 34 - Análise termogravimétrica do óxido de grafeno reduzido a $800{ }^{\circ} \mathrm{C}$ sob atmosfera de Nitrogênio 49

Figura 35 - Análise termogravimétrica do óxido de grafeno reduzido a $1000{ }^{\circ} \mathrm{Csob}$ atmosfera de Nitrogênio 49

Figura 36 - Análise termogravimétrica do Óxido de grafeno reduzido unificad 50 


\section{INTRODUÇÃ̃O}

O termo "grafeno" (G) foi recomendado pela comissão IUPAC para substituir o termo mais antigo "camadas de grafite". Andre Geim e Konstantin Novoselov (2007) receberam o prêmio Nobel de Física por suas pesquisas inovadoras sobre o grafeno, um material bidimensional encontrado em um lápis. O grafeno, um dos alótropos do carbono (nanotubo de carbono, diamante) elementar, é uma monocamada plana de átomos de carbono dispostos em estrutura bidimensional (2D) em honeycombstructure, que é estável a temperatura ambiente (Geim, 2007(b); Novoselov et al., 2009).

Novos estudos envolvendo o grafeno vêm crescendo nos últimos anos. A superioridade do grafeno em relação aos materiais tradicionais foi relatada nas principais aplicações de engenharia mecânica, térmica e elétrica (Lee et al., 2008; Dreyer et al., 2010). Seguindo essa tendência, o óxido de grafite, relatado pela primeira vez há 150 anos (Dreyer et al., 2010), ressurgiu com grande interesse e, motivou esta investigação, cujo objetivo é utilizá-lo como precursor para produção rentável e em larga escala de materiais à base de grafeno.

O óxido de grafite possui estrutura similar à do grafite, porém o plano de átomos de carbono no óxido de grafite contém grupos de oxigênio adsorvidos, que expandem a distância entre as camadas de carbono. Essas camadas oxidadas podem facilmente ser esfoliadas em meio aquoso por ultrassom, resultando em uma ou algumas camadas de átomos de carbono, como no grafeno, porém, neste caso, o material recebe o nome de óxido de grafeno (OG).

A propriedade mais atraente do OG é que este material pode ser parcialmente reduzido em grafeno, pela remoção dos grupos de oxigênio e a recuperação da estrutura. $\mathrm{O}$ material reduzido do OG recebe o nome de óxido de grafeno reduzido (OGr) e é considerado um dos derivados do grafeno. Alguns outros nomes também podem ser dados ao OGr, como: grafeno funcionalizado, grafeno quimicamente modificado, grafeno quimicamente convertido e grafeno reduzido (Eda e Chhowalla, 2010).

A meta internacional para os estudos de redução do óxido de grafeno é produzir um material idêntico ao grafeno obtido a partir da esfoliação mecânica direta de camadas individuais de grafite, tanto na estrutura quanto nas propriedades. Embora tenham sido feitos inúmeros esforços, o objetivo final está longe. Os grupos funcionais residuais e os defeitos 
alteram drasticamente a estrutura dos planos de carbono, por conseguinte, ainda não é apropriado referir-se como OGr ao grafeno, uma vez que as propriedades são diferentes.

No momento atual, além da redução do OG, o grafeno também pode ser produzido pelas técnicas: esfoliação micromecânica altamente ordenada do grafite (Geim e Novoselov, 2007), crescimento epitaxial (Berger et al., 2006; Land et al., 1992) e deposição química a vapor (CVD) (Eizenberg e Blakely, 1979). Esses três métodos podem produzir grafeno com excelente estrutura e propriedades. Porém, para a produção do grafeno de baixo custo e em grande escala, as técnicas citadas são ineficientes.

Como resultado, a utilização de matéria-prima de baixo custo (óxido de grafite) para produção do OG e posterior redução para OGr possui atenção na pesquisa e desenvolvimento do grafeno, especialmente no que diz respeito a aplicações em grande escala.

Portanto, a redução de OG é definitivamente um tema-chave, e os processos de redução resultam em diferentes propriedades que, por sua vez, afetam os dispositivos que utilizam OGr - no caso deste projeto, os supercapacitores. $\mathrm{O}$ objetivo final da ciência na redução do OG é alcançar o grafeno perfeito; os esforços contínuos das pesquisas têm, por sua vez, se aproximado de tal propósito. Os diferentes métodos de redução incluem: síntese (Sakamoto et al., 2009; Regis et al., 2010; Compton e Nguyen, 2010; Park e Ruoff, 2009; Zhu et al., 2010; Huang et al.,2011; Guo e Dong, 2011); métodos físicos (Neto et al., 2009; Geim e MacDonald, 2007; Katsnelson e Novoselov, 2007) e químicos (Rao et al., 2009; Loh et al., 2010; Boukhvalov e Katsnelson, 2009; Allen et al., 2009; Huang et al., 2012).

A redução do óxido de grafeno pode ocasionar mudanças na microestrutura e propriedades, algumas das quais podem ser diretamente observadas ou medidas para avaliar o efeito do processo de redução do OG. A observação óptica é a maneira direta de observar as alterações do OG, antes e após a redução. Uma vez que a redução pode melhorar drasticamente a condutividade elétrica do OG, o aumento da concentração dos portadores de carga e a mobilidade irão melhorar a reflexão de luz incidente. A mudança de cor do amarelo-marrom para o preto, em solução, é uma característica visível da redução do OG (Zhouet al., 2009).

A condutividade elétrica é o segundo método para de avaliar o critério de redução do $\mathrm{OG}$, uma vez que o objetivo da redução é principalmente restaurar a alta condutividade do grafeno. A mudança na condutividade pode ser notada diretamente na resistência interna (ESR) dos supercapacitores (Visentini et al., 2014). 
A redução do óxido de grafeno em pressões ultra baixas ou em atmosfera de argônio, hidrogênio ou ultra alto vácuo foi relatada na literatura (Yang et al.,2009; Becerril et al., 2008; Wang et al., 2008; Gao et al., 2009), e neste trabalho pode-se considerar como diferencial o uso do médio vácuo.

Yang e colaboradores (2009) estudaram o efeito da redução térmica do óxido de grafeno em três atmosferas (argônio, argônio/hidrogênio e ultra alto vácuo) e temperaturas diferentes $\left(500,800\right.$, e $\left.1000^{\circ} \mathrm{C}\right)$. Como resultado, reportaram que a melhor redução ocorreu com altas temperaturas. Porém, não relataram quais foram as condições de pressão utilizadas para o caso da redução em atmosfera gasosa.

Wang e colaboradores (2008) conseguiram reduzir um filme de óxido de grafeno via tratamento térmico (até $1100^{\circ} \mathrm{C}$ ) sob fluxo de gás $\left(\mathrm{Ar} / \mathrm{H}_{2}\right)$. A mudança de cor do castanho claro para cinzento claro da película $\mathrm{OG}$ em quartzo indicou a formação de grafeno reduzido (OGr).

Pesquisas sobre o mesmo tema realizadas por Gao e colaboradores (2009) também relataram o efeito da redução térmica via fluxo de gás e alta temperatura $\left.{ }^{\circ} \mathrm{C}\right)$. Porém, nesse caso, além de os autores detalharem o experimento, realizaram experimentos com outras rotas de redução. No caso da redução via alta temperatura, utilizaram fluxo de 1,3litro/min de argônio com $15 \%$ em volume de $\mathrm{H}_{2}$.

Dentre todas as estratégias desenvolvidas, a redução térmica do OG é considerada uma das rotas mais promissoras para obtenção do grafeno em grandes quantidades; no entanto, o mecanismo de redução ainda continua sendo pesquisado pela comunidade científica (Pei e Cheng, 2012; Huh, 2011).

Dentre os artigos relacionados, todos mostram o efeito da redução do OG com fluxo de gases ou em ultra alto vácuo. Nenhum destes trabalhos apresentou resultados utilizando pressões da ordem de $10^{-2} \mathrm{mbar}$ (vácuo produzido por bomba mecânica) - médio vácuo, o que tornaria muito menor o custo de processamento do óxido de grafeno. Este é um desafio como inovação tecnológica que será abordado neste trabalho de mestrado.

O desenvolvimento de sistemas de armazenamento de energia alternativa é, sem dúvida, um dos maiores desafios enfrentados pela sociedade moderna. Isto se deve às emergentes preocupações ecológicas, tais como poluição, redução do uso de combustíveis fósseis e resíduos, dentre outras. Os crescentes problemas ambientais e a necessidade de dispositivos de armazenamento de energia eficientes alavancaram as pesquisas nessa área de estudo, focadas principalmente em capacitores elétricos de dupla camada 
("electricdoublelayercapacitors - EDLCs"), conhecidos atualmente como supercapacitores (também chamados ultracapacitores ou capacitores eletroquímicos).

Porém, a melhoria no desempenho desses dispositivos está associada às propriedades dos materiais constituintes. Muitos resultados têm se dirigido para a combinação de óxidos metálicos $\left(\mathrm{Fe}_{3} \mathrm{O}_{4}, \mathrm{NiO}, \mathrm{MnO}_{2}, \mathrm{Mn}_{2} \mathrm{O}_{3}, \mathrm{Mn}_{3} \mathrm{O}_{4}, \mathrm{Co}_{3} \mathrm{O}_{4}\right)$ com materiais à base de carbono (carbono ativado, nanotubo de carbono, óxido de grafeno e grafeno) com o objetivo de obter-se altos valores de capacitância sem que ocorra perda da vida de ciclo associada à sua utilização (Fang et al., 2012; Miller e Simon, 2008; Gogotsi e Simon, 2011; Chen et al., 2010).

Os tipos de materiais que formam os eletrodos dos supercapacitores têm uma grande influência no desempenho, custo e estabilidade global do dispositivo. Os materiais considerados ideais para aplicação em supercapacitores devem possuir as seguintes características: elevada área superficial específica; alta estabilidade térmica e química; alta condutividade; alta porosidade e custo baixo.

Nesse contexto, os materiais à base de carbono emergem como a escolha para a fabricação de eletrodos de supercapacitores. Esses possuem todas as características enumeradas e tornam-se úteis como suporte para os óxidos metálicos (Zhi et al., 2013). Nos supercapacitores, a energia é armazenada através de polarização seguida pela migração de cargas iônicas na superfície dos eletrodos. Devido à elevada área superficial, a estrutura porosa e boa condutividade, eletrodos à base de carbono são promissores para aplicação em supercapacitores.O desenvolvimento de novos materiais para uso em dispositivos armazenadores de energia como baterias e supercapacitores é um tema em constante estudo internacional e que será abordado neste trabalho de mestrado.

$\rightarrow$ Custo de materiais envolvidos

Bomba mecânica de médio vácuo: aproximadamente $\mathrm{R} \$ 2000,00$.

Custo do Grafeno atual (fonte: China): U\$ 500,00 (o grama).

Custo do processo de redução química: aproximadamente $\mathrm{R} \$ 5000,00$ (considerar a compra dos reagentes e equipamentos). 


\section{OBJETIVOS}

O objetivo deste trabalho foi estudar o processamento do óxido de grafeno utilizando redução térmica em médio vácuo visando uma rota de baixo custo de produção. Pretendeu-se, também, avaliar a influência da temperatura de processamento na capacidade de reduzir esses materiais com eficiência. A partir disto, caracterizar e comparar o pó produzido utilizando várias temperaturas com o óxido precursor. O trabalho teve como objetivo aplicar o material obtido nos supercapacitores.

Foram utilizadas as seguintes etapas e processos para o atingimento do objetivo:

- Sintetizar o óxido de grafeno pelo método Hummers modificado.

- Caracterizar a matéria prima sintetizada utilizando fluorescência de raios X e microscopia eletrônica de varredura.

- Processar a matéria prima utilizando redução térmica a vácuo em diversas temperaturas.

- Caracterizar o material processado termicamente utilizando difração de raios X, espectroscopia de absorção no infravermelho com transformada Fourier e espectroscopia de fluorescência.

- Estimar o número de planos empilhados dos materiais.

- Produzir supercapacitores eletroquímicos utilizando o material reduzido em várias temperaturas e medir a capacitância específica e a resistência interna. 


\section{REVISÃO DA LITERATURA}

\subsection{CAPACITORES}

Os capacitores foram inicialmente chamados condensadores, pois tinham a capacidade condensar eletricidade em um determinado recipiente. O capacitor ficará carregado com cargas elétricas $(Q)$ quando conectado a um gerador ou bateria, ou seja, com excesso de elétrons em uma das placas. Pela ação da força eletromotriz do gerador os elétrons serão movimentados de uma placa para a outra. Portanto, após este ser desconectado do gerador, uma placa ficará carregada com cargas negativas dos elétrons e a outra com cargas positivas oriundas da perda de elétrons. O equilíbrio eletrônico é reestabelecido quando as placas são interligadas por um condutor elétrico. Neste estado o capacitor se encontra novamente descarregado. A carga elétrica de um capacitor é medida em coulombs (C) e o elétron tem uma carga elementar com valor absoluto de $1,6 \times 10^{-19} \mathrm{C}$ (Franco, 2014).

A capacidade ou capacitância de um capacitor de placas metálicas é diretamente proporcional à área $(A)$ das placas e inversamente proporcional a distancia $(d)$ entre elas. $\mathrm{A}$ Figura 1 mostra a representação esquemática de um capacitor de placas planas e paralelas. A carga elétrica positiva $(+Q)$ se refere à falta de elétrons no metal da placa (prótons), enquanto que a carga negativa $(-Q)$ indica um excesso de elétrons nesta placa ou eletrodo (Brescansin, 2013).

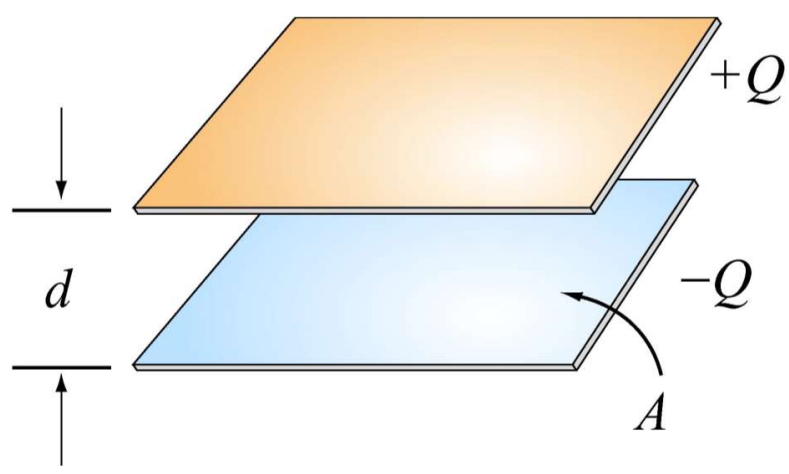

Figura 1 - Capacitor constituído por duas placas planas e paralelas. 
A capacitância de um capacitor composto por duas placas idênticas dispostas paralelamente e situadas em vácuo é dada por:

$$
C=\frac{{ }^{\varepsilon_{o}}{ }^{A}}{d}
$$

A constante de proporcionalidade $\varepsilon_{o}$ é denominada permissividade absoluta do vácuo e tem valor igual a $8,85 \times 10^{-12} \mathrm{Fm}^{-1}$. A capacitância é expressa em farad (F) ou submúltiplos $(\mu \mathrm{F}, \mathrm{nF}$ ou $\mathrm{pF})$.A carga elétrica que um capacitor pode armazenar está relacionada à capacitância e ao potencial elétrico $(V)$ aplicado:

$$
Q=C V
$$

onde: o potencial elétrico é expresso em volts (V).

A carga elétrica armazenada em capacitor a vácuo pode ser aumentada com uma maior área das placas ou menor separação entre elas e, também, com a aplicação de um potencial elétrico mais elevado entre as placas. Na prática existe um limite de potencial elétrico que pode ser aplicado aos eletrodos do capacitor para que este não se danifique. A carga elétrica de um capacitor também está relacionada ao tempo e à corrente elétrica $(I)$ que flui nas placas:

$$
Q=I t
$$

onde: a corrente é dada em amperes (A) e o tempo em segundos (s).

Os materiais condutores de corrente elétrica como os metais possuem elétrons livres. Estes são os elétrons das últimas camadas dos átomos do material condutor e são retirados com grande facilidade. Estes elétrons também podem se movimentar com grande facilidade dentro do material. Dielétricos ou isolantes são materiais que não possuem cargas elétricas livres em seu interior e não há condução de corrente elétrica ou movimentação de elétrons neste tipo de material (Brescansin, 2013).

Inserindo-se um material dielétrico entre as placas de um capacitor plano e paralelo, previamente carregado com uma carga eletrônica, ocorrerá uma redução do potencial elétrico. A constante dielétrica $(\kappa)$ de um material isolante pode ser determinada 
pela relação dos potenciais elétricos sem dielétrico $\left(V_{o}\right)$ e com o dielétrico inserido entre as placas do capacitor $(V)$ :

$$
k=\frac{V_{O}}{V}=\varepsilon_{r}
$$

O valor da constante dielétrica será maor que a unidade para a grande maioria dos materiais. Para o vácuo é igual à unidade enquanto que para o ar seco é muito próximo deste valor. A constante dielétrica também é denominada permissibilidade relativa do meio $\left(\varepsilon_{\mathrm{r}}\right)$

A capacitância do capacitor com um dielétrico entre as placas será então calculada por:

$$
C=\frac{\kappa \varepsilon_{o} A}{d}
$$

A capacitância de um capacitor com dielétrico é aumentada pelo valor numérico da constante dielétrica. As cargas elétricas existentes em um capacitor carregado provocam a presença de um campo entre suas placas. Quanto maior o potencial elétrico maior será a intensidade do campo entre as placas do capacitor. Um campo muito elevado pode remover elétrons dos átomos do dielétrico e ocasionar sua ionização e consequente condução elétrica.

O máximo valor de campo elétrico que um material isolante pode suportar sem se ionizar recebe a denominação de rigidez dielétrica do isolante. Alcançada a rigidez dielétrica do material isolante que ocupa o espaço entre as placas do capacitor ocorrerá ruptura do dielétrico. Neste caso o dielétrico passa a conduzir e o capacitor entra em curto circuito (Mussoi e Villaça, 2000).

$\mathrm{Na}$ prática, como os capacitores a vácuo tem um custo relativamente elevado, muitos capacitores usam ar como dielétrico, que embora tenha uma constante dielétrica semelhante ao vácuo possui uma rigidez dielétrica inferior. Portanto, a presença de um material dielétrico entre as placas de um capacitor não só aumenta a sua capacitância como também permite que um potencial elétrico mais elevado seja aplicado às placas.

A água, já sendo uma molécula com polarização permanente, tem uma constante dielétrica bastante elevada. A rigidez dielétrica, no entanto, é comparável à do ar seco. A 
constante dielétrica da água diminui com o aumento da temperatura e valores próximos a 80 são encontrados na prática para temperatura ambiente

Capacitores comerciais são apresentados com especificação da capacitância com o porcentual de tolerância (quanto pode variar o valor da capacitância), o potencial máximo que pode ser aplicado as suas placas e, também, o potencial de trabalho para funcionamento com segurança. Dentre os materiais dielétricos sólidos a mica foi muito utilizada em equipamentos eletrônicos. Com dielétricos líquidos são encontrados, com muita frequência, os capacitores a óleo. $\mathrm{O}$ ar é o dielétrico gasoso mais comum em capacitores pela própria simplicidade de construção. Já capacitores a vácuo são mais raros pelo próprio custo de fabricação (Mussoi e Villaça, 2000).

No modelo clássico do átomo formado por um núcleo envolto por uma nuvem de elétrons, as cargas positivas contrabalançam as negativas e o átomo apresenta-se eletricamente neutro. O modelo do átomo como um sistema planetário, embora limitado, auxilia explicar vários fenômenos que ocorrem com os dielétricos. Com a presença de um campo elétrico externo ocorre uma separação ou distanciamento das cargas elétricas no átomo. A simetria é desfeita e o átomo se apresenta como um dipolo elétrico, ou seja, composto de carga positiva em um polo e negativa no outro. Esta separação das cargas é denominada polarização.

A nuvem eletrônica do átomo tende a se distanciar dos elétrons que dão origem ao campo elétrico externo. Em outras palavras, os elétrons da nuvem são repelidos pelos elétrons que constituem o campo externo e atraídos pelas cargas positivas deste campo. Mesmo na condição polarizada o átomo continua neutro, mas agora com ação de forças eletrostáticas. Portanto, na presença de um campo elétrico externo o átomo polarizado se apresenta assimétrico.

A combinação de dois ou mais átomos dá origem as moléculas. Muitas moléculas tem distribuição simétrica de cargas elétricas e, portanto, apresentam-se eletricamente neutras. Algumas moléculas, contudo, não tem uma distribuição de cargas simétricas, formando um dipolo elétrico. Tais moléculas são chamadas polares.

A água é um exemplo importante de molécula polar, sendo constituída por dois átomos de hidrogênio e um de oxigênio $\left(\mathrm{H}_{2} \mathrm{O}\right)$. A molécula da água não é simétrica, pois os átomos de hidrogênio são repelidos para os lados com um ângulo de 104,5 entre eles. Elétrons estão em maior concentração em torno do núcleo de oxigênio fazendo com que esta região fique mais carregada negativamente. Esta separação inerente à molécula da água faz com que ela se oriente mais facilmente quando exposta a um campo elétrico externo. 
Moléculas com disposição simétrica não exibem polarização permanente, mas se polarizam quando submetidas a um campo ou cargas elétricas externas. O mecanismo de polarização das moléculas simétricas (não polares) é análogo ao apresentado anteriormente para o átomo, isto é, polarização induzida. Uma molécula polar apresenta um efeito de polarização mais pronunciado e consequentemente, maior constante dielétrica.

Em geral, os dipolos elétricos estão dispostos aleatoriamente no material, porém na presença de um campo elétrico os dipolos no material se alinham com este campo. A polarização do material isolante é também responsável pelo aumento da capacitância do capacitor e seu potencial máximo de operação. Quanto mais facilmente polarizado for o material maior será a sua constante dielétrica.

\subsection{SUPERCAPACITORES}

Os supercapacitores ou ultracapacitores possuem uma capacitância maior que a dos capacitores ou condensadores. O aumento desta pode se dar pelo aumento da área superficial das placas ou eletrodos, pela diminuição da espessura do dielétrico e, também, pelo tipo de dielétrico empregado (Franco, 2014).

Transformando as placas metálicas maciças do capacitor em um eletrodo poroso, a área superficial pode ser aumentada substancialmente e, com isso, a capacitância. Um material microscopicamente poroso pode ser comparado a nível macroscópico com uma esponja onde um líquido pode preencher o seu interior. Neste caso a área geométrica é substituída pela área superficial que inclui também a área da superfície interna do material.

Para que se possa fazer uso da superfície interna do material poroso, que agora também compõe o eletrodo, é então necessário um líquido iônico ou eletrólito para que haja condução elétrica dentro do eletrodo. Usando um dielétrico líquido na forma de eletrólito é possível utilizar o fenômeno da dupla camada elétrica e diminuir a nível atômico a espessura do dielétrico. Algumas dificuldades são introduzidas ao se utilizar composto iônico ou orgânico como dielétrico, como a existência de um potencial limite positivo e negativo, ou seja, uma faixa de potencial na qual é possível a utilização do supercapacitor.

Os vários componentes de um supercapacitor são ilustrados esquematicamente na Figura 2. O supercapacitor é composto de duas placas metálicas, de material condutor poroso (eletrodo) imerso em um eletrólito e isolado eletricamente por um separador. Diferentemente dos capacitores em que as placas constituem o próprio eletrodo, a principal 
função das placas metálicas do supercapacitor é coletar a corrente elétrica de maneira eficaz (Carvalho, 2014).

O carbono, por ser um material que pode atingir alta porosidade quando ativado por algum processo químico ou térmico e também, por ser condutor de eletricidade, é extensivamente empregado como elemento ativo dos eletrodos em supercapacitores. $\mathrm{O}$ ácido sulfúrico e hidróxido de potássio, diluídos em uma solução aquosa, são dois eletrólitos empregados em supercapacitores. Os compostos orgânicos também são usados, com a vantagem de poderem trabalhar em potenciais um pouco mais elevados que os compostos inorgânicos; a desvantagem está na sua menor condutividade elétrica. Devido a estas características estes dispositivos foram denominados no princípio de capacitores eletroquímicos.

O material condutor de alta porosidade é o mesmo nos dois lados e está em contato com placas sólidas de coleta da corrente elétrica. O separador é feito de um material isolante poroso de forma a impedir o contato físico e elétrico entre os materiais porosos e ao mesmo tempo permitir condução iônica.

Na Figura 2 também estão representadas as diferentes polarizações elétricas no material ativo e no eletrólito para um supercapacitor em que haja cargas eletrônicas. No lado da placa positiva existe falta de elétrons no material poroso e íons negativos (ânions) do eletrólito são atraídos para este, tanto superficialmente como internamente nos poros. Os ânions são representados por um sinal negativo dentro de um círculo. Na placa negativa existe excesso de elétrons e íons positivos (cátions) são atraídos para o material poroso. Neste caso, os cátions estão representados por um sinal positivo em um círculo. 
Placa +

Separador

Placa -

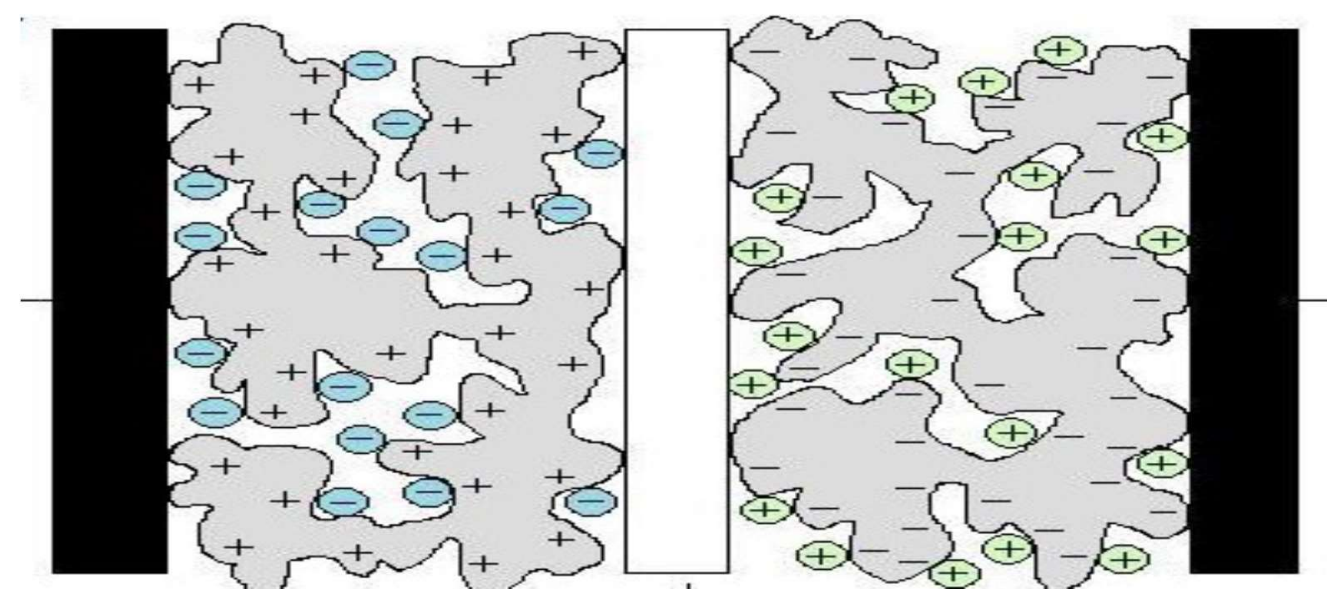

Material+eletrólito

Material+eletrólito

Figura 2 - Representação esquemática de um supercapacitor.

É a separação entre os íons e o material ativo, que neste caso é da ordem de nanômetros, que também proporciona uma elevada capacitância. Esta separação a nível molecular é conhecida com a dupla camada elétrica. Portanto, a elevada área superficial do material ativo em conjunto com uma separação nanométrica constituem o mecanismo de funcionamento do supercapacitores (Franco, 2014).

A capacitância teórica de um supercapacitor composto por um material de alta porosidade imerso em um eletrólito é dada por:

$$
C=\frac{\varepsilon_{O} \varepsilon_{r} A}{\delta}
$$

onde: $A$ é a área superficial ativa do material poroso exposta ao eletrólito ou que os íons do eletrólito tem acesso. A dupla camada elétrica $\delta$ ou separação das cargas elétricas existentes no material poroso e no eletrólito é um parâmetro dependente do eletrólito utilizado. $\varepsilon_{r}$ é a constante dielétrica relativa do eletrólito e $\varepsilon_{O}$ é a permissividade absoluta do vácuo $(8,85 \mathrm{x}$ $\left.10^{-12} \mathrm{Fm}^{-1}\right)$

A área superficial ativa $(A)$ de um material poroso é diferente da área geométrica medida por meios macroscópicos. A área superficial ativa de um eletrodo aparentemente liso é muito maior do que a medida de acordo com sua dimensão devido à rugosidade e a alta porosidade característica dos materiais para supercapacitores. 
A área superficial ativa pode ser determinada a partir de dados obtidos com métodos apropriados em equipamentos eletrônicos. Estes métodos fornecem a área superficial específica do material (S) em $\mathrm{m}^{2} \mathrm{~g}^{-1}$. A área superficial ativa de um material está relacionada à área superficial específica e a massa (m) de material ativo por:

$$
A=S m
$$

Com o auxilio de um microscópio eletrônico de varredura também é possível determinar o tamanho médio de partícula e estimar a área específica de um determinado material.

O conceito de capacitância específica advém do primeiro e mais simples modelo da dupla camada elétrica. Helmholtz idealizou este modelo em 1879 a partir do conceito de separação de cargas na interface entre o eletrodo metálico e uma solução eletrolítica. Um eletrodo carregado possui uma densidade de cargas elétricas provenientes tanto de um excesso como da deficiência de elétrons em sua superfície. A carga no eletrodo é balanceada pela redistribuição dos íons na solução eletrolítica por uma quantidade igual de íons, mas de cargas opostas. O resultado disto é a formação de duas camadas de cargas opostas separadas por uma distância com ordem de grandeza do raio atômico dos íons. Este comportamento é comparável ao do clássico capacitor de duas placas paralelas, ou seja, a dupla camada elétrica é capaz de armazenar cargas elétricas. Portanto, a capacitância por unidade de área ou capacitância específica de um supercapacitor $\left(\mathrm{Fm}^{-2}\right)$ é estabelecida rearranjando a equação da capacitância teórica da seguinte maneira:

$$
C_{H}=\frac{C}{A}=\frac{{ }^{\varepsilon_{o} \varepsilon_{r}}}{\delta}
$$

Embora o modelo seja limitado, não levando em consideração vários fatores que influenciam a dupla camada elétrica, ele serve como ponto de partida para o dimensionamento da capacitância para modelos posteriores (Gouy-Chapman e Stern). A capacitância por unidade de massa $\left(\mathrm{Fg}^{-1}\right)$ de um material poroso pode ser encontrada com a determinação experimental da área específica do material para o eletrodo do supercapacitor. 


\subsection{GRAFENO/ ÓXIDO DE GRAFENO E ÓXIDO REDUZIDO}

A grafita, também conhecida como grafite, é uma estrutura bem estudada e possui estrutura cristalina hexagonal. O óxido de grafita é um composto de intercalação, obtido por processos químicos nos quais grupos funcionais contendo oxigênio são intercalados entre os planos basais da grafita. Esta intercalação não altera a estrutura cristalina, apenas promove um aumento da distância interplanar dos planos 00L. Mesmo nos dias de hoje, não há um consenso sobre a estrutura da grafita oxidada. Dreyer e colaboradores (2010 e 2014) apresentam um excelente artigo de revisão sobre o assunto, onde o termo óxido de grafeno foi utilizado como definido pela IUPAC em 1995.

Nas últimas décadas, o crescente interesse pelas estruturas de pequenas dimensões culminou no aparecimento da nanociência e da nanotecnologia como áreas científicas de grande importância. Os materiais com escala nanométrica (1-100 nanômetros) apresentam diversas vezes comportamentos diferentes daqueles que são observados em escala macroscópica; os efeitos quânticos tornam-se mais pronunciados, possuem novas propriedades e os elementos químicos exibem padrões distintos de reatividade.

O carbono é um dos elementos mais versáteis da natureza, capaz de se organizar em diferentes estruturas, com escala nanométrica e com um tempo de vida muito curto, dando origem a uma variedade de estruturas estáveis com configurações poliatômicas diferentes, designadas como formas alotrópicas.

Estas são estruturas bem diferenciadas, com um ordenamento espacial exato dos orbitais em torno de um átomo central de carbono com distintos tipos de hibridação ( $s p 3$, $s p 2$ e $s p$ ). O número e a natureza das ligações ao átomo de carbono determinam a geometria e as propriedades dos vários alótropos (Pierson, 1993).

Até o início da década de 1920, as únicas estruturas organizadas conhecidas de carbono eram o diamante (hibridização $s p 3$ ) e a grafite (hibridização $s p 2$ ). Décadas mais tarde, o desenvolvimento de novos equipamentos de caracterização (como espectroscópios e microscópicos eletrônicos) e o constante interesse na investigação das cadeias carbonadas, levou à identificação de novas formas alotrópicas do carbono com hibridização do tipo sp2. Entre elas contam-se os fulerenos (C60), descobertos em 1985 por Robert F. Curl Jr., Sir Harold Kroto e Richard E. Smalley (Kroto et al., 1985) (prêmios Nobel da Química em 1996), os nanotubos de carbono, observados em 1991 por Sumiolijima (Iijima, 1991) e o grafeno, isolado e identificado em 2004 por Andre Geim e Konstantin Novoselov (prêmio Nobel da Física em 2010). 
O grafeno, nome dado à monocamada de grafite (Figura 3), foi observado experimentalmente muito antes do seu isolamento e identificação em 2004 (Novoselov et al., 2007). Consiste numa rede bidimensional constituída por uma estrutura hexagonal de átomos de carbono com hibridização $s p 2$, em que as distâncias C-C são aproximadamente $1,42 \AA$, com uma espessura de um átomo de carbono (aproximadamente 1 Angstrom $=10^{-8}$ $\mathrm{cm})$.

Para obter este material, o grupo liderado por Andre Geim, da Universidade de Manchester (Reino Unido), recorreu a um procedimento aparentemente simples, usando uma fita adesiva convencional, um lápis e aplicando um processo de esfoliação mecânica. $O$ grafeno é o elemento estrutural mais básico de alguns alótropos do carbono e, por este motivo, a sua estrutura é considerada a base de outras formas alotrópicas do carbono, como é mostrado na Figura 3 (Geim e Novoselov, 2007).

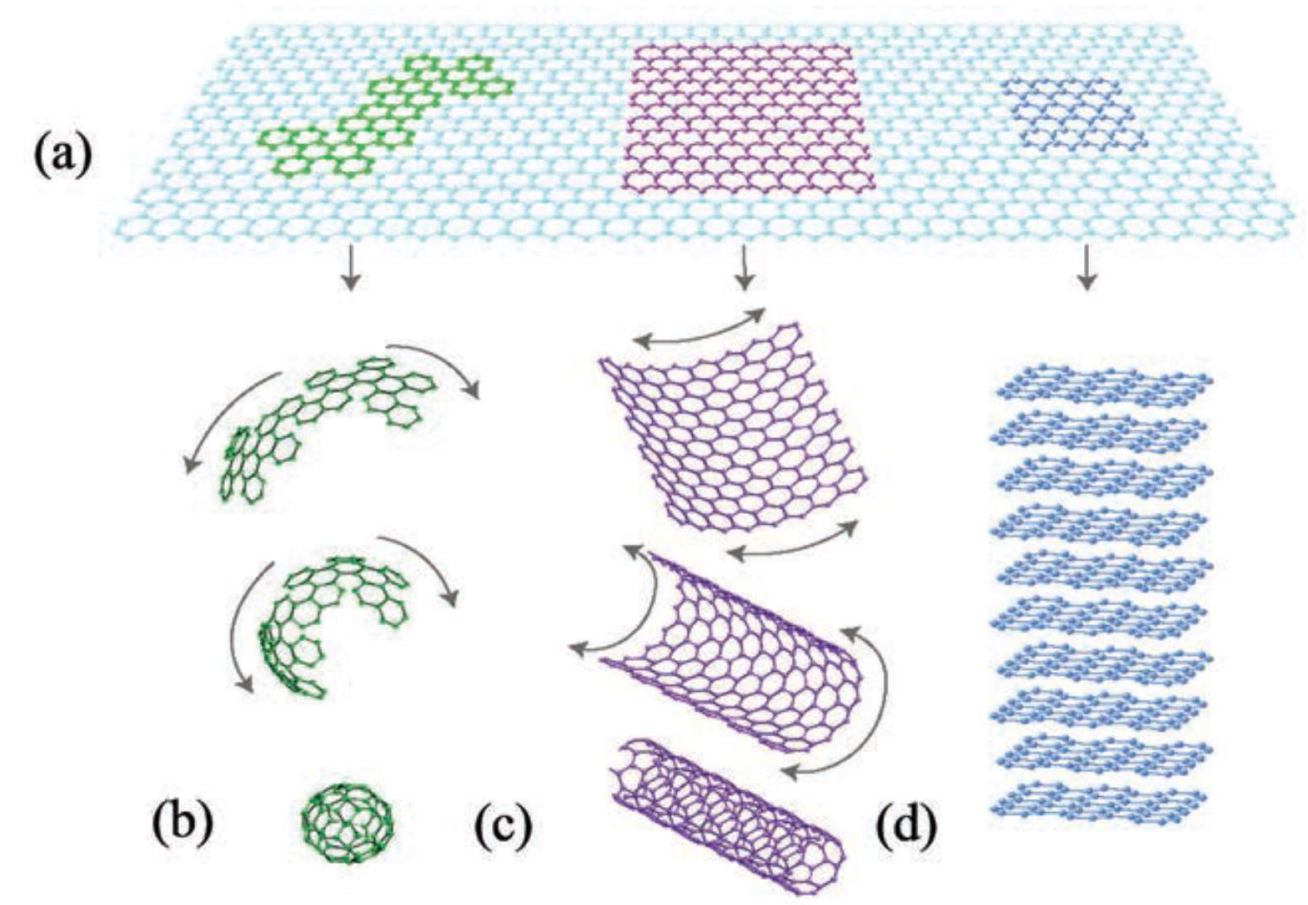

Figura 3 - (a) Grafeno, um material 2-D que serve de estrutura básica para alótropos de carbono em todas as dimensões. Pode (b) formar um fulereno, (c) ser enrolado na forma de um nanotubo ou (d) ser empilhado formando a grafite. (Geim e Novoselov, 2007).

\section{Propriedades do Grafeno}

O grafeno não só é o material mais fino de todos os materiais que são conhecidos, como também é considerado mais forte do que o diamante, sendo, além disso, flexível e 
extremamente duro. As propriedades eletrônicas do grafeno são únicas e constituem provavelmente o aspeto mais intrigante deste material. Além de conduzir corrente elétrica à temperatura ambiente melhor que qualquer outro material, também é transparente, absorvendo apenas 2,3\% da luz que incide sobre ele (Nair et al., 2008).

É a combinação de tais propriedades, além da alta resistência mecânica, a flexibilidade e o potencial para modificação química, que tem suscitado o grande interesse no grafeno.

\section{Métodos de síntese}

Entre os métodos de síntese mais usados para a produção de grafeno destaca-se a esfoliação das folhas de grafite por oxidação, utilizando oxidantes químicos fortes tais como $\mathrm{HNO}_{3}, \mathrm{KMnO}_{4}$ e $\mathrm{H}_{2} \mathrm{O}_{2}$. Como as folhas de carbono resultantes deste método contêm normalmente grupos funcionais, como ácidos carboxílicos, hidroxilos e epoxídios, o material é normalmente designado como óxido de grafeno. Estes grupos funcionais possibilitam a dispersão de folhas de óxido de grafeno em solventes polares, para assim permitir o seu estudo em meio líquido ou fluído.

Após o processo oxidativo, a rede sp2 é parcialmente distorcida, podendo ser restaurada através de metodologias de redução, tais como térmica (Schniepp et al., 2006), química (Gao et al., 2009), eletroquímica (Ramesha e Sampath, 2009), fototérmica (Abdelsayed et al., 2010), fotocatalítica (Ng et al., 2010), sonoquímica (Vinodgopal et al., 2010) ou com recurso a micro-ondas (Jasuja et al., 2010). A síntese de grafeno também é possível a partir do corte de nanotubos de carbono (Jiao et al., 2009; Bae et al., 2010).

Em 2004, Novoselov, Geim et al., obtiveram por esfoliação mecânica (fita adesiva) da grafita um número reduzido de camadas de grafeno tornando possível caracterizar propriedades físicas previstas para esta estrutura (Abdolhosseinzadeh et al., 2015).

O processo de esfoliação mecânica mostrou-se bastante ineficiente, portanto, a partir do trabalho de Novoselov e Geim novos estudos em busca de um método de produção de grafeno em larga escala e de suas possíveis aplicações tem crescido exponencialmente.

Dentre os métodos estudados a rota de oxidação da grafita seguida por esfoliação e redução tem se mostrada bastante promissora para obtenção de nanoestruturas com boas características físicas para diversas aplicações, tais como: sensores, supercapacitores etc. 
O produto obtido nesta rota foi sido definido como óxido de grafeno reduzido. A adoção deste termo é devida ao fato que o produto final obtido possui ainda ligados diversos grupos funcionais intercalados no processo de oxidação e defeitos cristalinos que determinam suas características físicas (Blanton e Majumdar, 2013).

Huh (2011) sugere o uso do número de planos 00L como forma de diferenciar o óxido de grafeno reduzido (ou grafeno) do grafite. Assim cristalitos com menos de dez planos 00L empilhados seriam definidos como óxido de grafeno reduzido.

\section{Aplicações}

Propriedades como elevada condutividade elétrica, combinada com sua resistência, flexibilidade e transparência, tornam o grafeno o material ideal para aplicações em dispositivos eletrônicos que sejam flexíveis. Devido à vantagem proveniente da elevada mobilidade dos elétrons, o grafeno é ideal na confecção de transístores de alta frequência para aplicações exigentes no domínio da eletrônica (Britnell et al., 2012). Estes componentes poderão ser essenciais para a criação de computadores ultrarrápidos.

O grafeno também pode ser usado como suporte para fixar nanopartículas metálicas ( $\mathrm{Au}, \mathrm{Pt})\left(\right.$ Kamat, 2009) e/ou semicondutoras $\left(\mathrm{ZnO}, \mathrm{TiO}_{2}\right)$, tendo já sido produzidos compósitos de óxido de grafeno-metal (Vinodgopal et al., 2010) e compósitos de óxido de grafeno-semicondutor ( $\mathrm{Ng}$ et al., 2010). Nestes materiais, o grafeno pode atuar simplesmente como suporte das nanopartículas ou mesmo de forma direta nas reações catalíticas.

O grafeno também desempenha um papel relevante como suporte para aumentar a área eletrocatalítica em células de combustível, bem como em outros sistemas de conversão de energia - na literatura encontram-se descritos exemplos muito promissores de aplicações em células de combustível e baterias de lítio (Seger e Kamat, 2009). Verificou-se também que a dispersão de nanopartículas de semicondutores em folhas de óxido de grafeno melhora o desempenho das células fotovoltaicas (Nget al., 2010). 


\section{MATERIAIS E MÉTODOS}

\subsection{PREPARAÇÃO DO ÓXIDO DE GRAFENO PELO MÉTODO HUMMERS}

O óxido de grafeno foi sintetizado utilizando o método Hummers modificado e consistiu na mistura de $3 \mathrm{~g}$ de grafite em pó da marca Merck (99\%), $3 \mathrm{~g}$ de nitrato de sódio $\left(\mathrm{NaNO}_{3}\right)$ da Merck e $140 \mathrm{~mL}$ de ácido sulfúrico $\left(\mathrm{H}_{2} \mathrm{SO}_{4}\right)$ da marca Vetec Química Fina, em banho de gelo. Em seguida foi adicionado gradualmente $18 \mathrm{~g}$ de permanganato de potássio $\left(\mathrm{KMnO}_{4}\right)$ Merck e a temperatura mantida em torno de $35^{\circ} \mathrm{C}$ por uma hora. Após este período, $200 \mathrm{~mL}$ de água deionizada foram adicionados lentamente e a solução mantida sob agitação a $90^{\circ} \mathrm{C}$. Ao final da reação, foram adicionados $100 \mathrm{~mL}$ de água deionizada, seguido por 18 $\mathrm{mL}$ de peróxido de hidrogênio $30 \%\left(\mathrm{H}_{2} \mathrm{O}_{2}\right)$, Merck. O produto foi lavado com água deionizada, $\mathrm{NaOH}(1 \mathrm{M})$ e $\mathrm{HCl}(1 \mathrm{M})$, procedentes da Casa Americana, até o pH 7. O óxido de grafeno foi separado da solução em uma centrífuga Hitachi a 12.000 rpm por 10 minutos.

As amostras de óxido de grafeno foram dispersas em etanol e esfoliadas usando um ultra sonicador (Sandersultrasonic, modelo Soniclean 2PS, $40 \mathrm{kHz}$ ) por uma hora e, subsequentemente, secas. A Figura 4a apresenta um fluxograma esquemático do processo de síntese descrito acima, e as Figuras 4ba 4e mostram fotos de diversas etapas deste processo.

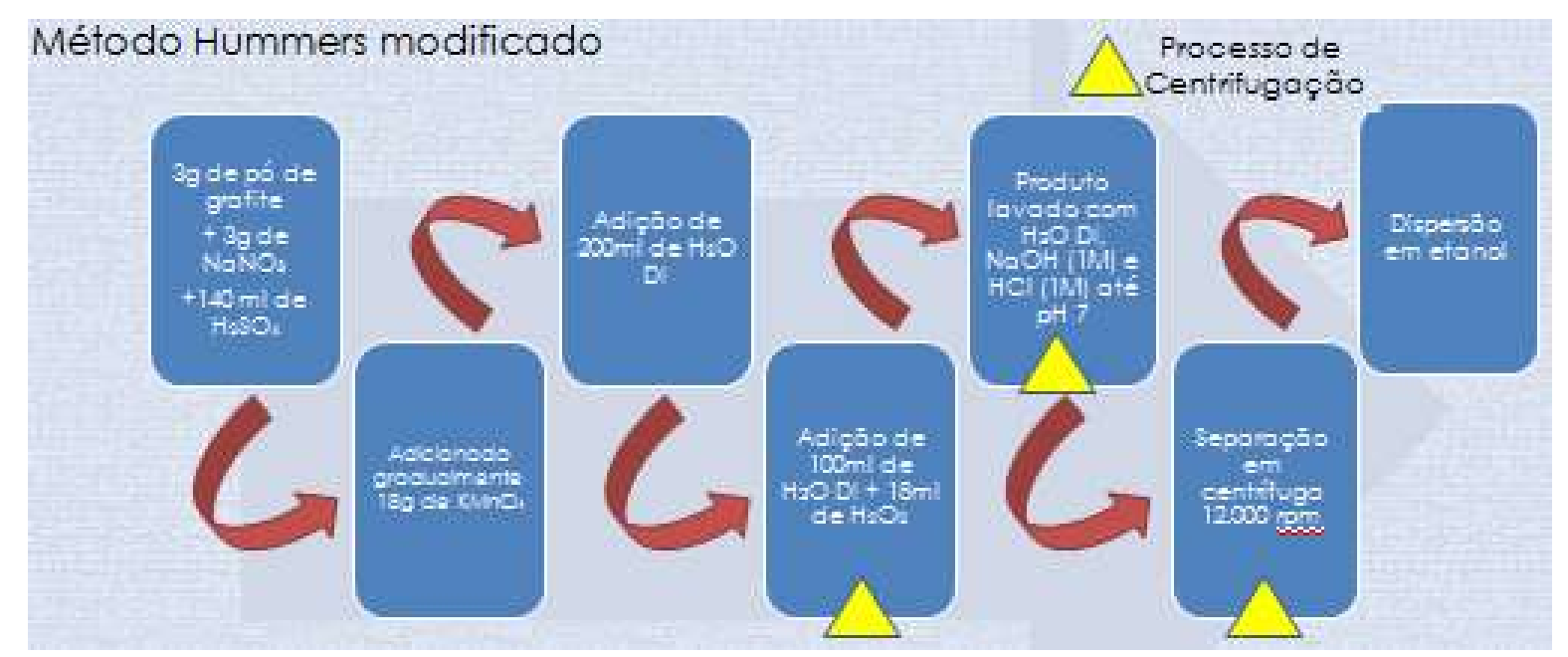

Figura 4a - Modelo esquemático do método de Hummers modificado para obtenção do óxido de grafeno. 


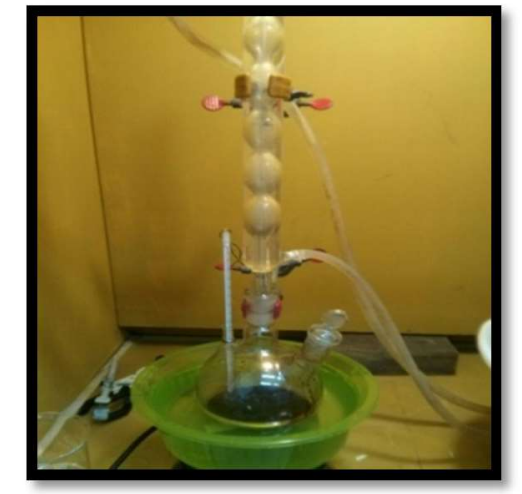

Figura 4b - Etapa inicial de preparação do óxido de grafeno através de reação sob resfriamento.

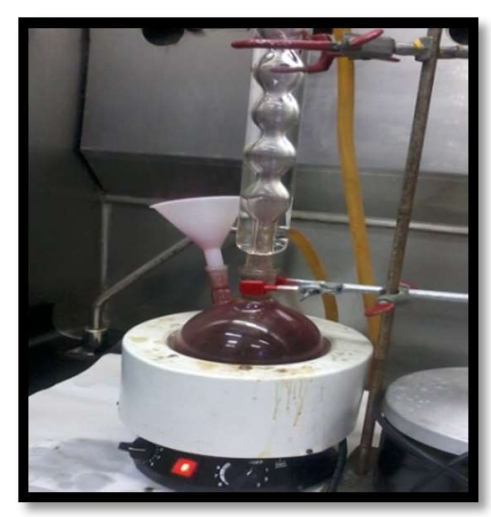

Figura 4c - Etapa intermediária de adição de água e aquecimento.

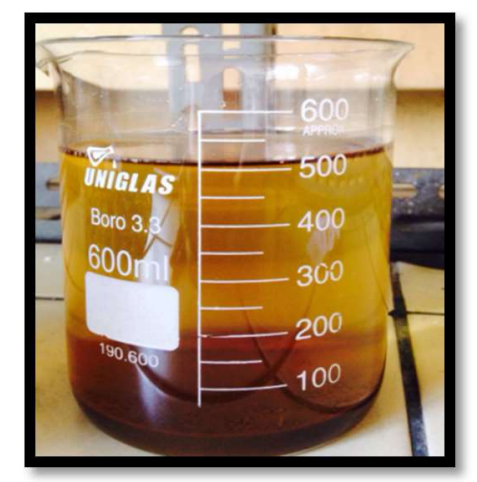

Figura 4d - Início da etapa de precipitação e adição de peróxido. 


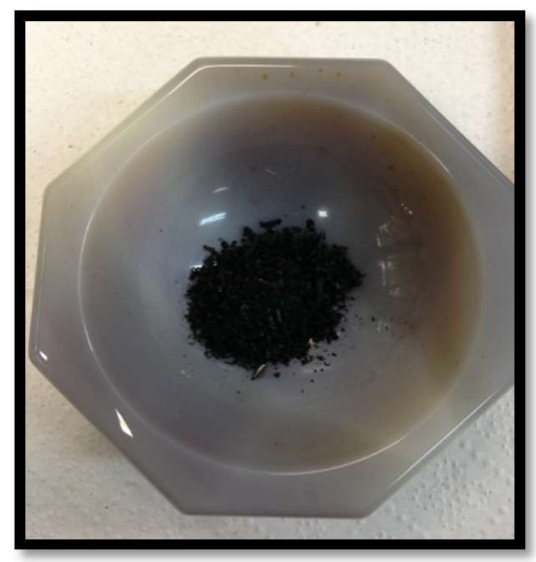

Figura 4e - processo de obtenção do óxido de grafeno finalizado por meio de separação em centrífuga e esfoliação em ultra sonicador.

\subsection{REDUÇÃO DO ÓXIDO DE GRAFENO}

Para a redução do óxido de grafeno em várias temperaturas foi adotado o procedimento descrito a seguir: o material foi colocado em um vaso de pressão de aço inoxidável para processamento em diversas temperaturas a pressão de 4,2 mbar, com bomba mecânica de duplo estágio a pressão reduzida a $10^{-2} \mathrm{mbar}$ e o sistema foi aquecido automaticamente até a temperatura de processo $\left(200,400,600,800\right.$ e $\left.1000^{\circ} \mathrm{C}\right)$. A taxa de aquecimento utilizada foi de $5{ }^{\circ} \mathrm{C} /$ minuto. Neste sistema, a pressão foi monitorada utilizando o sensor para a faixa de pressão $\left(10^{-1}-10^{-2} \mathrm{mbar}\right)$. Como meio de condicionar o óxido de grafeno, foi utilizado um cadinho de inox, com tampa. A tampa por sua vez possui um orifício para permitir a saída de ar no processo de redução. Na Figura 5 é mostrado o sistema utilizado para a redução do óxido de grafeno. 


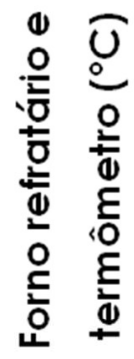

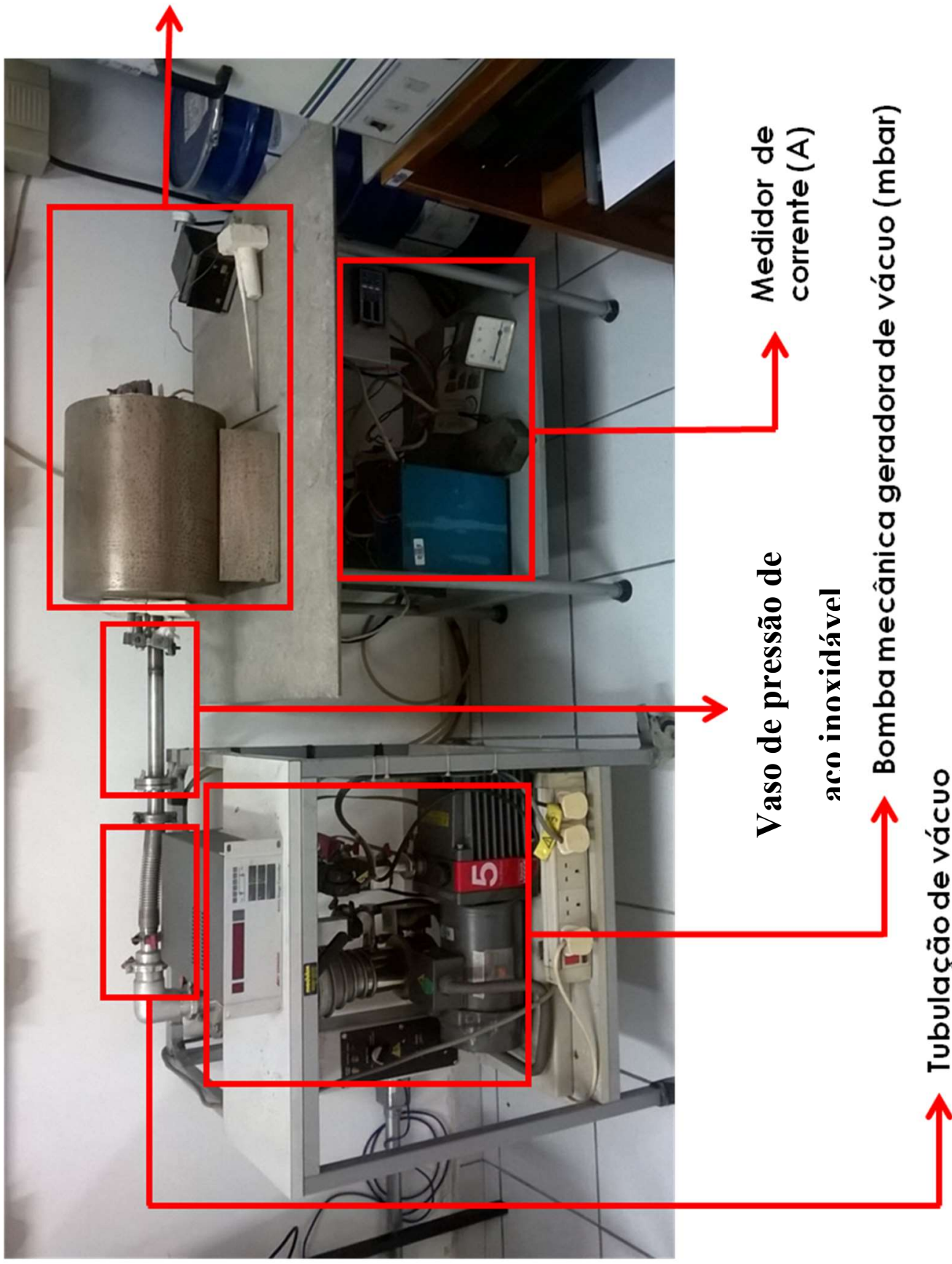

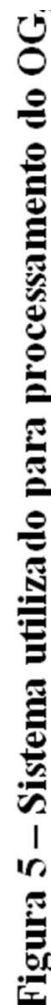




\subsection{CARACTERIZAÇÃO POR DIFRAÇÃO DE RAIOS X (DRX)}

A difração de raios $\mathrm{X}$ tem sido amplamente utilizada no estudo das características da grafita (Biscoe e Warren,1942; Iwashita et al., 2004; Hussain et al., 2000; Lu et al., 2001; Manoj e Kunjomana, 2012). Estes métodos de cálculo também são válidos para o caso do óxido de grafeno reduzido.

Foram efetuados cálculos para obtenção dos dados de distância interplanar, tamanho do cristalito na direção 00L e estimativa do número de planos empilhados em função do ajuste de curvas estatísticas do tipo Pseudo-Voigth1 e Pearson IV.

A distância interplanar é calculada pela fórmula de Bragg:

$$
n \lambda=2 d \operatorname{sen}(\theta)
$$

onde: $\lambda$ é o comprimento de onda utilizado, $d$ a distância interplanar e $\Theta$ o ângulo de difração da reflexão.O valor da posição do centro da banda 002 , isto é o valor de $2 \Theta$, foi calculado pelo ajuste da função de distribuição Pearson IV ao perfil da banda 002 .

Para um cálculo mais preciso deste valor é necessário corrigir o erro experimental da medida decorrente de um possível desalinhamento do equipamento. Este erro pode ser determinado adicionando-se um composto padrão, isto é, com a distância interplanar bem estabelecida em relação à amostra, ou através do refinamento do composto padrão pelo método de ajuste do padrão de difração completo.

Além do erro instrumental, por ser o OG um material higroscópico, o levantamento do difratograma em atmosfera ambiente (umidade ambiente) pode ser outra fonte de erro para o desvio do valor medido (Blanton e Majumdar, 2012; Buchsteiner et al., 2006; Lerf et al., 2006).

Para o cálculo da largura a meia altura (FWHM) utilizou-se a função PseudoVoight1 no ajuste do perfil da banda 002. Este valor foi utilizado no cálculo do tamanho de cristalito na direção 002:

$$
L_{c}=L_{002}=\frac{K \lambda}{\beta_{002} \cos (\theta)}
$$


A partir dos valores calculados para a distância interplanar e para o tamanho de cristalito na direção 002 foi estimado o número de planos empilhados pela relação:

$$
N=\frac{L_{002}+d_{002}}{d_{002}}
$$

No entanto, cabe aqui ressaltar que a técnica de DRX não pode ser utilizada individualmente para caracterizar o óxido de grafeno, pois, conforme definido anteriormente, é necessário confirmar a presença de ligações do tipo $s p 2$, e para isso diversas técnicas têm sido usadas (tais como: FITR, Raman, XPS) conjuntamente com a DRX.

A distância interplanar entre os planos 00L é utilizada para caracterizar o grau de oxidação da grafita. Na grafita não oxidada esta distância é de $3,34 \AA\left(2 \Theta \cong 26,7^{\circ}\right)$. Conforme ocorre a intercalação dos grupos funcionais com oxigênio esta distância aumenta para valores em torno de $9 \AA\left(2 \Theta \cong 10^{\circ}\right)$.

No padrão de difração de raios X (ou difratograma) este fenômeno é observado pelo deslocamento da reflexão $2 \Theta \cong 26^{\circ}$ para uma posição em torno de $10^{\circ}$ (Krishnamoorths et al., 2013; Abdolhosseinzadeh et al., 2015; Mehl et al., 2014).

O comportamento inverso é observado quando ocorre o processo de redução, isto é, a remoção dos grupos funcionais da grafita. A posição final da reflexão é esperada o mais próxima possível $2 \Theta \cong 26,7^{\circ}$, indicando a remoção quase total dos grupos funcionais.

Há diversos métodos para a redução do óxido de grafeno que resultam em materiais com características diferentes, de maneira que a distância entre os planos 002 após a redução é dependente do método utilizado.

$\mathrm{O}$ equipamento de difração de raios-X utilizado nesta pesquisa foi HIGAKU (Multiflex) radiação $\mathrm{CuK} \alpha$. 


\subsection{CARACTERIZAÇÃO POR ESPECTROSCOPIA NO INFRAVERMELHO COM TRANSFORMADA DE FOURIER}

As técnicas de espectroscopia estão baseadas na interação da radiação eletromagnética com a matéria e são os instrumentos mais eficazes na caracterização de materiais em qualquer campo do conhecimento. Dependendo da energia da radiação empregada, é possível obter informações sobre diferentes propriedades do sistema. Assim, o uso de radiação na região do ultravioleta ou do visível (UV-Vis) altera a energia dos elétrons em moléculas e íons (Faria et al.,2002).

Em contrapartida, a radiação no infravermelho altera as vibrações dos átomos nessas espécies químicas. Quando se incide radiação policromática sobre uma determinada amostra é possível registrar quais componentes dessa radiação são absorvidas por ela, já que essa absorção não se dá de forma contínua, mas acontece para valores específicos. E por isso que se diz que a energia armazenada na matéria pode ser somente quantizada e seu aumento ou diminuição também se dá através de quantidades discretas.

Apesar de a espectroscopia de absorção no UV-Vis ser uma técnica bastante difundida, o espectro correspondente apresenta bandas largas e a obtenção de informações específicas em amostras de natureza desconhecida é extremamente difícil. Nesse sentido, a espectroscopia de absorção no infravermelho (FTIR) é um recurso bastante valioso na caracterização de materiais, porque as vibrações dos átomos acontecem em valores específicos de frequência, característicos dos grupos funcionais que constituem a espécie química. Assim, vibrações referentes aos íons sulfato, carbonato, fosfato, nitrato etc. aparecem em faixas de frequência características, permitindo que estes íons sejam rapidamente identificados (Faria et al., 2002).

As análises FTIR permitem analisar o grau de oxidação do óxido de grafeno e grupos oxigenados, tais como hidroxilas, epóxi, carboxila e carbonila, que foram introduzidos durante processo de oxidação.

Os modos vibracionais de uma molécula são alterados quando sofrem a incidência de radiação infravermelha. Esta radiação, com número de ondas entre $10^{4} \mathrm{e} \quad 10^{2}$ $\mathrm{cm}^{-1}$, sendo absorvida por um composto, é transformada em energia vibracional. As energias com número de onda menor que $10^{2} \mathrm{~cm}^{-1}$ transformam-se em rotação molecular. Na Tabela 1 são listadas as principais bandas de absorção no infravermelho e respectivas atribuições aos grupos funcionais presentes no óxido de grafeno. 
Tabela 1- Identificação das principais bandas presentes no óxido de grafeno reduzido.

\begin{tabular}{|c|c|}
\hline Banda (cm-1) & Atribuição \\
\hline 3380 & Estiramento da ligação O-H \\
\hline 2968 & Estiramento da ligação $\mathrm{C}-\mathrm{H}$ de alifáticos \\
\hline 1597 e 1498 & Estiramento da ligação $\mathrm{C}=\mathrm{C}$ de anéis aromáticos \\
\hline 1456 & Dobramento assimétrico do grupo $\mathrm{CH} 3$ \\
\hline 1241 & $\begin{array}{l}\text { Deformação axial simétrica em fase das ligações C-C } \\
\text { e C-O de anéis epóxi }\end{array}$ \\
\hline 1176 & $\begin{array}{l}\text { Deformação axial da ligação C-O acoplada a } \\
\text { deformação axial da ligação C-C adjacente }\end{array}$ \\
\hline 1038 & Dobramento simétrico da ligação $\mathrm{Ar}-\mathrm{O}-\mathrm{R}$ \\
\hline 830 & Dobramento de anéis aromáticos fora do plano \\
\hline
\end{tabular}

As análises de FTIR do óxido de grafeno na forma bruta e reduzida foram realizadas no espectrômetro da Perkin Elmer, modelo Frontier 100 em pastilhas de KBr. 


\subsection{MICROSCOPIA ELETRÔNICA DE VARREDURA}

A microscopia eletrônica de varredura (MEV) foi utilizada para o estudo da superfície dos materiais utilizados neste estudo. Para realizar a caracterização microestrutural, as amostras foram preparadas utilizando as técnicas convencionais além da adesão do material em fita condutora. Foi utilizado um microscópio eletrônico de varredura TM-3000 com EDS (Figura 6).

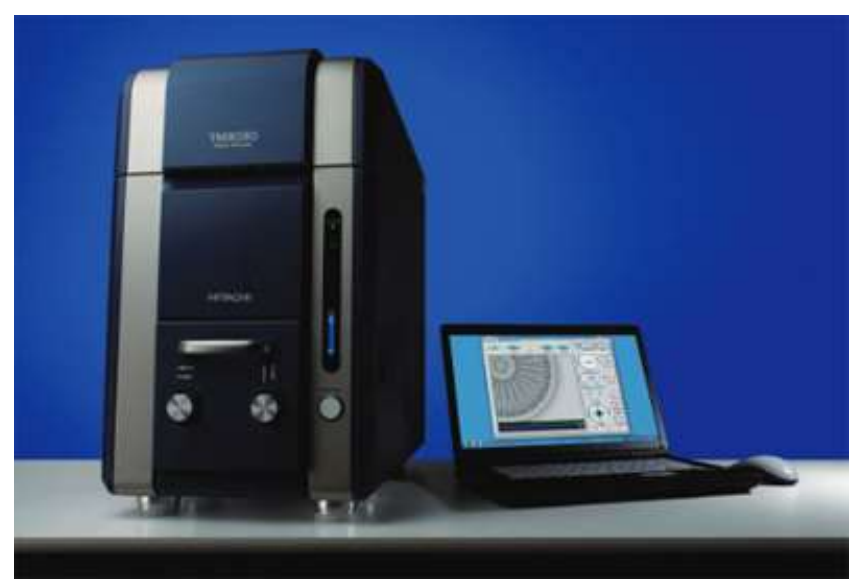

Figura 6 - Microscópio Eletrônico de Varredura - Tabletop Hitachi

\subsection{TERMOGRAVIMETRIA (TG)}

A termogravimetria (TG) é a técnica termoanalítica responsável por acompanhar a variação da massa em função do tempo, a uma temperatura constante, ou em função da temperatura.

Pode-se dizer que o equipamento da análise termogravimétrica é composto basicamente por uma termobalança. O equipamento (Figura 7) pode mudar de parâmetros de uma empresa para outra, mas os princípios fundamentais de todos eles são iguais.

A termobalança é um instrumento que permite a pesagem contínua de uma amostra em função da temperatura.

Os principais componentes de uma termobalança são: balança registradora, forno, suporte de amostra e sensor de temperatura, programador de temperatura do forno, sistema registrador e controle da atmosfera do forno. A Figura 7 representa a imagem do equipamento de termogravimetria utilizado para as análises. 


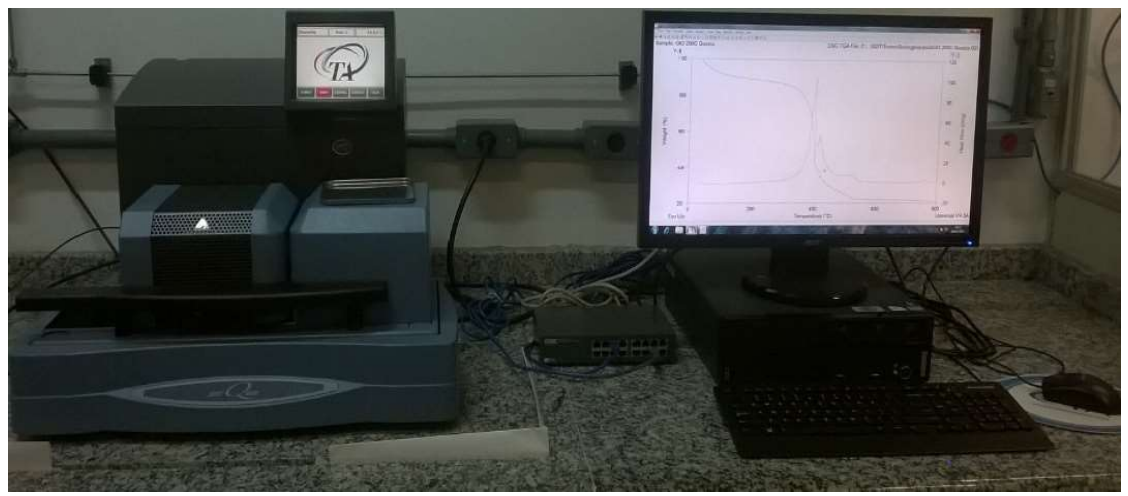

Figura 7: equipamento utilizado para as análises termogravimétricas TA Instruments SDT-Q600

Normalmente a razão de aquecimento pode atingir de $1^{\circ} \mathrm{C} \min ^{-1}$ até $100^{\circ} \mathrm{C} \min ^{-1}$ dependendo do fabricante. A temperatura final vai depender do forno, podendo chegar a, até, $2000^{\circ} \mathrm{C}$. A sensibilidade é da ordem de $0,1 \mu \mathrm{g}$, geralmente com capacidade de até 1 g. (Cavalheiro, 2011).

No presente trabalho utilizou-se o equipamento de análise termogravimétrica (TG - SDT Q6000). Os experimentos de termogravimetria (TGA) do OG e dos óxidos reduzidos a $200{ }^{\circ} \mathrm{C}, 400{ }^{\circ} \mathrm{C}, 600{ }^{\circ} \mathrm{C}, 800{ }^{\circ} \mathrm{C}$ e $1000{ }^{\circ} \mathrm{C}$ foram realizados em atmosfera inerte (N2) sob condição de fluxo de $100 \mathrm{ml} / \mathrm{min}$, rampa de aquecimento de $20^{\circ} \mathrm{C} / \mathrm{min}$ e cadinho de platina.

\subsection{ESPECTROSCOPIA DE FLUORESCÊNCIA}

A técnica analítica de fluorescência de raios-X (XRF - X-Ray Fluorescence) foi introduzida na década de 50 e vem sendo utilizada para a avaliação quali-quantitativa da composição química em diversos tipos de amostras. Por ser uma técnica de baixo custo e que permite uma análise eficaz e simultânea de diversos elementos, pode ser aplicada em múltiplas áreas a fim de se obter uma correlação entre os elementos componentes de uma amostra.

A análise por fluorescência se baseia em medir as intensidades (números de raios-X detectados por unidade de tempo) de radiação emitidas pelos componentes constituintes de uma determinada amostra quando um elemento químico é devidamente excitado, ocorrendo emissão de uma radiação característica (Serpa, 2007). 
Quando um elemento presente na amostra é irradiado por um feixe de fóton com energia equivalente ou superior à energia de ligação característica de um elétron localizado em um determinado orbital, este tende a ejetar os elétrons do interior dos níveis dos átomos, os quais se encontram instáveis (Potts et al., 2002).

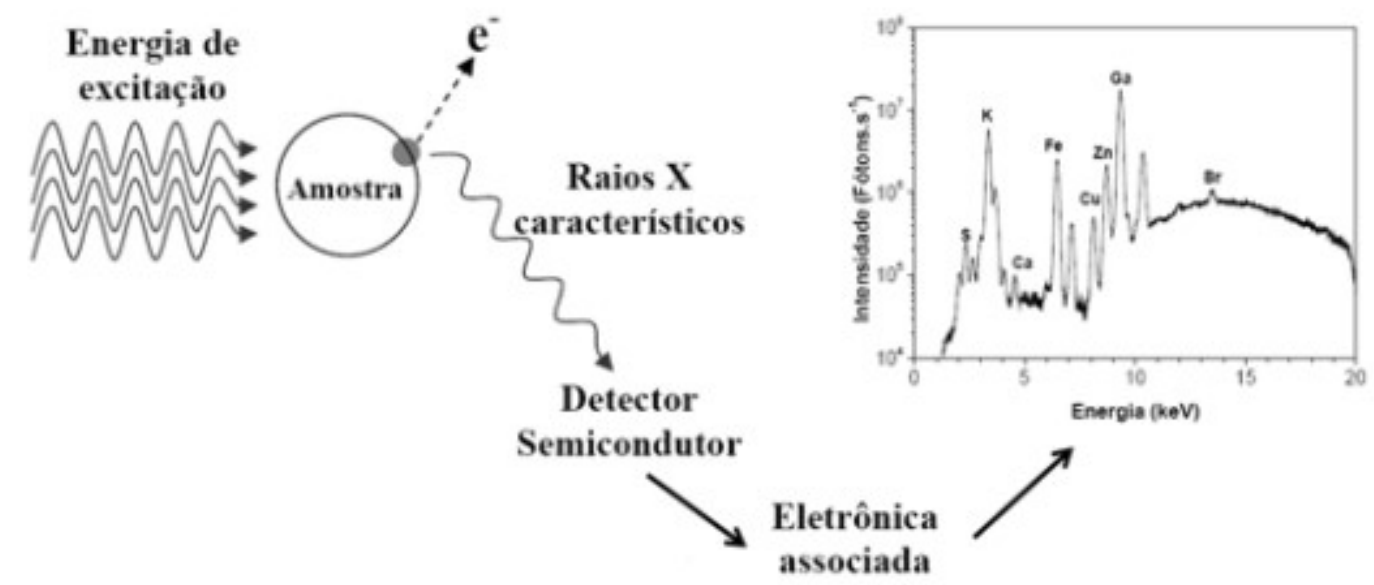

Figura 8. Processo básico da FRX (Serpa, 2007).

\subsection{PREPARAÇÃO DE SUPERCAPACITORES DE ÓXIDO DE GRAFENO}

A montagem dos eletrodos de óxido de grafeno reduzido para os supercapacitores foi realizada utilizando eletrólito biocompatível de sulfato de sódio em concentração fixa $(1 \mathrm{M})$. Cerca de $60 \mathrm{mg}$ de óxido de grafeno reduzido em vácuo foi classificado ( $<53 \mu \mathrm{m}$ ), misturado com 12,5 mg de Vulcan XC-72-R (Cabot Corporation) e $64 \mathrm{mg}$ de politetrafluoroetileno (PTFE com 60\% $\mathrm{H}_{2} \mathrm{O}: \sim 40 \mathrm{mg}$ de PTFE). Álcool isopropílico (isopropanol; $\mathrm{C}_{3} \mathrm{H}_{8} \mathrm{O}$ ) foi utilizado como meio diluente durante a homogeneização da mistura. O Vulcan XC-72-R foi misturado primeiramente com o PTFE para formar um ligante condutor e posteriormente o óxido de grafeno reduzido foi adicionado à mistura. Durante a etapa de homogeneização a mistura foi sempre mantida em isopropanol, que foi posteriormente evaporado em estufa $\left(\sim 80^{\circ} \mathrm{C}\right)$.

A mistura já seca foi prensada $(2 \mathrm{t})$ em uma matriz de metal duro $(\phi=10 \mathrm{~mm})$ por 5 minutos. Estes eletrodos com 40 45 mg de material ativo foram aderidos em um coletor de corrente de aço inoxidável $(\phi=14 \mathrm{~mm})$ utilizando cola condutora de carbono. Os supercapacitores foram montados utilizando papel poroso para filtragem como separador dos eletrodos que foram mantidos juntos com clipes de metal após 1 hora de imersão no 
eletrólito. O coletor de corrente de aço inoxidável provido com fio de níquel (fixado com solda ponto) está mostrado na Figura 9 ao lado do clipe de metal. O separador foi substituído após cada medida nos diferentes potenciais. $\mathrm{O}$ arranjo com o clipe de metal facilitou bastante a substituição do separador (potenciais acima do potencial de decomposição da água, 1,23 $\mathrm{V}$, propiciam o depósito de resíduos no separador).
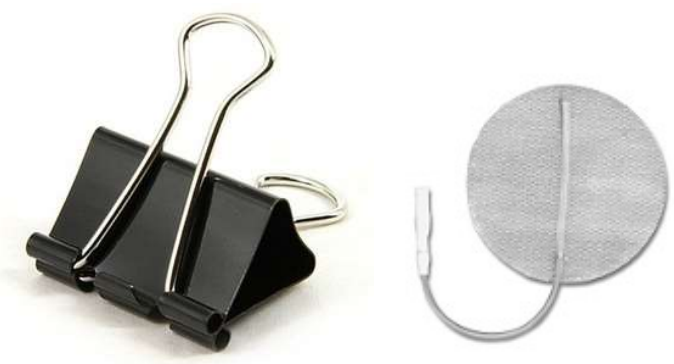

Figura 9 - Clipe de metal utilizado para unir os eletrodos do supercapacitor.

A caracterização elétrica dos supercapacitores foi realizada utilizando o analisador Arbin BT-4 (Software MITS Pro-4) (Figura 10).

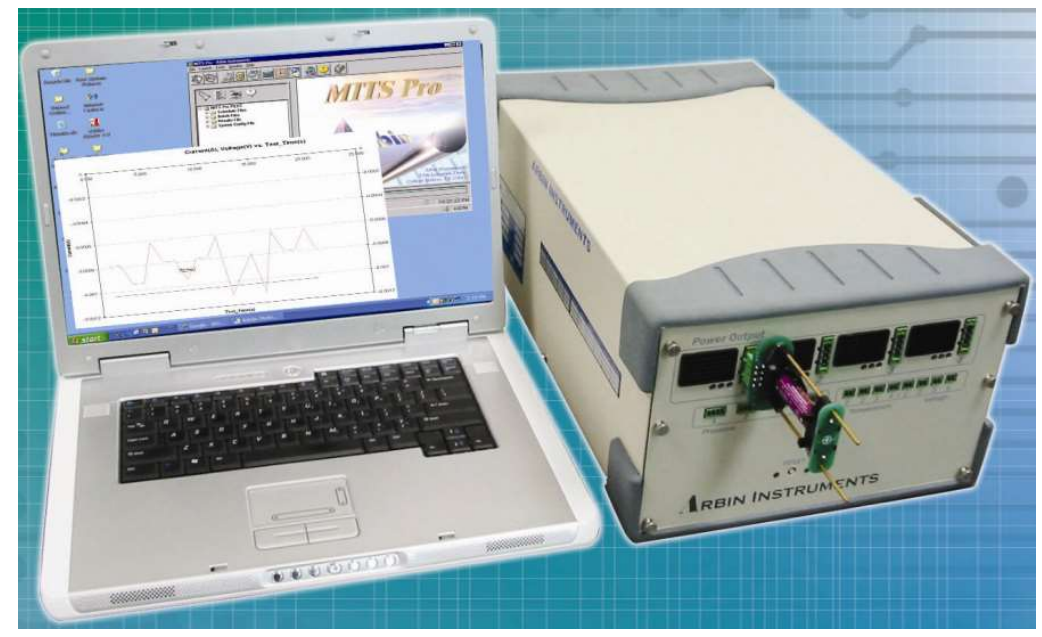

Figura 10 - analisador Arbin BT-4 com Software MITS Pro-4

A capacitância específica $\left(\mathrm{Fg}^{-1}\right)$ está relacionada com a quantidade de carga elétrica efetivamente armazenada no supercapacitor por unidade de massa.

A capacitância foi determinada utilizando o método de descarga de corrente constante, com base na curva de descarga. Os supercapacitores foram carregados em valores não excedendo o potencial máximo $(1,6 \mathrm{~V})$ permitido pelo eletrólito de sulfato de sódio (Demarconnay et. al., 2010). Neste método, a capacitância é calculada utilizando a eq.1 (Casini et al., 2016): 


$$
C=\frac{I\left(t_{2}-t_{1}\right)}{\left(V_{1}-V_{2}\right)}(F)
$$

O período de tempo $t_{2}-t_{1}$ é medido durante o qual o potencial entre os supercapacitores diminui de $80 \%$ a $40 \%$ do potencial de carga $\left(\mathrm{V}_{1}=0,8 \mathrm{~V}_{\text {máx }}\right.$ e $\mathrm{V}_{2}=0,4$ $\left.\mathrm{V}_{\text {máx }}\right)$ e $I$ é a corrente constante de descarga. $\mathrm{O}$ valor da capacitância de cada eletrodo é o dobro da capacitância determinada para o supercapacitor composto por duas duplas camadas elétricas (erro: $\pm 0,1 \%$ ). A capacitância específica é dada em função da capacitância do eletrodo dividido pela média da massa de material ativo presente em um eletrodo. A densidade de corrente por eletrodo utilizada é da ordem de $40 \mathrm{mAg}^{-1}$.

A resistência interna de um supercapacitor é especificada pela resistência em série equivalente (ESR). A ESR representa a soma da resistividade dos componentes do supercapacitor (eletrodos de grafeno, eletrólito e coletor de corrente). A melhoria na eficiência do supercapacitor está associada à diminuição da ESR, sendo que, a maior contribuição para o valor da ESR vem do próprio óxido de grafeno. O método de medição mais comum é denominado "interrupção da corrente", no qual se mede a variação da tensão no momento da interrupção. A ESR é calculada, então, pela eq.2 (Casini et al., 2016):

$$
E S R=\frac{V_{f}-V_{i}}{I}(\Omega)
$$

$V_{f}-V_{i}$ representa a variação da tensão após a interrupção da corrente por 5 segundos e $I$ representa a corrente de descarga constante. 


\section{RESULTADOS}

\subsection{CARACTERIZAÇÃO DO ÓXIDO DE GRAFENO}

\subsubsection{MICROSCOPIA ELETRÔNICA DE VARREDURA}

A Figura 11 mostra uma micrografia por micorscopia eletrônica de varredura do óxido de grafeno preparado pelo método Hummers. O material apresenta um aglomerado de placas finas com predominância de estrutura mais colunar do que equiaxial. O óxido de grafeno preparado nestas condições mostrou uma aparência morfológica bastante homogênea.

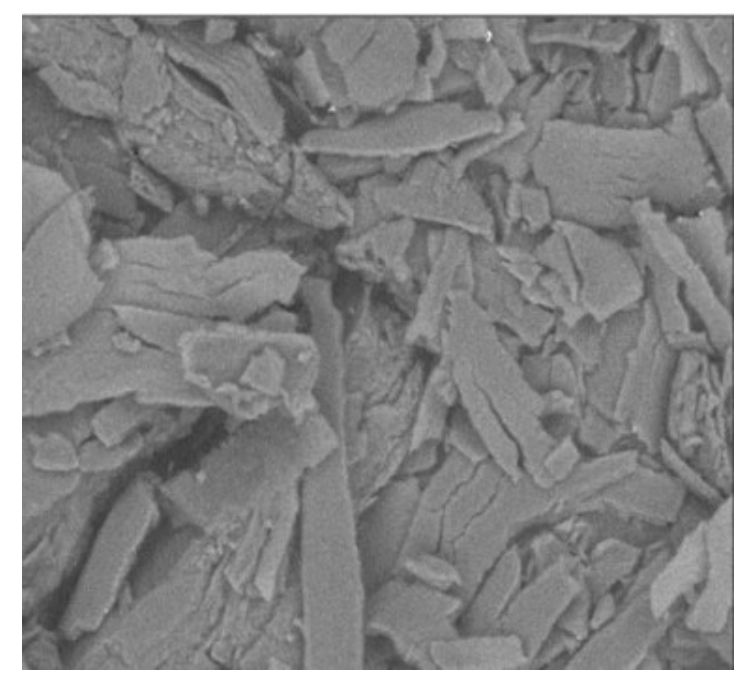

Figura 11 - Micrografia do óxido de grafeno preparado pelo método Hummers modificado. 


\subsubsection{FLUORESCÊNCIA DE RAIOS-X}

A Figura 12 mostra um espectro obtido por fluorescência de raios $\mathrm{X}$ do óxido de grafeno preparado pelo método Hummers. A análise qualitativa do material produzido apresentou a presença de mangânes devido ao uso do permanganato de potássio como agente oxidante da grafite e chumbo, ferro e cobre possivelmente provinentes dos reagentes constituintes do processo de fabricação ou da própria matéria-prima de partida.
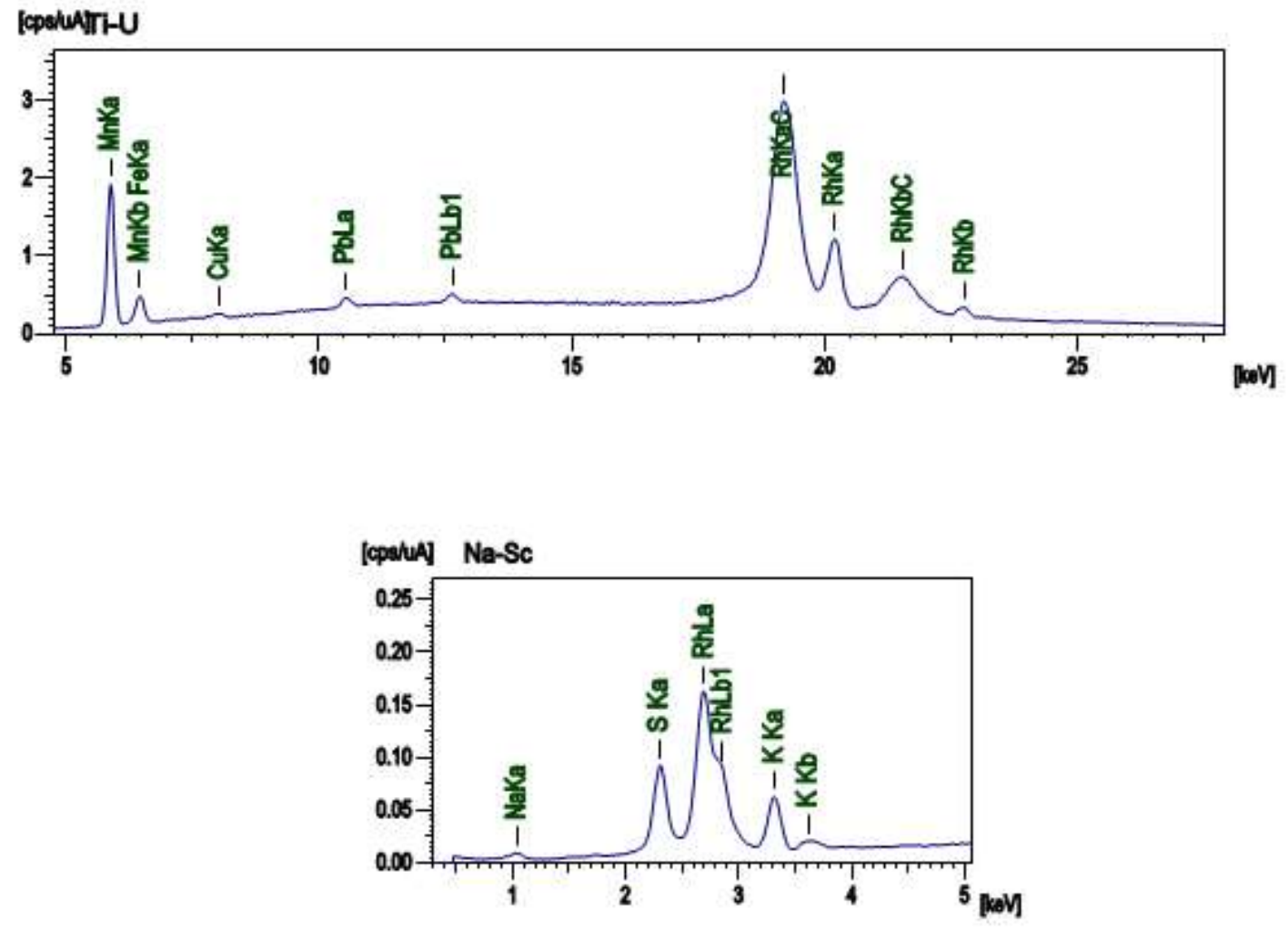

Figura 12 - Espectro de fluorescência de raios X do material do óxido de grafeno preparado pelo método Hummers modificado. 
Tabela 2. Análise de fluorescência de raios-X semiquantitativa do óxido de grafeno.

\begin{tabular}{|c|c|c|c|c|}
\hline Elemento & $\begin{array}{c}\text { Quantidade } \\
(\%)\end{array}$ & Desvio Padrão & $\begin{array}{r}\text { Linha - } \\
\text { (c) }\end{array}$ & $\begin{array}{l}\text { Intensidade } \\
\mathrm{os} / \mu \mathrm{A})\end{array}$ \\
\hline $\mathrm{Na} 2 \mathrm{O}$ & 72,64 & 2,00 & $(\mathrm{NaK} \alpha)$ & 0,06 \\
\hline $\mathrm{SO}_{3}$ & 12,47 & 0,06 & $(\mathrm{~S} \mathrm{~K} \alpha)$ & 1.07 \\
\hline MnO & 8,37 & 0,04 & $(\mathrm{Mn} \mathrm{K} \alpha)$ & 15,40 \\
\hline $\mathbf{K}_{2} \mathbf{O}$ & 5,28 & 0,04 & $(\mathrm{~K} \mathrm{~K} \alpha)$ & 0,62 \\
\hline $\mathrm{Fe}_{2} \mathrm{O}_{3}$ & 0,55 & 0,02 & $(\mathrm{Fe} \mathrm{K} \alpha)$ & 1,22 \\
\hline PbO & 0,53 & 0,02 & $(\mathrm{~Pb} \mathrm{~L} \beta 1)$ & 1,86 \\
\hline $\mathrm{CuO}$ & 0,16 & 0,01 & $(\mathrm{Cu} \mathrm{K} \alpha)$ & 0,67 \\
\hline
\end{tabular}

\subsection{REDUÇÃO DO ÓXIDO DE GRAFENO EM VÁCUO}

A pressão durante o processamento se manteve na faixa de $1 \times 10^{-2} \mathrm{a} \quad 10 \times 10^{-}$ ${ }^{2}$ mbar e isto pode ser atribuído à pequena quantidade óxido de grafeno utilizada $(0,3 \mathrm{~g})$ nos experimentos de redução em vácuo por bomba rotativa, com plena capacidade de bombeamento dos gases liberados pelo material em processamento.

Nas Figuras 13 a 17 é mostrada a variação da pressão de processamento do óxido de grafeno preparado pelo método Hummers com o aumento da temperatura. Observa-se um aumento da pressão por volta de 250 a $300{ }^{\circ} \mathrm{C}$ e outro a aproximadamente $700{ }^{\circ} \mathrm{C}$, que podem ser atribuídos a liberação de gases das amostras. 


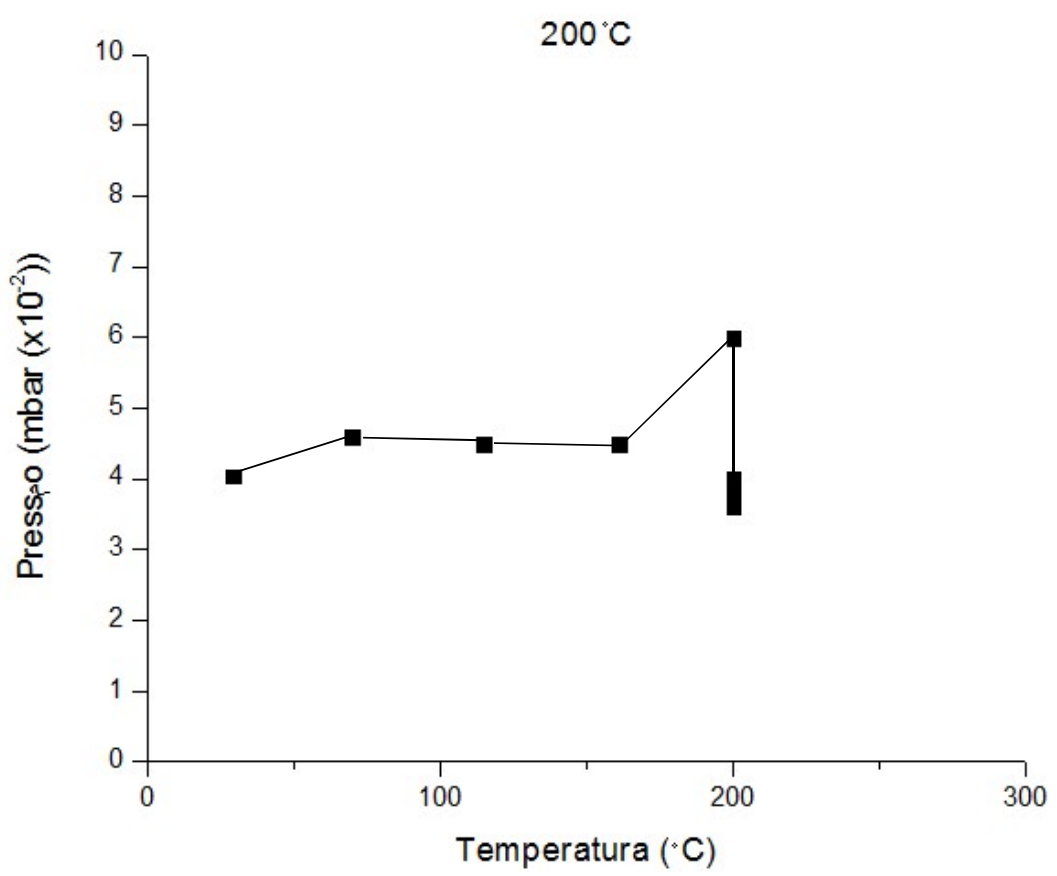

Figura 13- Variação da pressão em função da temperatura a $200^{\circ} \mathrm{C}$.

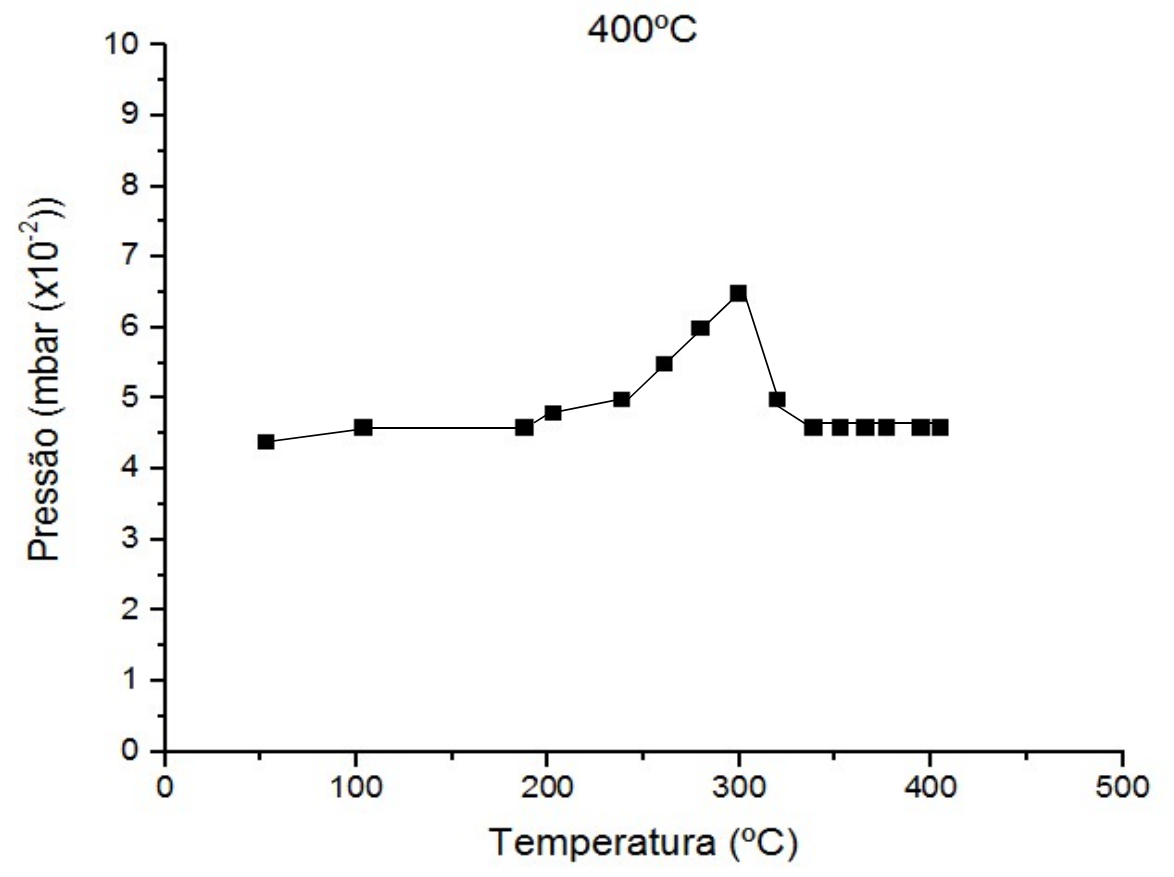

Figura 14 - Variação da pressão em função da temperatura a $400^{\circ} \mathrm{C}$ 


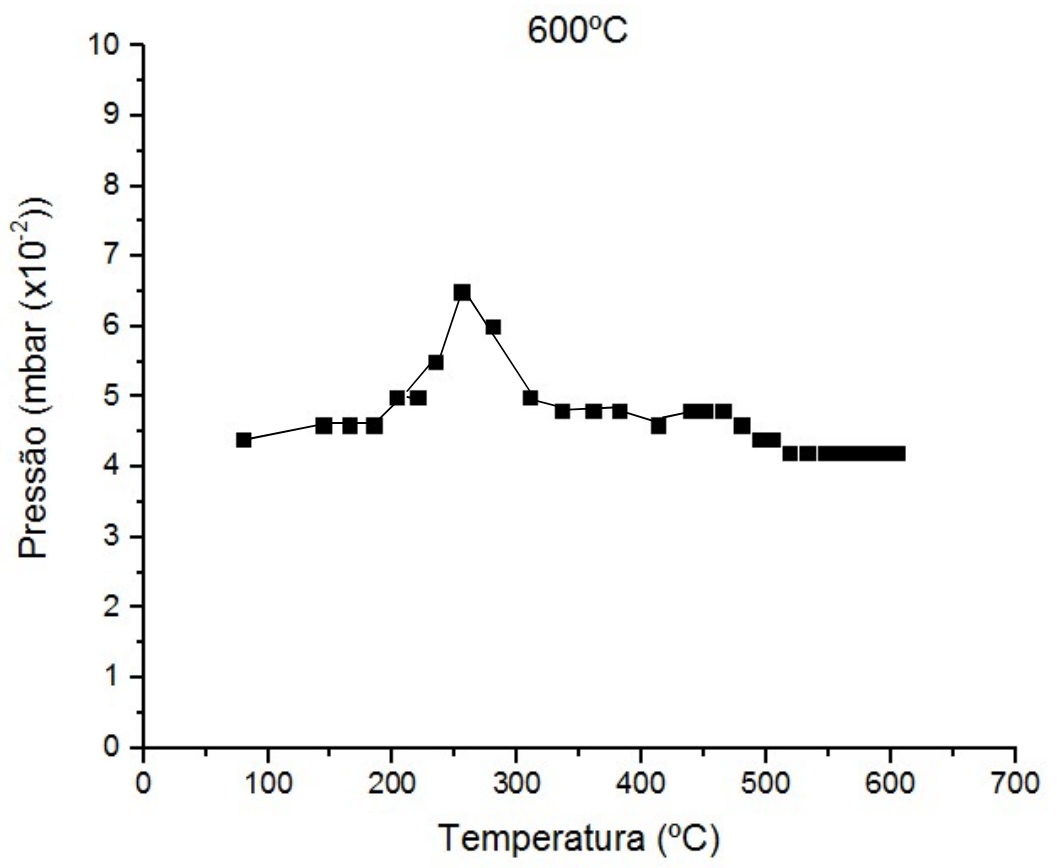

Figura 15 - Variação da pressão em função da temperatura a $600^{\circ} \mathrm{C}$.

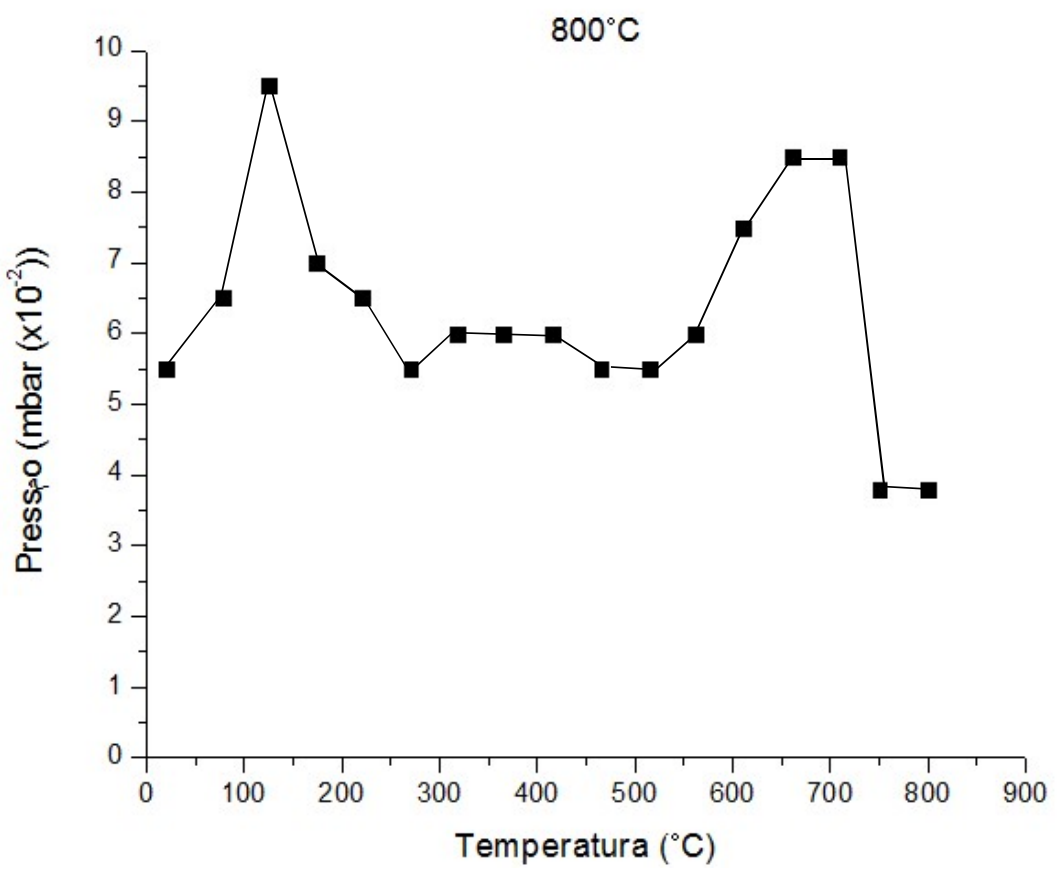

Figura 16 - Variação da pressão em função da temperatura a $800^{\circ} \mathrm{C}$. 


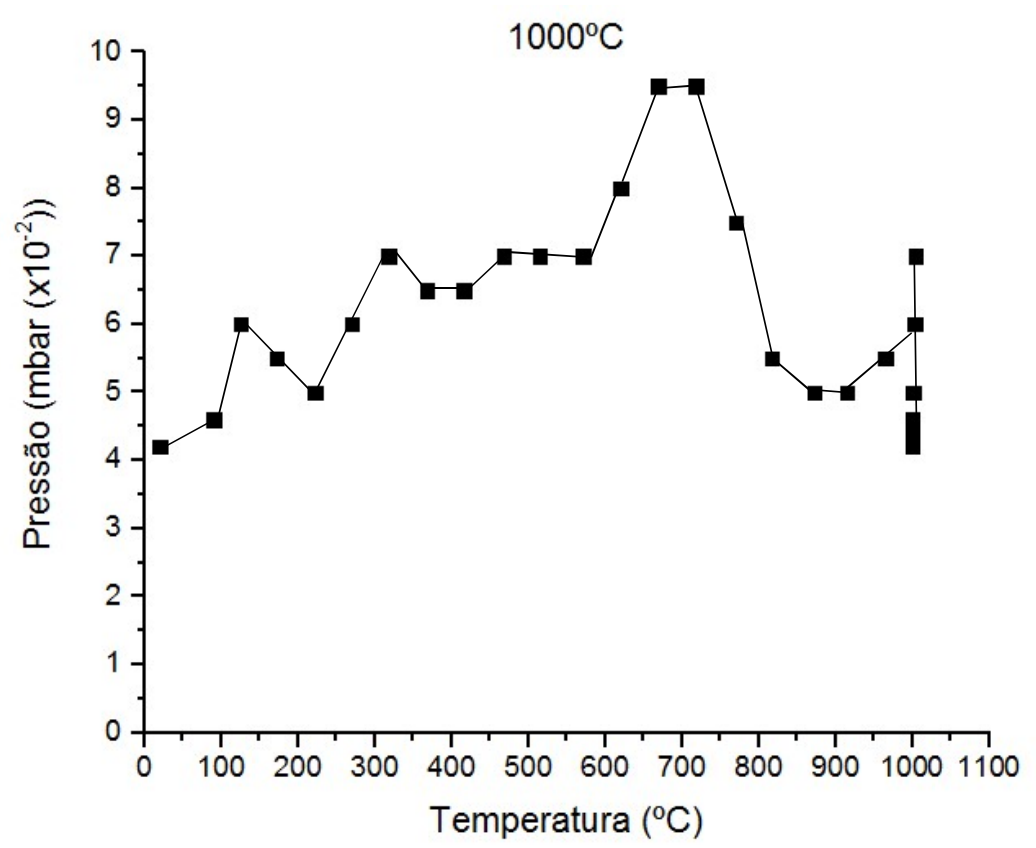

Figura 17 - Variação da pressão em função da temperatura a $1000^{\circ} \mathrm{C}$.

\subsection{ESPECTROSCOPIA NO INFRAVERMELHO COM TRANSFORMADA DE FOURIER (FTIR)}

Nas Figuras 18 a 21 são mostrados os espectros de FTIR para as amostras processadas a $200,400,600,800$ e $1000^{\circ} \mathrm{C}$, respectivamente. Na Figura 22 é apresentado, por sua vez, o espectro FTIR da amostra do óxido de grafeno não processado. Considerável variação na intensidade das bandas pode ser observada com o aumento da temperatura de processamento. $\mathrm{O}$ espectro do óxido de grafeno processado em vácuo a $200^{\circ} \mathrm{C}$ apresenta uma banda bem definida entre 1500 e $2000 \mathrm{~cm}^{-1}$. Esta banda por sua vez desaparece em temperaturas de processamento superiores a $200^{\circ} \mathrm{C}$. Por outro lado, uma banda entre 3700 e $3000 \mathrm{~cm}^{-1}$ tornou-se substancialmente pronunciada na amostra de óxido de grafeno processada em vácuo a $800^{\circ} \mathrm{C}$.

No espectro da amostra de óxido de grafeno submetido a $200^{\circ} \mathrm{C}$ (Figura 18), é possível verificar que existe a presença de uma banda espectral na faixa de $3417 \mathrm{~cm}^{-1}$, o que permite uma associação que nesta região nitrogênio $(\mathrm{C}-\mathrm{H}, \mathrm{O}-\mathrm{H}$ e N-H), conferindo então uma característica essencial para a presença de óxido de grafeno reduzido. Na região do comprimento de onda de $1730 \mathrm{~cm}^{-1}$ verificam-se grupos carbonilas provenientes de ácidos carboxílicos. Esta vibração é de suma importância uma vez que para obtenção do óxido de grafeno reduzido esta característica é uma "prova" de redução. 
A amostra submetida à redução térmica em $400^{\circ} \mathrm{C}$ (Figura 19) evidencia uma banda espectral em $1452 \mathrm{~cm}^{-1}$ a qual é presente quando ocorrem vibrações de núcleos aromáticos. Embora sútil, uma banda na região de $3400 \mathrm{~cm}^{-1}$ confirma que a redução do óxido de grafeno foi obtida e, em tal temperatura, ainda há resquícios do mesmo.

É possível verificar comportamento semelhante no espectro de análise da amostra submetida à redução a $600^{\circ} \mathrm{C}$ (Figura 20). Bandas espectrais na região de vibração do grupo carbonila estão presentes, em menor quantidade.

$\mathrm{Na}$ última amostra, submetida a uma temperatura de $1000{ }^{\circ} \mathrm{C}$ (Figura 21), praticamente tem-se somente a presença de bandas espectrais na região das vibrações de $1140 \mathrm{~cm}^{-1}$ e $1380 \mathrm{~cm}^{-1}$, nas quais conferem-se grupos de $\mathrm{O}-\mathrm{H}$ terciários e grupos $\mathrm{C}-\mathrm{O}$ provenientes de grupos carboxílicos.

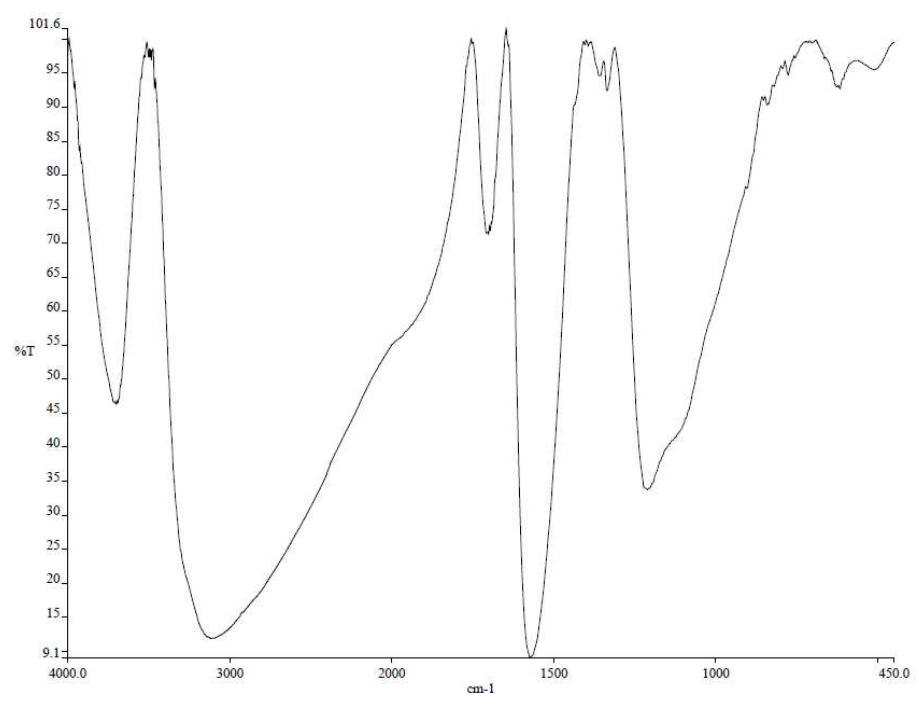

Figura 18 - Espectro FTIR para a amostra de óxido de grafeno reduzida a $200^{\circ} \mathrm{C}$. 


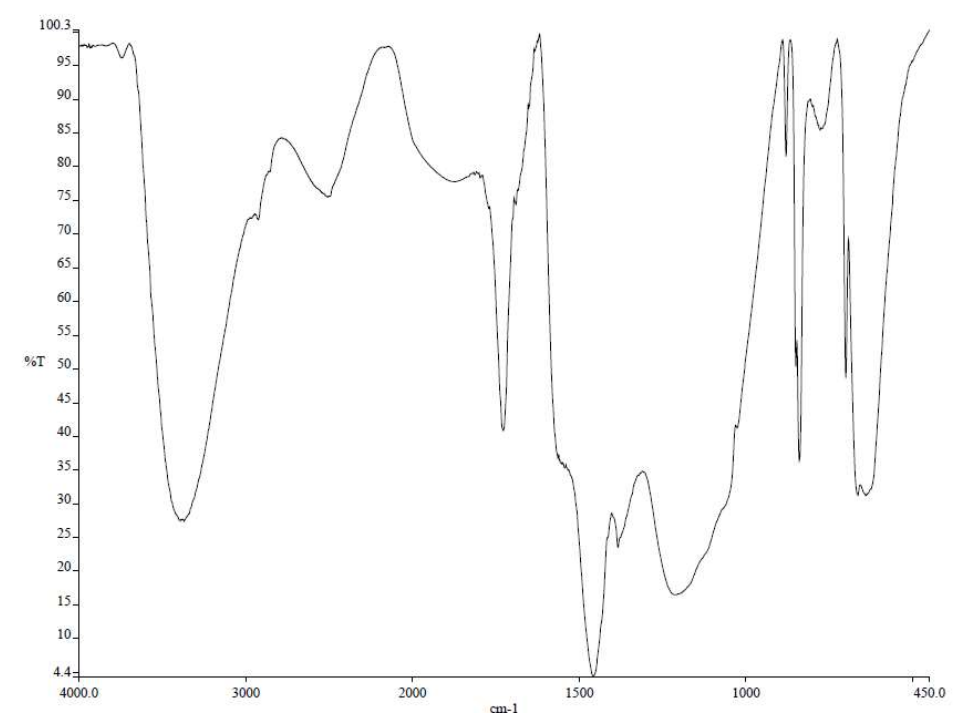

Figura 19 - Espectro FTIR para a amostra de óxido de grafeno reduzida a $400^{\circ} \mathrm{C}$.

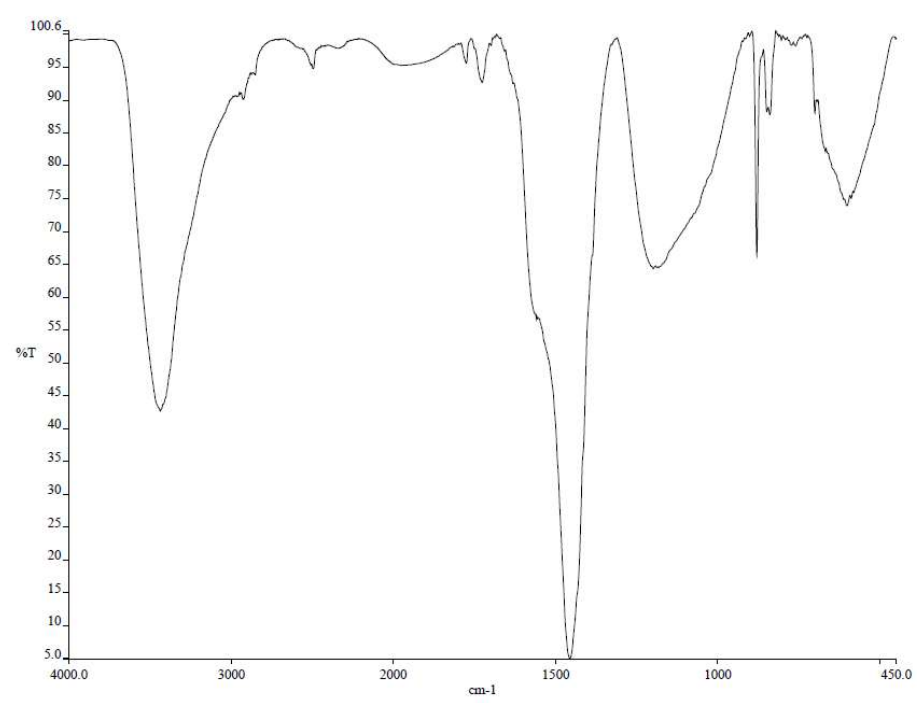

Figura 20- Espectro FTIR para a amostra de óxido de grafeno reduzida a $600^{\circ} \mathrm{C}$. 


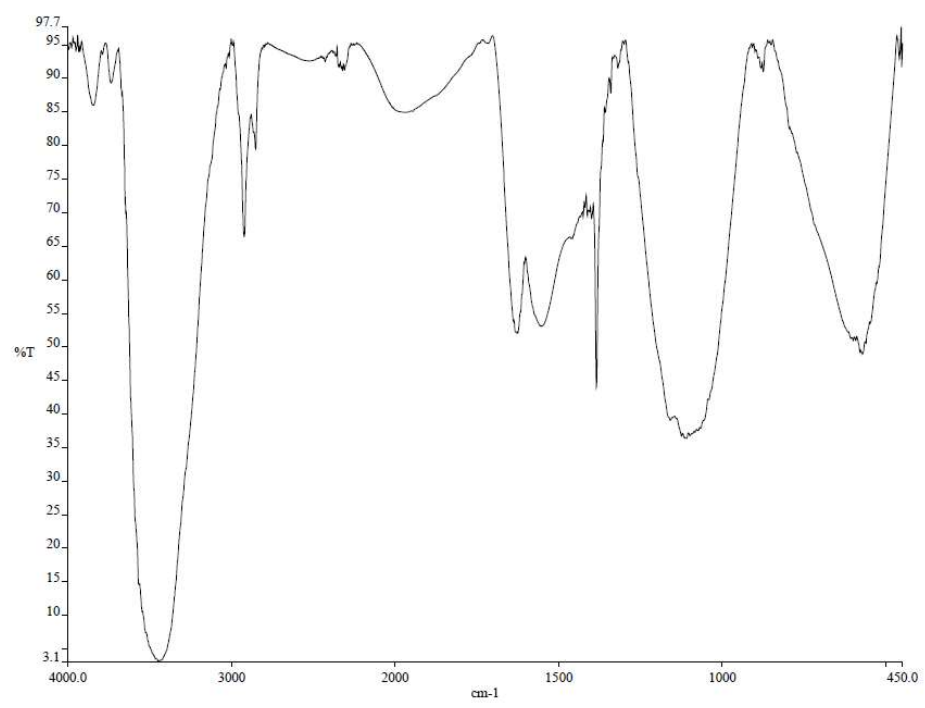

Figura 21 - Espectro FTIR para a amostra de óxido de grafeno reduzida a $1000^{\circ} \mathrm{C}$.

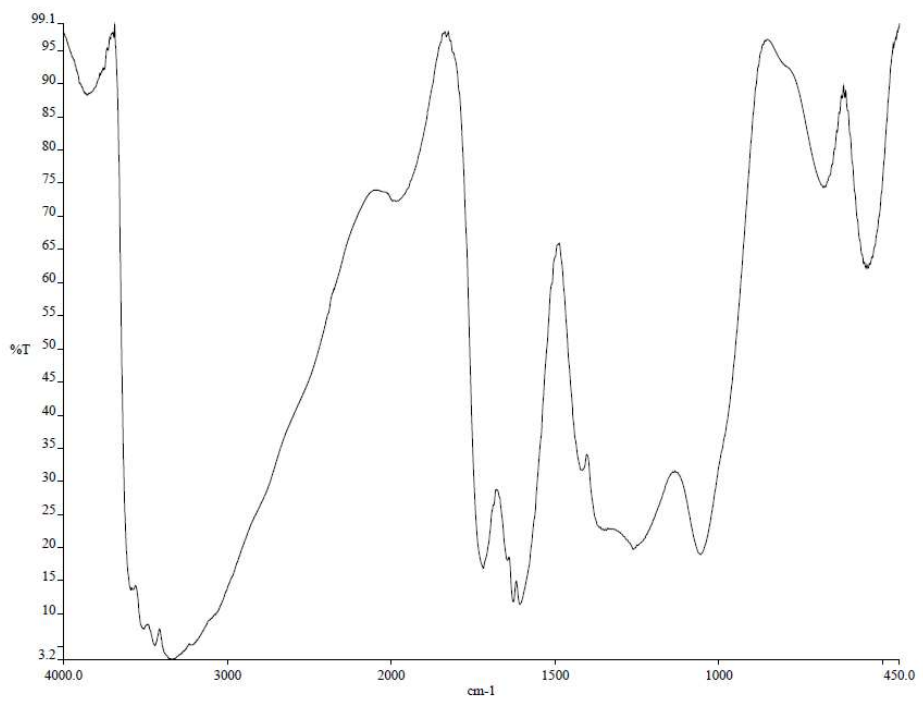

Figura 22 - Espectro FTIR para a amostra de óxido de grafeno. 


\subsection{DIFRAÇÃO DE RAIOS X}

Nas Figuras 23 a 28 são apresentados os difratogramas de raios $\mathrm{X}$ do óxido de grafeno e das amostras processadas a $200,400,600,800$ e $1000^{\circ} \mathrm{C}$, respectivamente. No espectro do óxido de grafeno são observados dois picos: o primeiro, mais intenso em $2 \Theta$ $=10,81^{\circ}$ e o segundo, de menor intensidade, em $2 \Theta=42,59^{\circ}$. Após a processo de redução térmica a vácuo observa-se a mudança na posição do primeiro pico para a região próxima a $2 \Theta \cong 25^{\circ}$, decorrente da eliminação dos grupos funcionais. A diminuição da distância interplanar para temperaturas de processamento acima de $600{ }^{\circ} \mathrm{C}$ pode ser atribuída a quebra do grafeno pela remoção dos grupos mais fortemente ligados. A Tabela 2 apresenta a posição destes picos com temperatura de processamento do óxido de grafeno a vácuo.

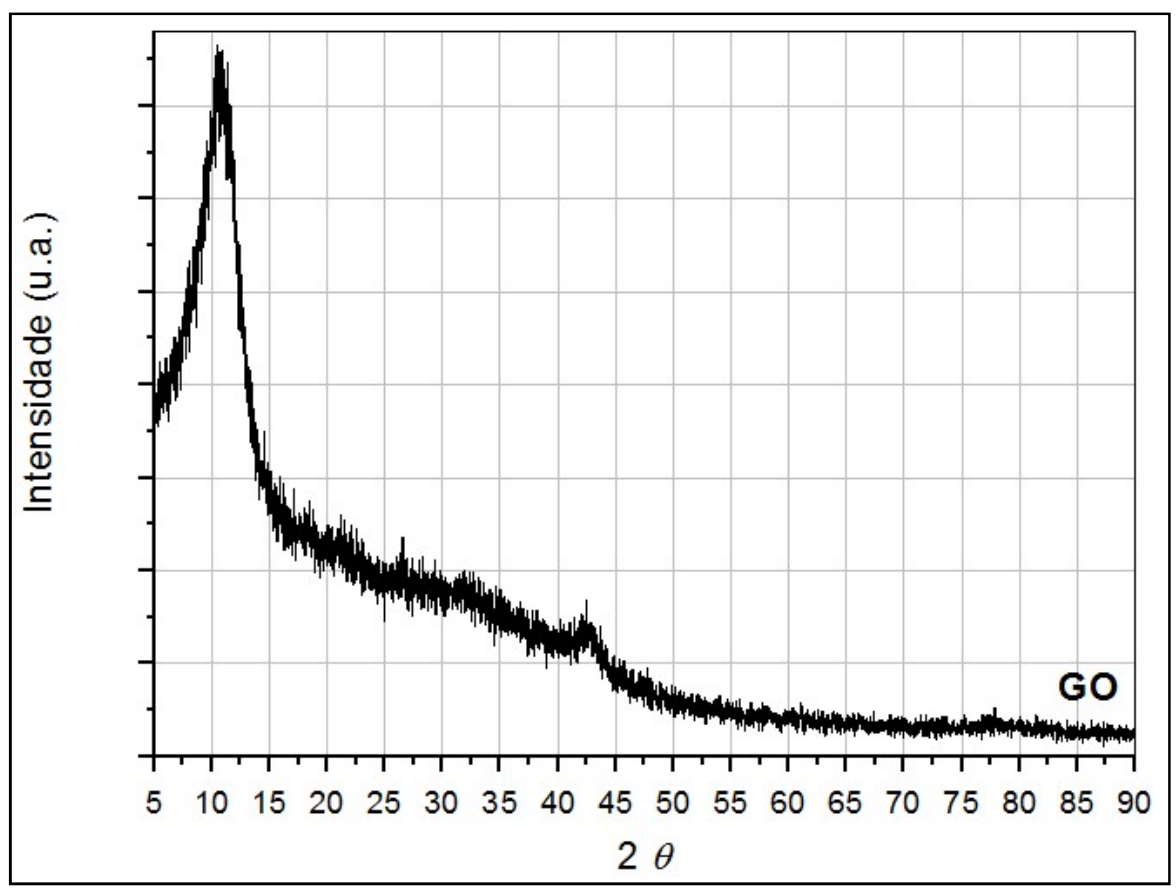

Figura 23 - Difratograma de raios $\mathrm{X}$ do óxido de grafeno. 


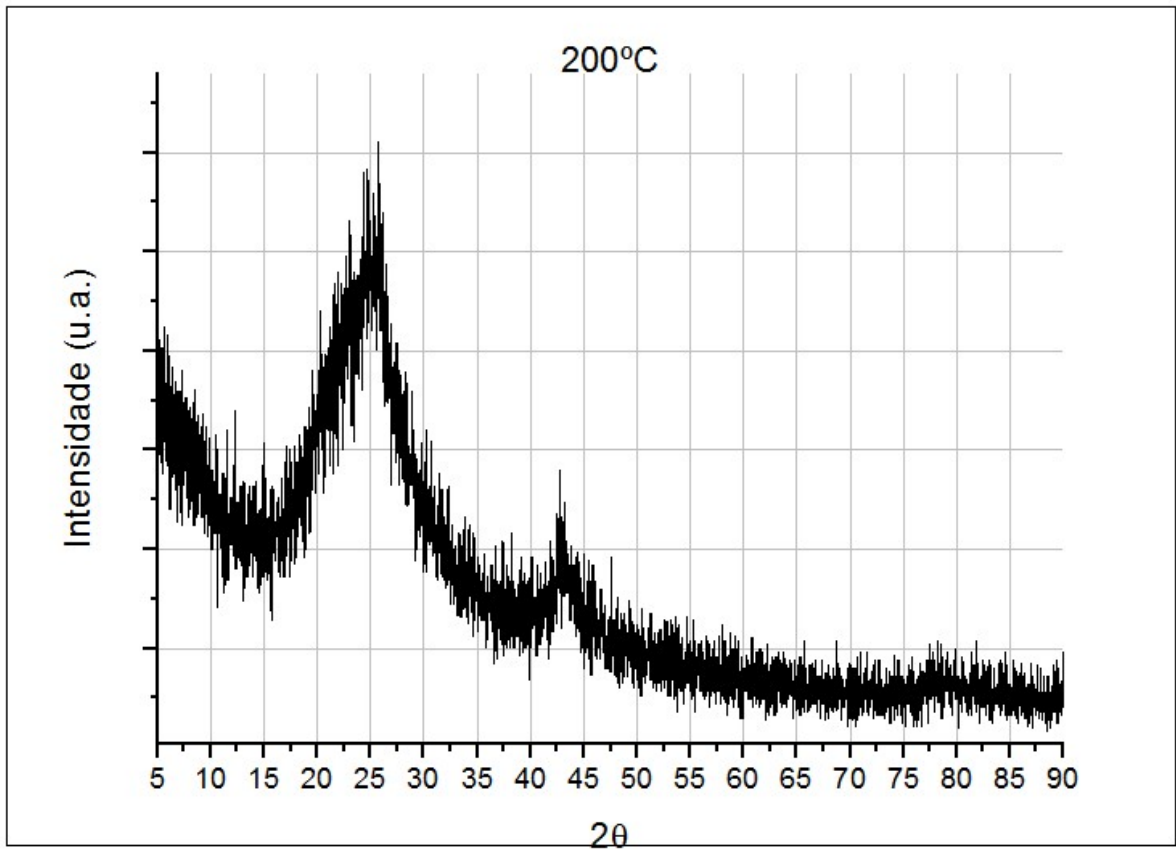

Figura 24 - Difratograma de raios $\mathrm{X}$ do óxido de grafeno reduzido a $200^{\circ} \mathrm{C}$.

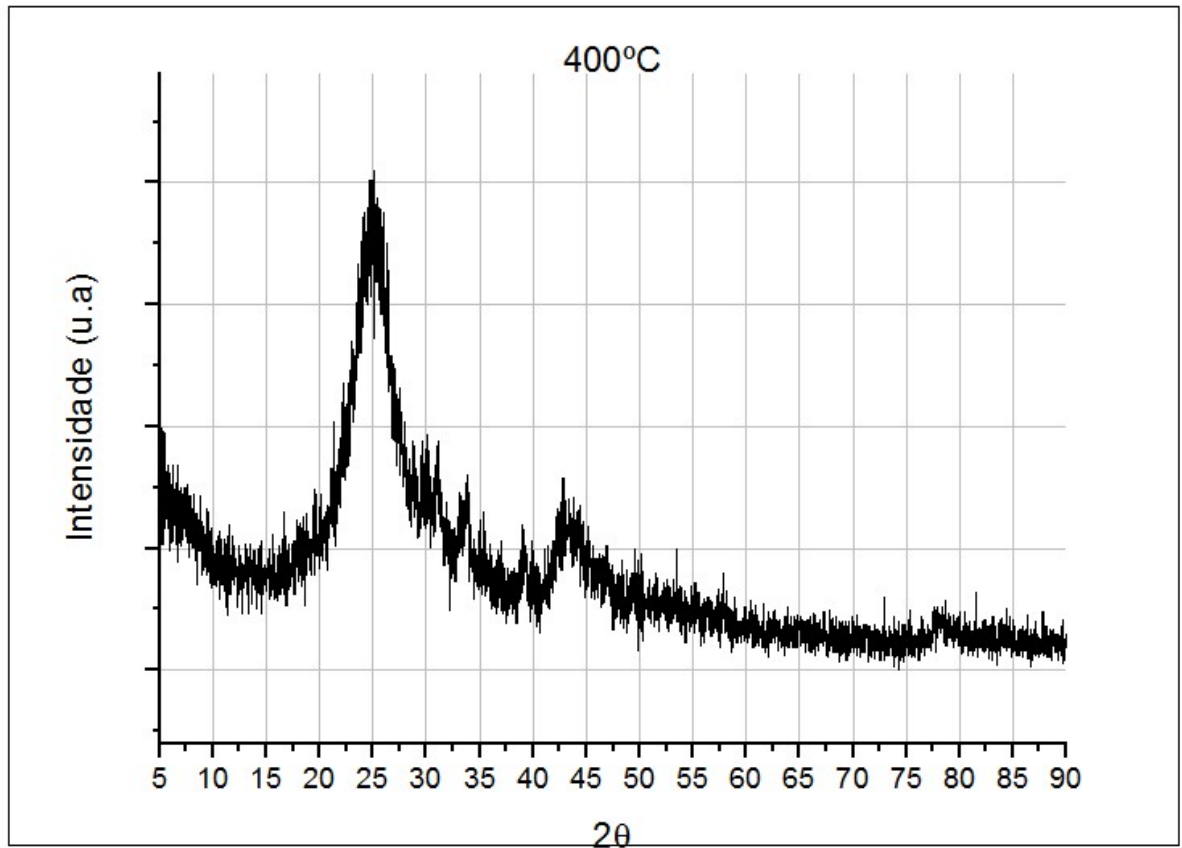

Figura 25 - Difratograma de raios $\mathrm{X}$ do óxido de grafeno reduzido a $400^{\circ} \mathrm{C}$. 


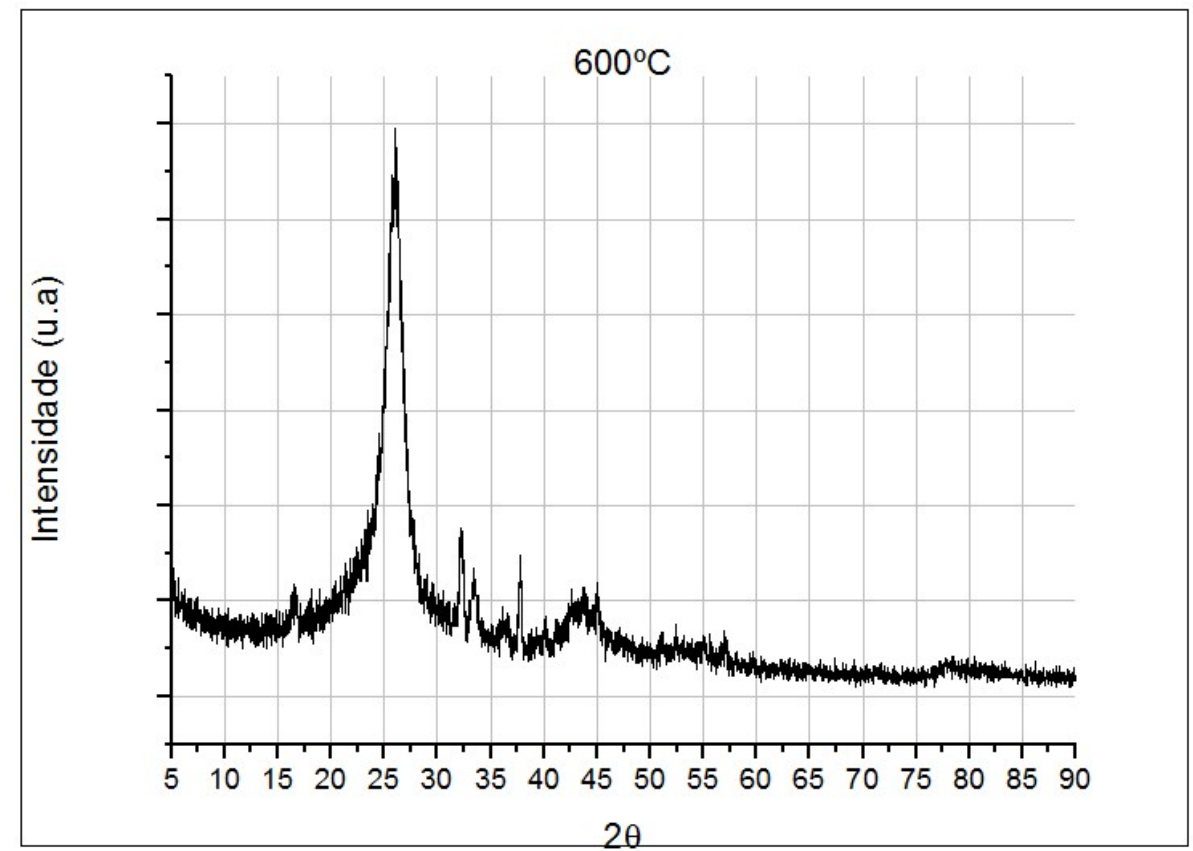

Figura 26 - Difratograma de raios $\mathrm{X}$ do óxido de grafeno reduzido a $600^{\circ} \mathrm{C}$.

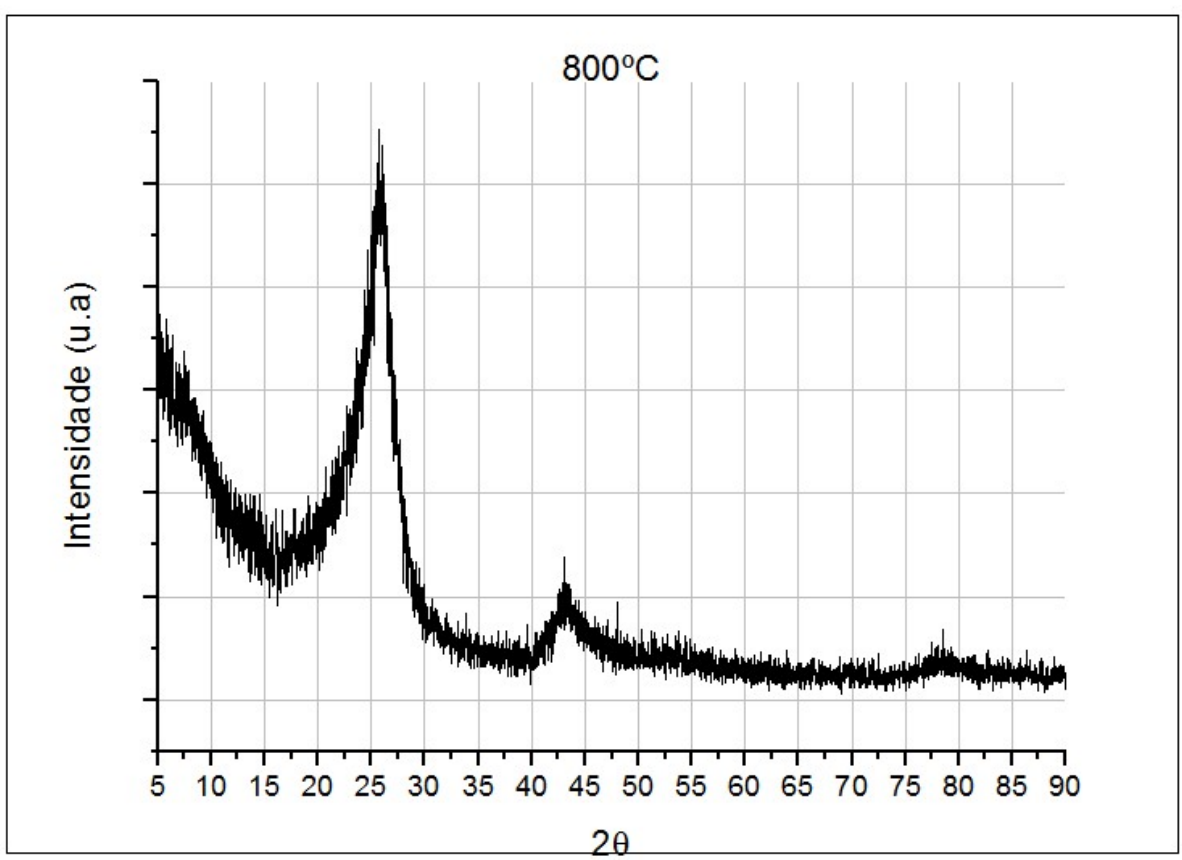

Figura 27 - Difratograma de raios $\mathrm{X}$ do óxido de grafeno reduzido a $800^{\circ} \mathrm{C}$. 


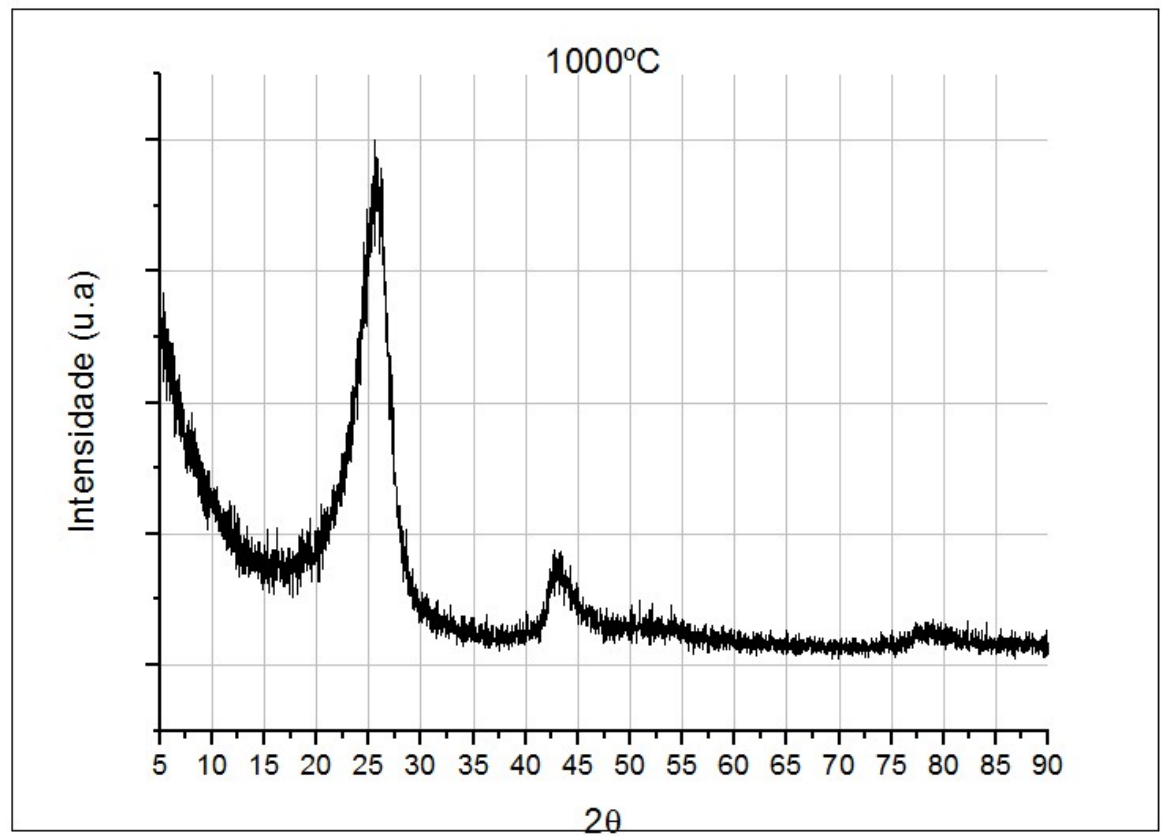

Figura 28 - Difratograma de raios $\mathrm{X}$ do óxido de grafeno reduzido a $1000^{\circ} \mathrm{C}$.

Tabela 3 - Posição dos picos em diferentes condições de processamento.

\begin{tabular}{|c|c|c|}
\hline \multirow{2}{*}{$\begin{array}{c}\text { Temperatura } \\
\left({ }^{\circ} \mathbf{C}\right)\end{array}$} & \multicolumn{2}{|c|}{ Plano cristalográfico } \\
\cline { 2 - 3 } & $\begin{array}{c}(\mathbf{0 0 2}) \\
(\mathbf{2 \theta})\end{array}$ & $\begin{array}{c}\mathbf{( 1 0 0 )} \\
\mathbf{( 2 \theta )}\end{array}$ \\
\hline OG & 10,81 & 42,59 \\
\hline 200 & 25,73 & 42,77 \\
\hline 400 & 25,01 & 42,89 \\
\hline 600 & 25,96 & 43,48 \\
\hline 800 & 25,84 & 43,00 \\
\hline 1000 & 25,49 & 42,89 \\
\hline
\end{tabular}




\subsection{ESTIMATIVA DO NÚMERO DE PLANOS EMPILHADOS}

Neste trabalho a etapa de tratamento térmico teve por objetivo a redução do óxido de grafite/grafeno, tendo sido a esfoliação realizada anteriormente por ultrassom. Esta observação é de vital importância, pois em diversos trabalhos o tratamento térmico objetivou também a esfoliação.

Pei e Cheng (2012) discorreram sobre a alta taxa de aquecimento e as relações entre temperatura e pressão necessárias para a ocorrência de esfoliação e redução concomitantes. Os autores indicaram que este processo resultou em um óxido de grafeno reduzido com elevado número de defeitos devido à perda de átomos de carbono. Existem no artigo referências sobre a utilização do tratamento térmico apenas como etapa de redução. Na tabela apresentada no artigo, os autores comparam a eficiência de três métodos para redução do óxido de grafeno, na eliminação dos grupos funcionais.

Ju et al. (2010) utilizaram a DRX no estudo de dois tipos de tratamentos térmicos para redução do óxido de grafeno/grafita. A descrição do processo de oxidação é semelhante, porém com tempos bastante diferentes. Não há no artigo indicação de uma etapa de esfoliação por ultrassom, porém os autores utilizaram um tempo de agitação de 5 dias. $\mathrm{O}$ produto resultante da oxidação da grafita foi depositado sobre o porta-amostra de platina de uma câmara de alta temperatura acoplada a um difratômetro de raios $\mathrm{X}$, formando um filme fino. Foram obtidos difratogramas em diversas temperaturas até $1000^{\circ} \mathrm{C}$, limite máximo do equipamento. $\mathrm{O}$ outro tratamento foi realizado no pó em forno tubular com fluxo de nitrogênio até a temperatura de $2000^{\circ} \mathrm{C}$. Os autores discutiram as diferenças entre os dois processos de redução.

Na Figura 29 são apresentados os difratogramas para cada temperatura de processamento em vácuo. Nos difratogramas individualizados é possível observar que na redução térmica a vácuo a $200^{\circ} \mathrm{C}$ a banda em torno de $26^{\circ}$ assemelha a fusão de duas bandas, indicando ainda a presença de vários grupos funcionais entre os planos basais. Na redução térmica a vácuo a $400^{\circ} \mathrm{C}$, esta banda adquiri um perfil mais simétrico com o centro calculado em aproximadamente $2 \Theta=24,6^{\circ}$, correspondendo a uma distância interplanar de 3,61 Å. Já o processo de redução realizado a $600^{\circ} \mathrm{C}$ promove uma acentuada cristalização da estrutura, conforme pode ser inferido pelo estreitamento da banda.

$\mathrm{O}$ alargamento e a assimetria da banda 002 , observados para as temperaturas de 800 e $1000^{\circ} \mathrm{C}$, podem ser atribuídos a um processo de quebra de parte da estrutura do plano basal em decorrência da remoção de grupos mais fortemente ligados. As reflexões de baixa 
intensidade vistas até 40 graus, nos difratogramas das amostras tratadas termicamente a 400 e $600^{\circ} \mathrm{C}$, podem ser atribuídas aos contaminantes no sistema de acondicionamento da amostra para tratamento térmico.

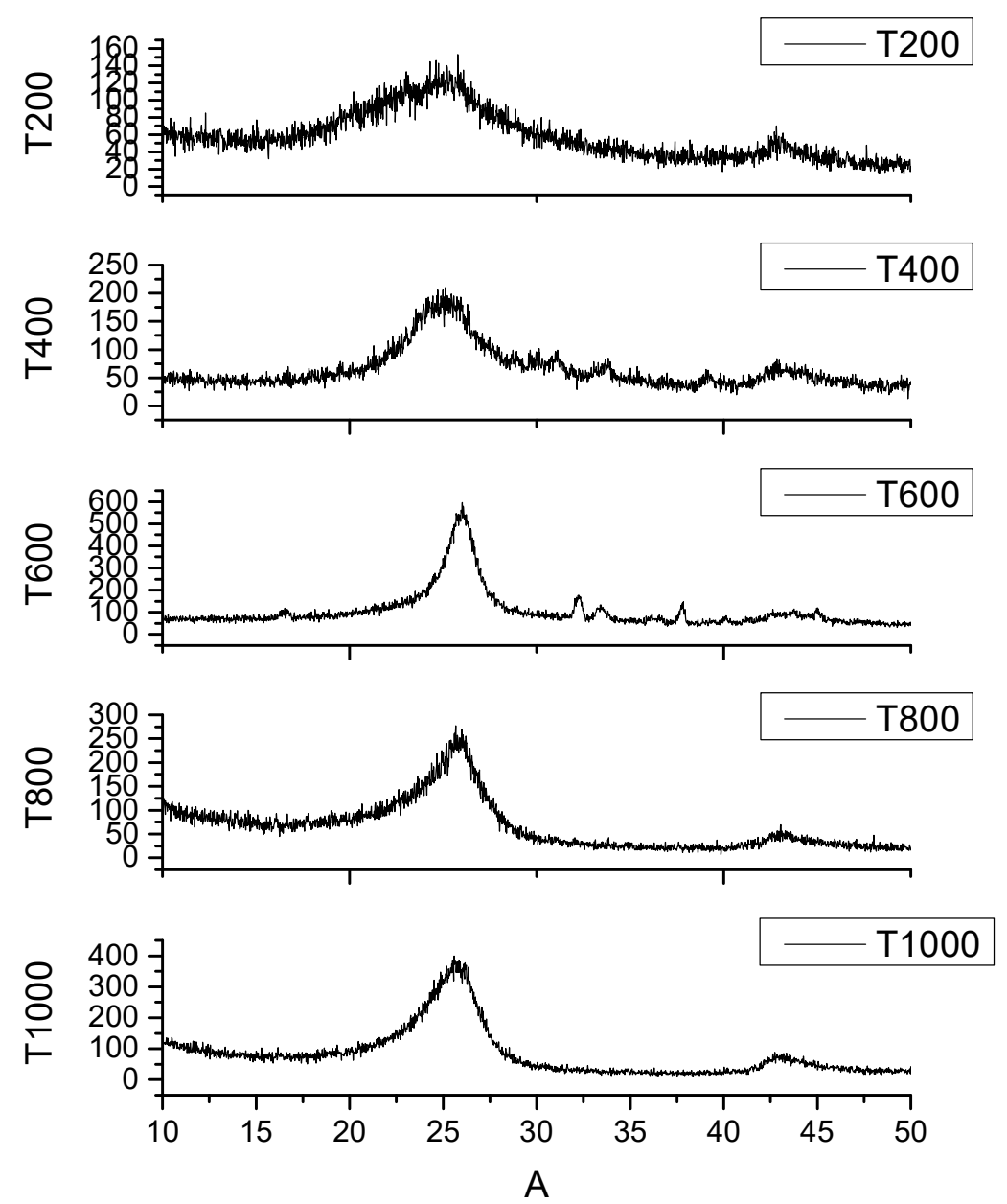

Figura 29 - Padrões de difração de raios X.

A Figura 30 apresenta um gráfico com a região em torno de $2 \Theta=25^{\circ}$ ampliada. Neste detalhamento é possível perceber a diminuição da distância interplanar até a temperatura de $600^{\circ} \mathrm{C}$ e, acima desta temperatura, observa-se pouca variação na posição do centro da banda, sendo esta apenas afetada pelo aumento na assimetria do perfil. 


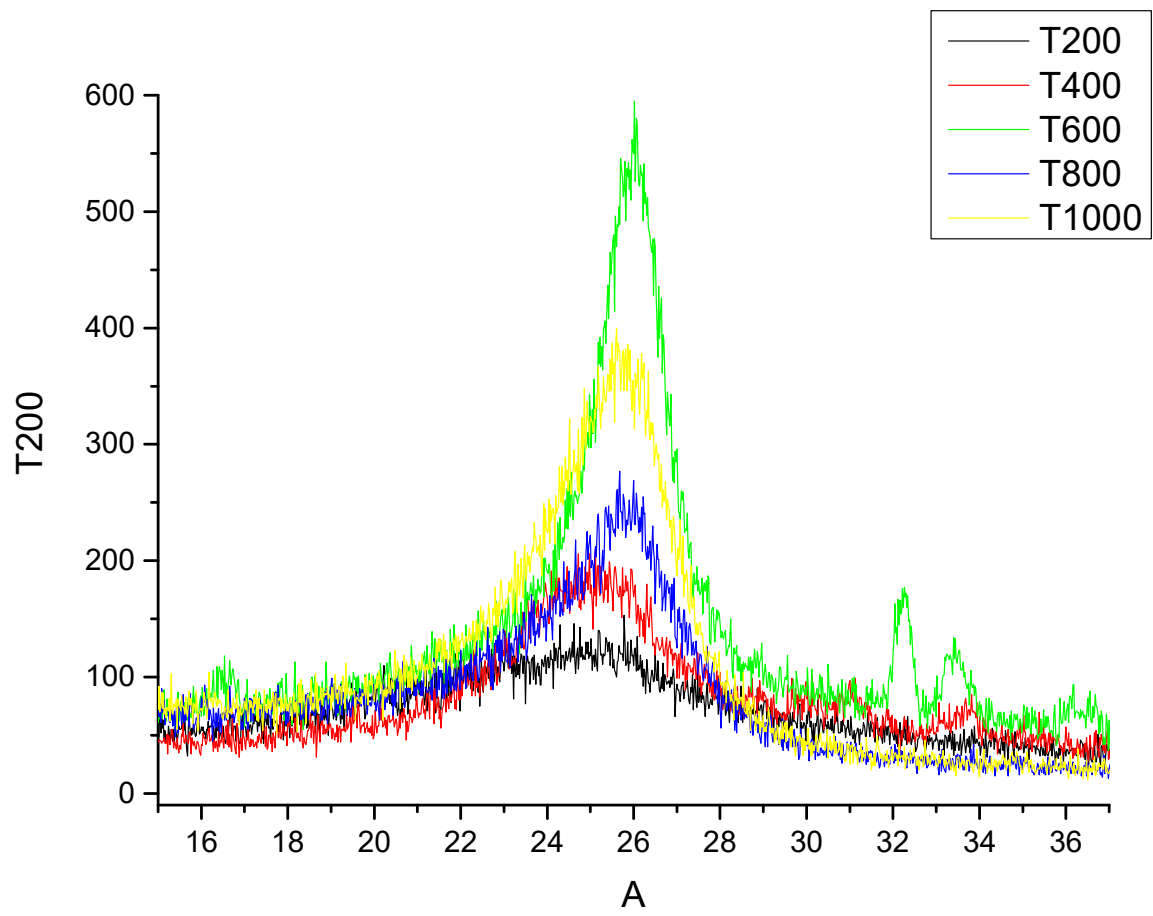

Figura 30 - Detalhamento reflexão 002.

A Tabela 4 apresenta os resultados obtidos para o tamanho do cristalito em função da temperatura de tratamento térmico e o valor estimado de planos 002 empilhados.

Tabela 4 - Tamanho do cristalito (L002) e número de planos 00L empilhados (N).

\begin{tabular}{|l|l|l|}
\hline \multicolumn{1}{|c|}{ Amostra } & L002 & N \\
\hline OG & 13,20 & 3 \\
\hline 200 & 10,06 & 4 \\
\hline 400 & 18,65 & 6 \\
\hline 600 & 43,36 & 14 \\
\hline 800 & 21,75 & 7 \\
\hline 1000 & 22,92 & 8 \\
\hline
\end{tabular}




\subsection{ANÁLISE TERMOGRAVIMÉTRICA DOS ÓXIDOS DE GRAFENO REDUZIDOS}

As curvas termogravimétricas dos óxidos de grafeno foram submetidos à redução térmica $\left(200^{\circ} \mathrm{C}, 400^{\circ} \mathrm{C}, 600^{\circ} \mathrm{C}, 800^{\circ} \mathrm{C}\right.$ e $\left.1000^{\circ} \mathrm{C}\right)$ estão apresentadas nas Figuras 31 a 35 , respectivamente. Na Figura 36 tem-se uma representação unificada das várias curvas termogravimétricas obtidas.

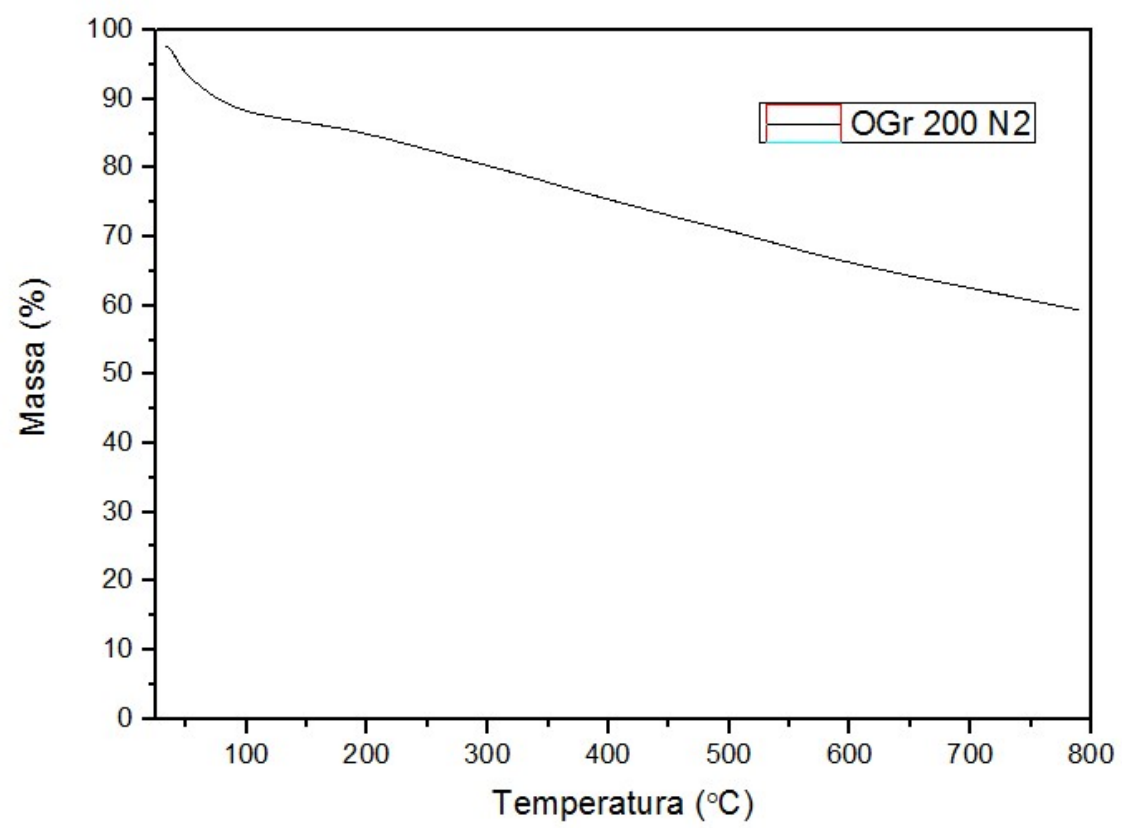

Figura 31. Curva termogravimétrica do óxido de grafeno reduzido a $200{ }^{\circ} \mathrm{C}$ sob atmosfera de Nitrogênio 


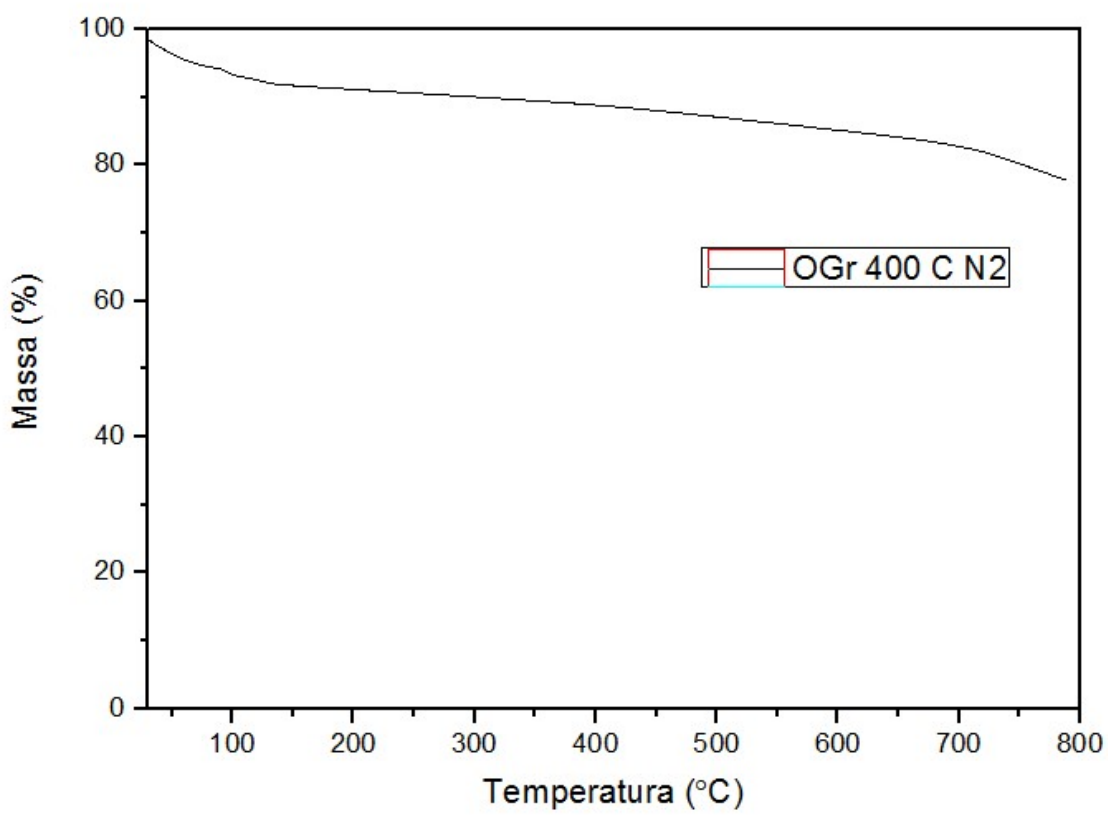

Figura 32. Curva termogravimétrica do óxido de grafeno reduzido a $400{ }^{\circ} \mathrm{C}$ sob atmosfera de Nitrogênio.

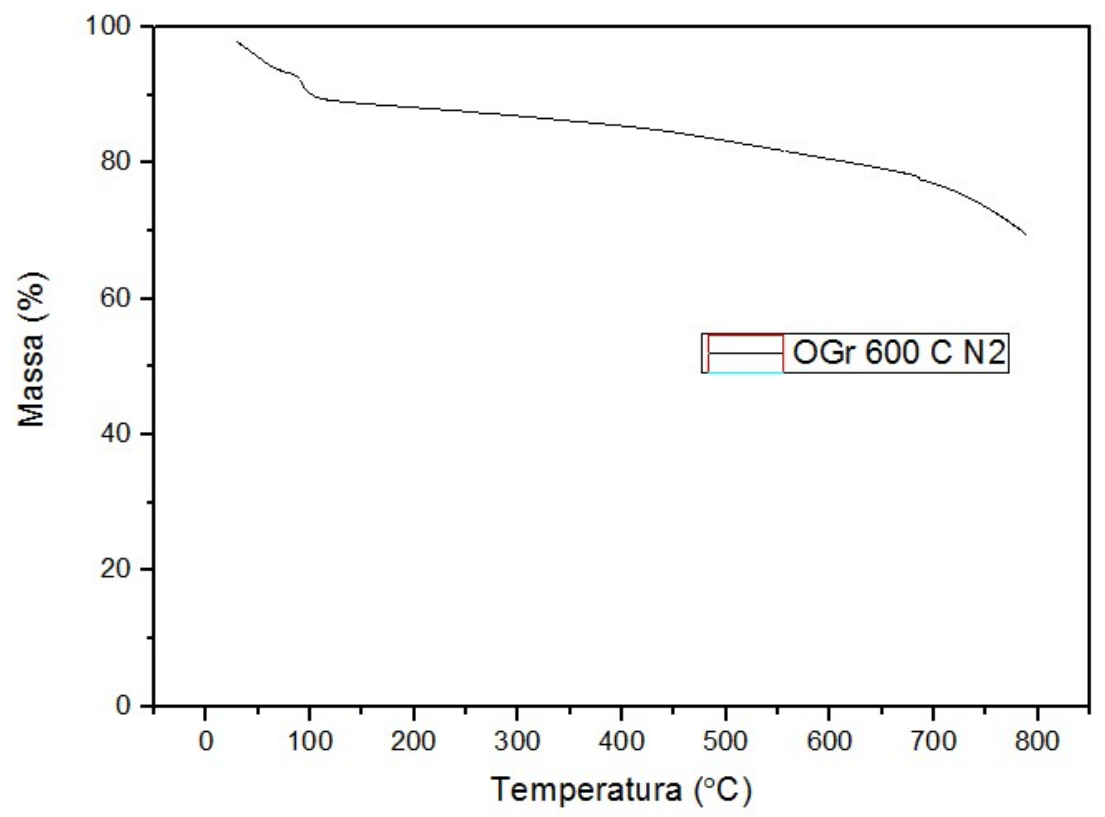

Figura 33. Curva termogravimétrica do óxido de grafeno reduzido a $600{ }^{\circ} \mathrm{C}$ sob atmosfera de Nitrogênio. 


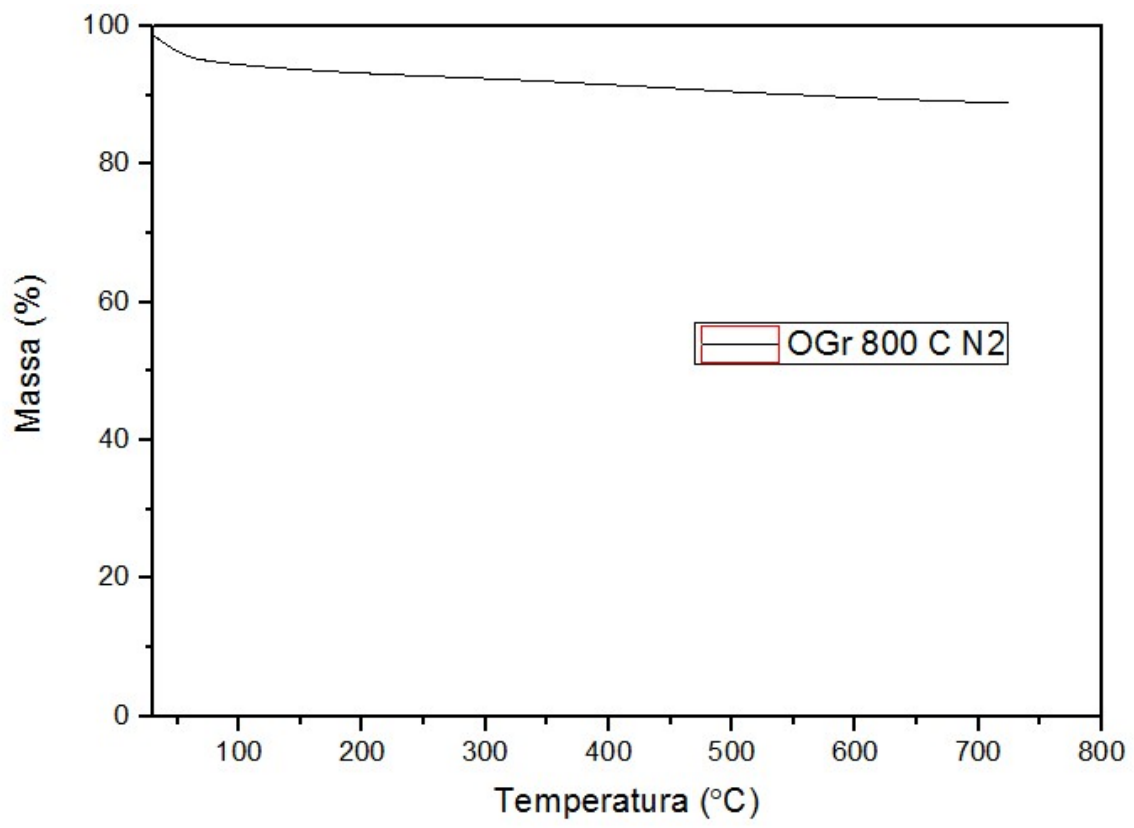

Figura 34. Curva termogravimétrica do óxido de grafeno reduzido a $800{ }^{\circ} \mathrm{C}$ sob atmosfera de Nitrogênio.

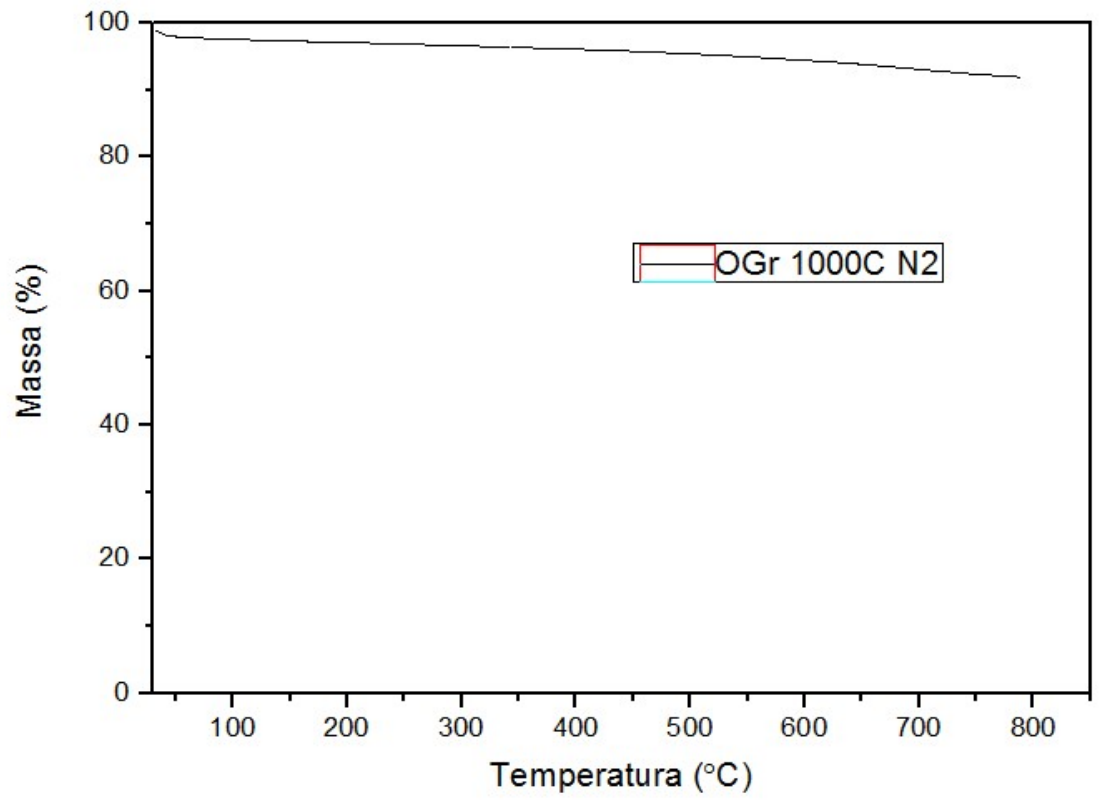

Figura 35. Curva termogravimétrica do óxido de grafeno reduzido a $1000{ }^{\circ} \mathrm{C}$ sob atmosfera de Nitrogênio. 


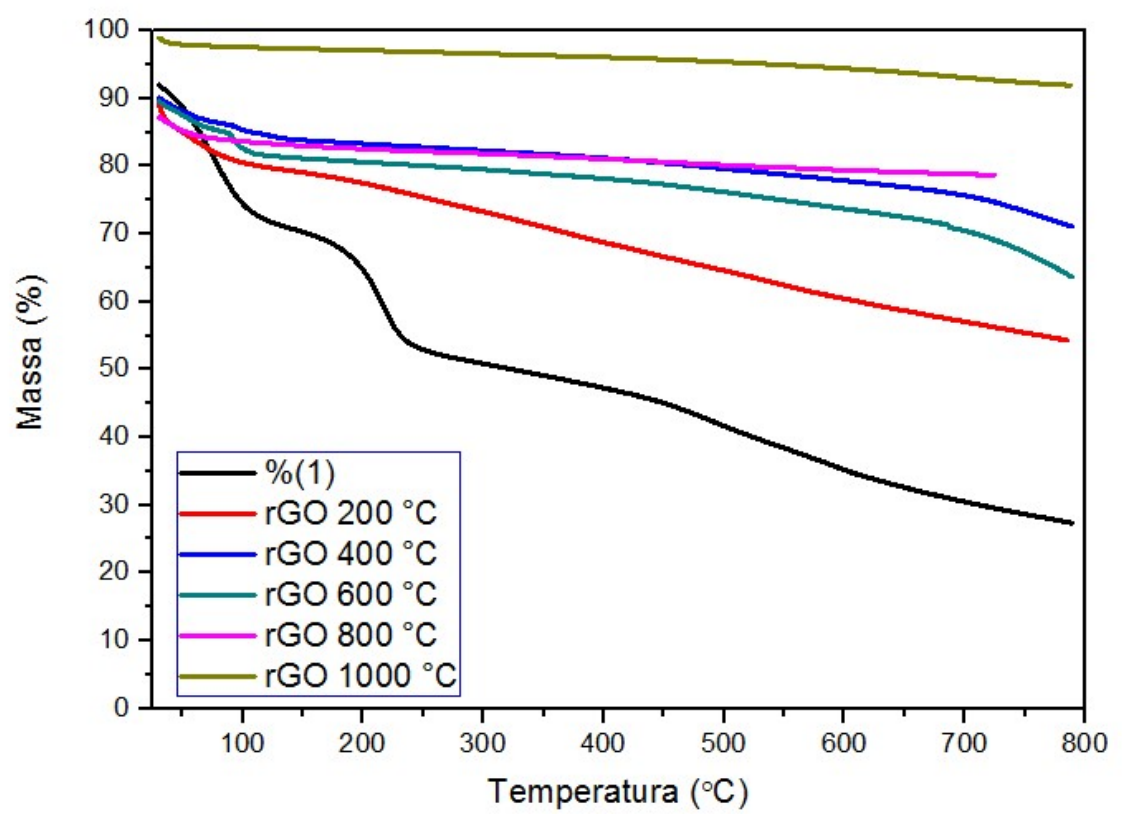

Figura 36. Curvas termogravimétricas do óxido de grafeno reduzido unificado.

As amostras de OG e o OGr foram analisadas por termogravimetria (TGA) e foi possível observar duas perdas de massa com o aumento da temperatura.

O OG evidenciou que até $100{ }^{\circ} \mathrm{C}$ uma perda em massa de $18,40 \%$ é referente a água absorvida e, de $200{ }^{\circ} \mathrm{C}$ a $250{ }^{\circ} \mathrm{C}$ com perda de $22,20 \%$ em massa de grupos oxigenados (hidroxila, carbonilas, epóxi grupos e carboxilatos) (Li, et al. 2008; Su, et al. 2009; DIKIN, et al. 2007).

A perda de massa é de fato menor para o $\mathrm{OGr}$ a $200{ }^{\circ} \mathrm{C}$ em relação a perda de massa do OG, principalmente na região dos grupos oxigenados (de $200^{\circ} \mathrm{C}$ a $250{ }^{\circ} \mathrm{C}$ ) com o valor de 7,6 \% de perda, indicando uma porcentagem de grupos oxigenados menor após a redução térmica. (ZHANG et al. 2014), o que corrobora com o resultado de FTIR, indicando a obtenção do óxido de grafeno reduzido.

As outras faixas de temperatura que as amostras foram submetidas, de $400{ }^{\circ} \mathrm{C}$ a 1000 ${ }^{\circ} \mathrm{C}$, não mostraram perdas de massa na região de $200{ }^{\circ} \mathrm{C}$ a $250{ }^{\circ} \mathrm{C}$, referentes aos grupos 
oxigenados revelando um material com maior estabilidade a decomposição com o aumento da temperatura. Suas porcentagens em massa podem ser observadas na Tabela 5.

Tabela 5 - Porcentagem de perdas de massa para o GO e suas respectivas reduções.

\begin{tabular}{|c|c|c|c|}
\hline Amostra & $\mathrm{H}_{2} \mathrm{O} \%$ massa & $\begin{array}{ll}\text { Grupos } & \mathrm{O}_{2} \% \\
\text { massa } & \end{array}$ & Resíduo \%massa \\
\hline OG & $18,4 \%$ & $22,2 \%$ & $28,8 \%$ \\
\hline OGr $200^{\circ} \mathrm{C}$ & $10,0 \%$ & $7,4 \%$ & $21,8 \%$ \\
\hline OGr $400^{\circ} \mathrm{C}$ & $6,8 \%$ & - & $15,0 \%$ \\
\hline OGr $600^{\circ} \mathrm{C}$ & $9,0 \%$ & - & $6,0 \%$ \\
\hline OGr $800^{\circ} \mathrm{C}$ & $4,2 \%$ & - & $1,8 \%$ \\
\hline OGr $1000^{\circ} \mathrm{C}$ & $1,4 \%$ & - & $0,4 \%$ \\
\hline
\end{tabular}




\subsection{PROPRIEDADES ELÉTRICAS DOS SUPERCAPACITORES DE ÓXIDO DE GRAFENO}

A Tabela 6 mostra as propriedades elétricas dos supercapacitores preparados com o óxido de grafeno antes e depois da redução em vácuo. Verificou-se que o processamento a vácuo influenciou significantemente a resistência interna equivalente em série (ESR) do supercapacitor, que foi reduzida de $95 \Omega \mathrm{cm}^{2}$ para $14 \Omega \mathrm{cm}^{2}$, com o aumento da temperatura de processo. Esta redução afeta diretamente as perdas de energia dentro do supercapacitor, ou seja, diminui consideravelmente o aquecimento do dispositivo. $\mathrm{O}$ processamento não influenciou a capacitância específica do material da mesma forma que a resistência interna. O supercapacitor preparado utilizando o óxido de grafeno reduzido a 600 ${ }^{\circ} \mathrm{C}$ apresentou uma capacitância específica baixa sem grande aumento em ESR, também indicando que a melhor temperatura de redução do óxido de grafeno em vácuo produzido por bomba mecânica para aplicação em supercapacitores deve ser inferior a $600{ }^{\circ} \mathrm{C}$.

Tabela 6 - Propriedades elétricas dos supercapacitores de óxido de grafeno antes e depois da redução em vácuo. Os valores apresentados utilizam a média de medidas realizadas em potenciais distintos.

\begin{tabular}{|c|c|c|c|}
\hline CONDIÇÃO & C (F) & Cs (F/g) & ESR $\left(\Omega \mathrm{cm}^{2}\right)$ \\
\hline OG & 1,4 & 60 & 95 \\
\hline OGR - 200'C & 1,0 & 46 & 63 \\
\hline OGR - 400'C & 1,3 & 58 & 16 \\
\hline OGR - 600 & & & \\
\hline
\end{tabular}

O óxido de grafeno reduzido utilizando o processo HDDR mostrou-se um pouco mais favorável neste sentido com um aumento na capacitância especifica do material processado e redução na ESR (Casini et al., 2015). Com o processamento via HDDR a capacitância especifica passou de $176 \mathrm{Fg}^{-1}$ para $181 \mathrm{Fg}^{-1}$, enquanto que a resistência interna diminuiu de $61 \Omega$ para $44 \Omega$. O valor de ESR obtido após a redução em vácuo a $400{ }^{\circ} \mathrm{C}(20$ $\Omega)$ foi superior ao obtido por $\operatorname{HDDR}(44 \Omega)$. 
O valor de capacitância especifica obtido por Casini et al. com o processo HDDR não pode ser comparado diretamente com os deste trabalho uma vez que os valores absolutos dependem das características físicas (grau de porosidade) e químicas (presença elementos químicos) do óxido de grafeno utilizado, das condições de preparação dos eletrodos (tamanho de partículas e espessura do eletrodo), da concentração e do tipo de eletrólito utilizado (força iônica) e, também, da densidade de corrente utilizada nas medidas (maiores densidades afetam o valor da capacitância específica).

O eletrólito $(\mathrm{KOH})$ utilizado naquele estudo em HDDR realizado por Casini et al. contava com uma concentração muito mais elevada (6M), a qual contribuiu bastante para o aumento da capacitância específica daquele material (também com características físicas e químicas distintas das utilizadas no presente estudo). Por outro lado, a utilização do sulfato de sódio apresenta a distinta vantagem de ter um menor impacto ao meio ambiente, além de ter maior segurança no manuseio em laboratório.

Os valores de capacitância específica obtidos com eletrólitos orgânicos são superiores devido ao potencial mais elevado $(2,75 \mathrm{~V})$ permitido por esta classe de eletrólitos. O valor da capacidade específica é dependente do potencial máximo permitido pelo eletrólito - quanto mais alto este potencial, maior o valor da capacitância especifica. A desvantagem do eletrólito orgânico está no maior valor de ESR. Como a energia armazenada pelo supercapacitor varia com o quadrado do potencial máximo aplicado no dispositivo, ainda é vantajoso utilizar eletrólito orgânico com maior ESR. Por esta razão, mesmo sendo altamente tóxicos, os eletrólitos orgânicos são amplamente empregados pela indústria de supercapacitores. 


\section{CONCLUSÕES}

Uma considerável modificação na intensidade dos picos nas análises por espectroscopia no infravermelho com trasformada de Fourier pode ser observada com o aumento da temperatura de processamento do óxido de grafeno. O óxido de grafeno processado em vácuo a $200^{\circ} \mathrm{C}$ apresentou um pico bem definido entre 1500 e $2000 \mathrm{~cm}^{-1}$. Este pico desapareceu em temperaturas de processamento superiores a $200^{\circ} \mathrm{C}$. Distintamente, um pico entre 3700 e $3000 \mathrm{~cm}^{-1}$ tornou-se substancialmente pronunciado somente na amostra de óxido de grafeno processada em vácuo a $800^{\circ} \mathrm{C}$.

Foram observados dois picos nos difratogramas obtidos das análises por difração de raios $\mathrm{X}$ do óxido de grafeno produzido pelo metodo Hummers modificado. O primeiro e mais intenso em $2 \Theta=10,81^{\circ}$ e o segundo de menor intensidade em $2 \Theta=42,59^{\circ}$. Com o processamento em vácuo deste óxido de grafeno a posição do primeiro pico foi deslocada para $2 \Theta \approx 25^{\circ}$. Esta mudança na posição deste pico mostrou que houve a redução do óxido de grafeno. A posição do segundo pico de menor intensidade permaneceu dentro de uma faixa relativamente estreita $\left(2 \Theta \approx 42^{\circ}-43^{\circ}\right)$. Isto está em conformidade com a alteração somente nos planos basais 00L com a modificação da distância interplanar pela intercalação dos grupos funcionais contendo oxigênio.

Com os resultados da preparação de supercapacitores, verificou-se que o processamento em vácuo em temperaturas distintas influenciou significantemente a resistência interna equivalente em série do supercapacitor. O processamento a $400{ }^{\circ} \mathrm{C}$ reduziu consideravelmente a ESR do supercapacitor sem alterar o valor da capacitância específica do óxido de grafeno reduzido, sendo esta considerada a temperatura ideal de processo. O supercapacitor preparado utilizando o óxido de grafeno reduzido a $600{ }^{\circ} \mathrm{C}$ apresentou uma baixa capacitância específica e ESR, também indicando que a melhor temperatura de redução do óxido de grafeno em vácuo produzido por bomba mecânica para aplicação em supercapacitores deve ser inferior a $600{ }^{\circ} \mathrm{C}$.

Com base nas análises realizadas neste estudo concluiu-se que o processo de redução de óxido de grafeno em vácuo produzido com bomba mecânica foi possivel a partir dos $200^{\circ} \mathrm{C}$. Isto eleva consideravelmente a viabilidade econômica para produção em escala industrial do óxido de grafeno reduzido (OGr) utilizando temperaturas relativamente baixas e um sistema de vácuo de baixo custo com bomba mecânica de duplo estágio $\quad\left(\leq 10^{-3} \mathrm{mbar}\right)$. 


\section{REFERÊNCIAS BIBLIOGRÁFICAS}

ABDELSAYED, V.; MOUSSA, S.; HASSAN, H.M.; ALURI, H.S.; COLLINSON, M.M.; EL-SHALL, M.S. The Journal of Physical Chemistry Letters, v. 1, p. 2804- 2809, 2010.

ABDOLHOSSEINZADEH, S.; ASGHARZADEH, H.; KIM, H.S. Fast and fully-scalable synthesis of reduced graphene oxide. Scientific Reports, 2015, DOI 10.1038/srep10160, www.nature.com/scientificreports

ALLEN, M.J.; TUNG, V.C.; KANER, R.B. Honeycomb carbon: a review of graphene. Chem Rev.,p. 132-145, 2009.

BAE, S.; KIM, H.; LEE, Y.; XU, X.; PARK, J.-S.; ZHENG, Y.; BALAKRISHNAN, J.; LEI, T.; KIM, H.; SONG, Y.I.; KIM, Y.-J.; KIM, K.S.; OZYILMAZ, B.; AHN, J.-H.; HONG, B.H.; IIJIMA, S. Nature Nanotechnology, v. 5, p. 574-578, 2010.

BAI, H.; LI, C.; SHI, G. Advanced Materials,v. 23, p. 1089-1115, 2011.

BALADIN, A.; GOSH, S.; BAO, W.; CALIZO, I.; TEWELDEBRHAN, D.; MIAO, F. Superior thermal conductivity of single-layer graphene. Nano Letters, v. 8, p. 902-907, 2008.

BECERRIL, H.A.; MAO, J.; LIU, Z.; STOLTENBERG, R.M.; BAO, Z.; CHEN, Y. Evaluationofsolution-processedreducedgraphene oxide films as transparentconductors. ACS Nano,v. 2, p. 463-470, 2008.

BERGER, C.; SONG, Z.; LI X.; WU, X.; BROWN, N.; NAUD C.

Electronicconfinementandcoherence in patterned epitaxial graphene. Adv. Mater., v. 312, p. 1191-1196, 2006.

BISCOE, J.; WARREN, B.E. An X-Ray studyofcarbonblack, Journal of Applied Physics, v. 13, p. 364, 1942.

BLANTON, T.N.; MAJUMDAR, D. Denver X-rayConference (DXC) onApplicationsof X-rayAnalysis, Denver, 2013. Disponível em: www.dxcicdd.com

BOUKHVALOV, D.W.; KATSNELSON, M.I. Chemical functionalization of graphene. Phys.Condens.Matter., v. 21, p. 344205, 2009.

BRESCANSIN L. M. Cursos UNICAMP, Curso Regular de Graduação. FÍSICA GERAL III - Aula 5 Capacitores e Dielétricos, 2013

BRITNELL, L.;GORBACHEV, R.V.; JALIL, R.; BELLE, B.D.; SCHEDIN, F.; MISHCHENKO, A.; GEORGIOU, T.; KATSNELSON, M.I.; EAVES, L.; MOROZOV, S.V.; PERES, N.M.R.; LEIST, J.; GEIM, A.K.; NOVOSELOV, K.S.; PONOMARENKO, L.A. Field-effecttunneling transistor basedon vertical grapheneheterostructures. Science, v.335,p. 947-950, 2012. 
BUCHSTEINER, A.; LERF, A.; PIEPER, J. Water dynamics in graphite oxide investigated with neutron scaterring. Journal of Physics and Chemical B, v.110, p. 2232822338, 2006.

CARVALHO, L. L. Construção e caracterização eletroquímica de eletrodos baseados em grafeno. Dissertação apresentada ao Instituto de Química da Universidade de São Paulo, 2014

CASINI, J.C.S.; FERNANDEZ, A.P.R.; OLIVEIRA, R.R.; SAKATA, S.K.; FARIA, R.N. Supercapacitor application of powder prepared using the hydrogenation disproportionation desorption and recombination (HDDR) process in graphene oxide. Tenth International Latin American Conference on Powder Tecnology, 08-11 November, 2015, Mangaratiba, RJ. Brazil.

CHEN, S.; ZHU, J.;WU, X.; HAN, Q.; WANG, X. Graphene oxide $-\mathrm{MnO}_{2}$ nanocomposites for supercapacitors. ACS Nano., v. 4, p. 2822-2830, 2010.

COMPTON, O.C.; NGUYEN, S.T. Graphene oxide, highly reduced graphene oxide, and graphene: versatile building blocks for carbon-based materials. Small., v. 6, p. 711-723, 2010 .

DEMARCONNAY, L.; RAYMUNDO-PIÑERO, E.; BÉGUIN, F. A symmetric carbon/carbon supercapacitor operating at $1.6 \mathrm{~V}$ by using a neutral aqueous solution. Electrochemistry Communications,v. 12, p. 1275-1278, 2010.

DIKIN, D. A., STANKOVICH, S., ZIMNEY, E. J., PINER, R. D., DOMMETT, G. H., EVMENENKO, G., ...\&RUOFF, R. S. (2007). Preparation and characterization of graphene oxide paper. Nature, 448(7152), 457-460

DREYER, D.R.; PARK, S.; BIELAWSKI, C.W.; RUOFF, S.R. The chemistry of graphene oxide. Chem. Soc. Rev., v. 39, p. 228-240, 2010.

DREYER, D.R.; RUOFF, S.R.; BIELAWSKI, C.W. From conception to realization: anhistorial account of graphene and some perspectives for its future. AngewandteChemie, v.49, p. 9336-9344, 2010.

EDA, G.;CHHOWALLA, M. Chemically derived graphene oxide: towards large-area thinfilm electronics and optoelectronics. Adv. Mater., v. 22, p. 2392-2415, 2010.

EIZENBERG, M.; BLAKELY, J.M. Carbon monolayer phase condensation on Ni (111). Surf.Sci., v. 82, p. 228-236, 1979.

FANG, Y.;LUO. B.; JIA, Y.; LI, X.; WANG, B.;SONG.Q.Renewing functionalized graphene as electrodes for high-performance supercapacitors. Advanced Materials, v. 24, p. 6348-6355, 2012.

FARIA, D.L.A.; AFONSO, M.C.; EDWARDS, H.G.M. Espectroscopia Raman: uma nova luz no estudo de bens culturais. Rev. do Museu de Arqueologia e Etnologia, São Paulo, v. 12, p. 249-267, 2002. 
FRANCO, J. R. Caracterização Eletroquímica de material ativo de eletrodo de supercapacitor baseado em nanocompósitos de nanotubos de carbono e óxido de níquel. Viçosa, Minas Gerais, Brasil, 2014

GAO, W.; ALEMANY, L.B.; CI, L.; AJAYAN, P.M. New insights into the structure and reduction of graphite oxide.Nat Chem., v. 1, v. 403-408, 2009.

GAO, X.; JANG, J.; NAGASE,S. Hydrazine and Thermal Reduction of Graphene Oxide: Reaction Mechanisms, Product Structures, and Reaction Design .The Journal of Physical Chemistry C, v. 114, 2009.

GEIM, A.K.; MACDONALD, A.H. Graphene: exploring carbon flatland. Phys. Today, v. 60, p. 35-41, 2007.

GEIM, A.K.; NOVOSELOV, K.S. The rise of graphene.Nature Materials, v. 6, p. 183$191,2007$.

GEIM A.K. Graphene: status and prospects. Science, v. 19, p. 1530-1534, 2009.

GOGOTSI, Y.; SIMON, P. True performance metrics in electrochemical energy storage. Science, v. 334, p. 917-918, 2011.

GUO, S.; DONG, S. Graphene nanosheet: synthesis, molecular engineering, thin film, hybrids, and energy and analytical applications. Chem. Soc.Rev., v. 40, p. 2644-2672, 2011.

HUANG, X.; QI, X.; BOEY, F.; ZHANG, H. Graphene-based composites.Chem. Soc. Rev., v. 41, p. 666-686, 2012.

HUANG, X.; YIN, Z.; WU, S.; QI, X.; HE, Q.; ZHANG, Q. Graphene-based materials: synthesis, characterization, properties, and applications. Small, v. 7, p. 1876-1902, 2011.

HUH, S.H. Thermal Reduction of Graphene Oxide. Physics and Applications of Graphene - Experiments, Dr. Sergey Mikhailov (Ed.). 2011. ISBN: 978-953-307-217-3, InTech, Disponível em: http://www.intechopen.com/books/physics-and-applications-ofgraphene-experiments/thermal-reduction-of-graphene-oxide

IIJIMA, S. Helical microtubules of graphitic carbon. Nature, v. 354, p. 56-58, 1991.

IWASHITA, N.; PARK, C.R.; FUJIMOTO, H.; SHIRAISHI, M.; INAGAKI, M. Specification for a standard procedure of X-ray diffraction measurements on carbon materials. Carbon, v. 42, p. 701-704, 2004.

JASUJA, K.; LINN, J.; MELTON, S.; BERR. V., Microwave-Reduced Uncapped Metal Nanoparticles on Graphene: Tuning Catalytic, Electrical, and Raman Properties, The Journal of Physical Chemistry Letters, v. 1, p. 1853-1860, 2010.

JIAO, L.; ZHANG, L.; WANG, X.;DIANKOV, G.; DAI, H., Narrow graphene nanoribbons from carbon nanotubos, Nature, v. 458, p. 877- 880, 2009. 
JU, H.; HUH, S.H.; CHOI, S.; LEE, H. Structures of thermally and chemically reduced graphene. Matter. Lett., v. 64, n. 3, p. 357-360, 2010.

KAMAT, P.V., The Journal of Physical Chemistry Letters 1 (2009) 520-527

KATSNELSON, M.I.; NOVOSELOV, K.S. Graphene: new bridge between condensed matter physics and quantum electrodynamics. Solid State Commun., v. 143, p. 3-13, 2007.

KIM K.S.; ZHAO, Y.; JANG, H.; LEE, S.Y.; KIM, J.M.; KIM, K.S. Large-scale pattern growth of graphene films for stretchable transparent electrodes. Nature, v. 457, p. 706-710, 2009.

KRISHNAMOORTHY, K.; VEERAPANDIAN, M.; YUN, K.; KIM, S.-J. The chemical and structural analysis of graphene oxide with different degrees of oxidation. Carbon, v. 53, p. 38-49, 2013.

KROTO, H.W; HEATH, J.R.; O’BRIEN, S.C.; CURL, R.F.; SMALLEY, R.E., C60: Buckminsterfullerene, Nature, v. 318, p. 162-163, 1985.

LAND, T.A.;MICHELY, T.; BEHM, R.J.; HEMMINGER, J.C.; COMSA, G.STM investigation of single layer graphite structures produced on $\mathrm{Pt}$ (111) by hydrocarbon decomposition. Surf. Sci., v. 264, p. 261-270, 1992.

LEE, C.; WEI, X.; KYSAR, J.W.; HONE, J. Measurement of the elastic properties and intrinsic strength of monolayer graphene. Science, v. 321, p. 1379, 2008.

LERF, A.; BUCHSTEINER, A.; PIEPER, J.; SCHÖTTL, S.; DEKANY, I.; SZABO, A.; BOEHM, H.P. Hydration behavior and dynamics of water molecules in graphite oxide. Journal of Physics and Chemistry of Solids, v. 67, p. 1106-1110, 2006.

LI, X., ZHANG, G., BAI, X., SUN, X., WANG, X., WANG, E., \& DAI, H. (2008). Highly conducting graphene sheets and Langmuir-Blodgett films. Nature nanotechnology, 3(9), 538-542.

LOH, K.P.;BAO, Q.; ANG, P.K.; YANG, J. The chemistry of graphene. Mater. Chem., p. 2277-2289, 2010.

LU, L.; SAHAJWALLA, V.; KONG, C.; HARRIS, D. Quantitative X-ray diffraction analysis and its application to various coals. Carbon, v. 39, p. 1821-1833, 2001.

MANOJ, B.; KUNJOMANA, A.G.; Study of Stacking structure of amorphous carbon by $\mathrm{X}$-ray diffraction technique. InternationalJournalofElectrochemical Science, v. 7, p. 3127-3134, 2012.

MEHL, H.; MATOS, C.F.; NEIVA, W.G.C.; DOMINGUES, S.H.; ZARBIN, A.J.G. Efeito da variação de parâmetros reacionais na preparação de grafeno via oxidação e redução do grafite. Química Nova, v. 37, p. 1639-1645, 2014.

MILLER, J.R.; SIMON, P. Electrochemical capacitors for energy management. Science, v. 321, p. 651-652, 2008. 
MUSSOI, F. L. R; VILLAÇA, M. V. M. Capacitores. Centro Federal de Educação Tecnológica de Santa Catarina, 2000

NAIR, R.R.; BLAKE, P.; GRIGORENKO, A.N.; NOVOSELOV, K.S.; BOOTH, T.J.; STAUBER, T.; PERES, N.M.R.; GEIM, A.K., Fine structure constant defines visual transparency of graphene. Science, v. 320, p. 1308-1308, 2008.

NG, Y.H.; LIGHTCAP, I.V.; GOODWIN, K.; MATSUMURA, M.;KAMAT, P.V., To What Extent Do Graphene Scaffolds Improve the Photovoltaic and Photocatalytic Response of TiO2 Nanostructured Films. The Journal of Physical Chemistry Letters, v. 1, p. 2222-2227, 2010.

NETO, A.H.C.; GUINEA, F.; PERES, N.M.R.; NOVOSELOV, K.S.; GEIM, A.K. The electronic properties of graphene. Rev. Mod. Phys., v. 81, p. 109-162, 2009.

NOVOSELOV, K.S.; GEIM, A.K.; MOROZOV, S.V.; JIANG, D.; ZHANG, Y.; DUBONOS, S.V.; GRIGORIEVA, I.V.; FIRSOV, A.A., Electric Field Effect in Atomically Thin Carbon Films. Science, v.306, p. 666-669, 2004.

NOVOSELOV,K.S.; JIANG, Z.; ZHANG, Y.; MOROZOV, S.V.; STORMER, H.L.; ZEITLER, U. Room-temperature quantum hall effect in graphene. Science, v. 315, p. 1379, 2007.

ORLITA, M.; FAUGERAS, C.; PLOCHOCKA, P.; NEUGEBAUER, P.; MARTINEZ, G.; MAUDE, D.K. Approaching the dirac point in high-mobility multilayer epitaxial graphene. Phys. Rev. Lett., v. 101, p. 267601, 2008.

PARK, S.; RUOFF, R.S. Chemical methods for the production of graphenes. Nat Nanotechnol., v. 4, p. 217-224, 2009.

PEI, S.; CHENG, H.M. The reduction of graphene oxide. Carbon, v. 50, p. 3210-3228, 2012.

PIERSON, H.O. Handbook of Carbon, Graphite, Diamond and Fullerenes - Properties, Processing and Applications, William Andrew Publishing, Noyes, 1993.

POTTS, P. J. et al. Atomic spectrometry update: X-ray fluorescence spectrometry. Journal of Analytical Atomic Spectrometry, v. 17, n. 10, p. 1439-1455, 2002.

RAO, C.N.R.; SOOD, A.K.; SUBRAHMANYAM, K.S.; GOVINDARAJ, A. Graphene: the new two-dimensional nanomaterial. Angew. Chem. Int., v. 48, p. 7752-7777, 2009.

RAMESHA, G.K.; SAMPATH, S. Electrochemical Reduction of Oriented Graphene Oxide Films: An in Situ Raman Spectroelectrochemical Study. The Journal of Physical Chemistry C, v. 113, p. 7985-7989, 2009.

REGIS, Y.N.G.; SPYROU, K.; RUDOLF, P. A roadmap to high quality chemically prepared graphene. J. Phys. D, v. 43, p. 374015, 2010. 
SAKAMOTO, J.; HEIJST, J.; LUKIN, O.; SCHLUTER, A.D. Two-dimensional polymers: just a dream of synthetic chemists. Angew. Chem. Int., v. 48, p. 1030-1069, 2009.

SCHNIEPP, H.C.; LI, J.-L.; MCALLISTER, M.J.; SAI,H.; HERRERA-ALONSO, M.; ADAMSON, D.H.; PRUD'HOMME, R.K.; CAR, R.; SAVILLE, D.A.; AKSAY, I.A., Functionalized Single Graphene Sheets Derived from Splitting Graphite Oxide. The Journal of Physical Chemistry B, v. 110, p. 8535-8539, 2006.

SEGER, B.;KAMAT, P.V., Electrocatalytically Active Graphene-Platinum Nanocomposites. Role of 2-D Carbon Support in PEM Fuel Cells. The Journal of Physical Chemistry,C 113,p. 7990-7995, 2009.

SERPA, RENATA DE FARIA BARBOSA, Análise multielementar de tecidos cerebrais através da Microfluorescência de Raios X e Fluorescência de Raios X por Reflexão Total [Rio de Janeiro], 2007, XVIII, 196p (COPPE.UFRJ, D.Sc. Engenharia Nuclear, 2007).

SU, Q., PANG, S., ALIJANI, V., LI, C., FENG, X., \&MÜLLEN, K. (2009). Composites of graphene with large aromatic molecules. Advanced materials, 21(31), 3191-3195.

VINODGOPAL, K.; NEPPOLIAN, B.; LIGHTCAP, I.V.; GRIESER, F.; ASHOKKUMAR, M.; KAMAT, P.V., Sonolytic Design of Graphene-Au Nanocomposites. Simultaneous and Sequential Reduction of Graphene Oxide and Au(III).The Journal of Physical Chemistry Letters, v. 1, p. 1987- 1993, 2010.

VISENTINI, V.R.S.; ZARPELON, L.M.C.; FARIA, R.N. Self-discharge and microstructrure of supercapacitors tested at room temperature and at $333 \mathrm{~K}$. Materials Science Forum, p. 802:427, 2014.

WANG, X.; ZHI, L.; MULLEN, K. Transparent, conductive graphene electrodes for dyesensitized solar cells. NanoLett.,v.8, p. 323-327, 2008.

WINTTERLIN, J.; BOCQUET, M.L. Graphene on metal surface.Surf.Sci.,v. 603, p. 1841$1852,2009$.

YANG. D.;VELAMAKANNI, A.; BOZOKLU, G.; PARK, S.; STOLLER, M.; PINER R.D. Chemical analysis of graphene oxide films after heat and chemical treatments by Xray photoelectron and micro-Raman spectroscopy. Carbon, v. 47, p. 145-152. 2009.

ZHANG, C., CHEN, M., XU, X., ZHANG, L., ZHANG, L., XIA, F., ...\& GAO, J. (2014). Graphene oxide reduced and modified by environmentally friendly glycylglycine and its excellent catalytic performance. Nanotechnology, 25(13), 135707.

ZHI, M.; XIANG, C.; LI, J.; LI, M.; WU, N. Nanostructured carbon-metal oxide composite electrodes for supercapacitors: a review. Nanoscale, v. 5, p. 72-88, 2013.

ZHOU, Y.; BAO, Q.; TANG, L.A.L.; ZHONG, Y.; LOH, K.P. Hydrothermal dehydration for the "green" reduction of exfoliated graphene oxide to graphene and demonstration of tunable optical limiting properties. Chem. Mater., v. 21, p. 2950-2956, 2009. 
ZHU, Y.; MURALI, S.; CAI, W.; LI, X.; SUK, J,W.; POTTS, J.R. Graphene and graphene oxide: synthesis, properties, and applications. Adv. Mater., v. 22, p. 3906-3924, 2010.

\section{PRODUÇÃO TÉCNICO-CIENTÍFICA}

1) CARDOSO Q.A.; CASINI J.C.S.; BARBOSA L.P.; SERNA M.M.; GALEGO E., SAKATA S.K.; FARIA R. N.;X-ray diffraction evaluation of the average number of layers in thermal reduced graphene powder for supercapacitor nanomaterial. Artigo a ser apresentado no Congresso Brasileiro de Cerâmica, 04 a 07 de Junho de 2017, Gramado - RS. A ser publicado no Materials Science Forum em 2017.

2) CARDOSO Q.A.; SILVA F,M.; VIEIRA L.S.; CASINI J.C.S.; SAKATA S.K.; FARIA R. N.; The production of reduced graphene oxide by a low-cost vacuum system for supercapacitors applications, Artigo apresentado no Congresso Brasileirode Engenharia e Ciência dos Materiais, 06 a 10 de Novembro de 2016 CBECIMAT, Natal - RN. A ser publicado no Materials Science Forum em 2017. 